
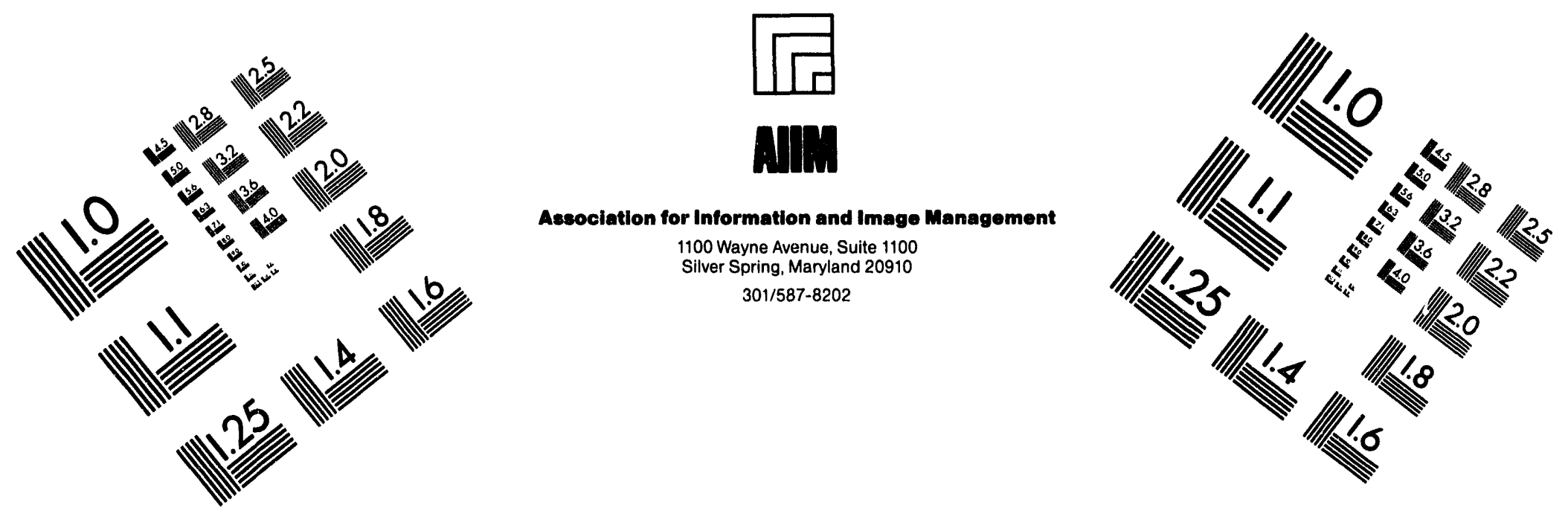

\title{
Centimeter
}

$\begin{array}{llllllllllllllll}1 & 2 & 3 & 4 & 5 & 6 & 7 & 8 & 9 & 10 & 11 & 12 & 13 & 14 & 15 & \mathrm{~mm}\end{array}$ Lши Inches

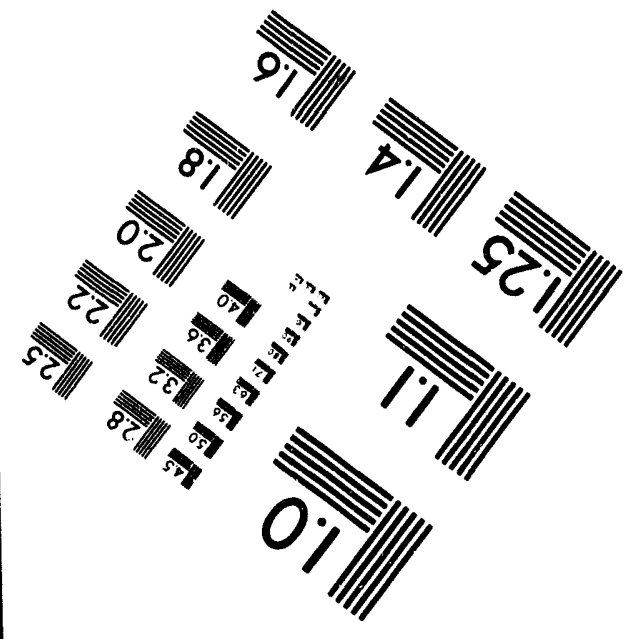

MANUFACTURED TO AIIM STANDARDS BY APPLIED IMAGE, INC.

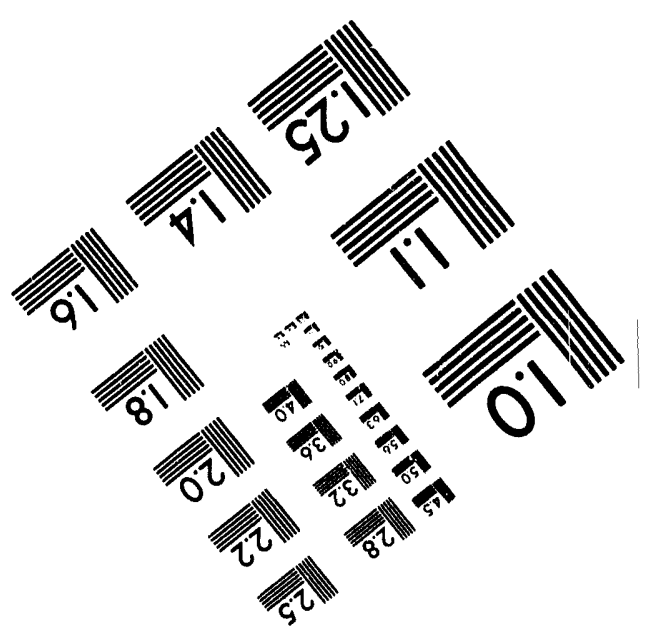



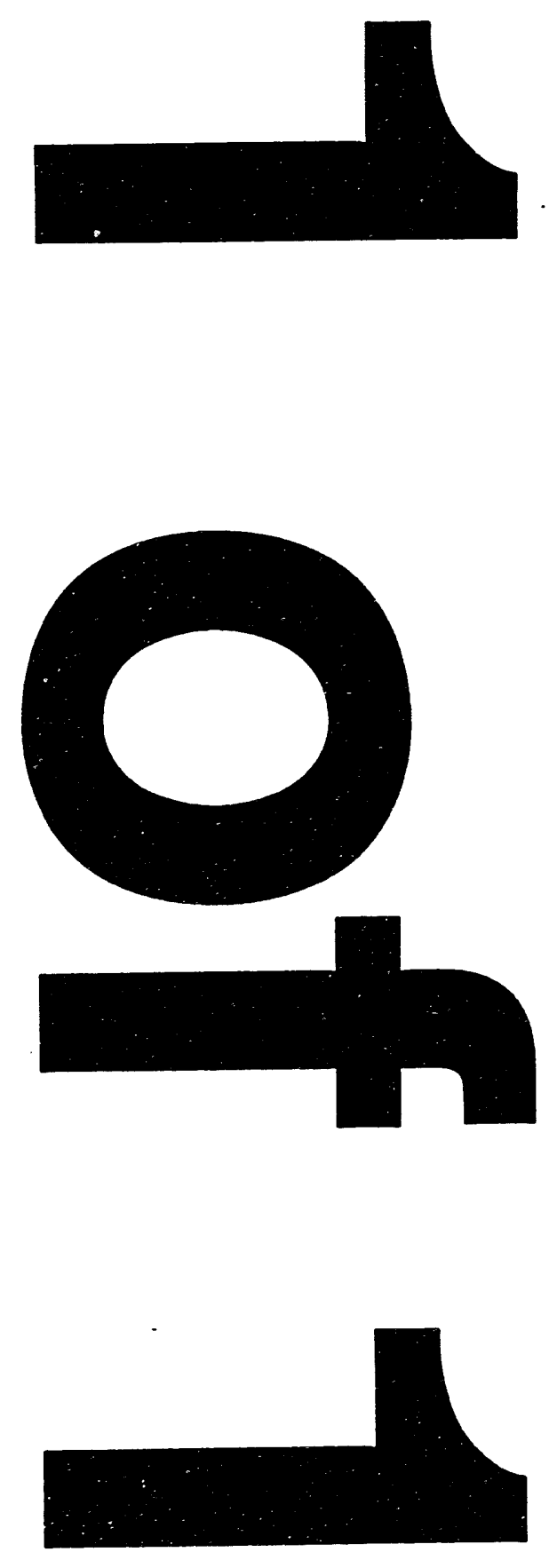


\section{SURFACTANT STUDIES FOR BENCH-SCALE OPERATION}

FINAL TECHNICAL PROGRESS REPORT:

July 1, 1992 - March 31, 1994

DCE IA NO.DE-Al22-92PC92150

Gregory S. Hickey

Pramod K. Sharma

March 31, 1994

Prepared for:

U.S. Department of Energy

Pittsburgh Energy Technology Center

Pittsburgh, PA 15236

Technical Project Officer: S. Kornfeld

Through an Agreement with

National Aeronautics and Space Administration

by

Jet Propulsion Laboratory

California Institute of Technology

Pasadena, California 
Prepared by the Jet Propulsion Laboratory, California Institute of Technology, for the U.S. Department of Energy, through an agreement with the National Aeronautical and Space Administration.

This report was prepared as an account of work sponsored by an agency of the United States Government. Neither the United States Government nor any agency thereof, nor any of their employees, makes any warranty, express or implied, or assumes any legal liability or responsibility for the accuracy, completeness, or usefulness of any information, apparatus, product, or process disclosed, or represents that its use would not infringe privately owned rights.

Reference herein to any specific commercial product, process, or service by trade name, trademark, manufacturer, or otherwise, does not necessarily constitute or imply its endursement, recommendation, or favoring by the United States Government or any agency thereof. The views and opinions of authors expressed herein do not necessarily state or reflect those of the United States Government or any agency thereof.

This work was sponsored through the DOE/NASA Interagency Agreement No. DE-Al212-92-PC92150. 


\section{TABLE OF CONTENTS}

A. Executive Summary 1

1. Introduction 3

2. Experimental Methods 5

3. Experimental Results 14

4. Mechanism Study 29

5. HRI Bench Scale Test 37

6. Conceptual Design and Economic Analysis 41

7. Conclusions 52

8. Recommendations For Future Work 54

9. References 55

10. Acknowledgments 57

11. Appendix 58 


\section{EXECUTIVE SUMMARY}

The liquefaction of coals is a promising technology for producing alternate fuels that may eventually replace petroleum-based fuels. This technology has implications toward the goal of attaining self sufficiency in the Nation's energy needs. However, in order to make coal liquefaction technology competitive with existing energy sources, high carbon conversion without subjecting the coal to extensive processing steps is desired. The fact that the operating conditions (such as solvent type and structure, the hycirogen to carbon $(H / C)$ ratio, temperature etc.) play a significant part in the dissolution of the organic coal matter is long known 1,2. The possible effects of the lowering of the viscosity and the surface tension of the liquid phase in a reactor have mostly been speculated and not systematically investigated. Further, the research emphasis in coal liquefaction has recently shifted away from intensive processing to emphasizing both maximizing the liquid yields and conversions, and to obtain a more economically attractive slate of products at milder processing conditions.

The present work effort relates to an investigation of surfactant-assisted coal liquefaction with the objective of quantifying the enhancement in overall coal conversions and the product quality. It was planned to obtain optimum conditions for a surfactant assisted coal liquefaction run through a set of comprehensive batch autoclave tests and verify those in a continuous-flow bench scale test. It was also proposed to evaluate the economic advantage of such a surfactantassisted coal liquefaction process.

Based on the results of a Phase I preliminary study on the effect of several surfactants on coal liquefaction, sodium lignosulfonate was chosen as the surfactant for a detailed parametric study to be conducted at JPL using a batch autoclave reactor. These tests primarily related to thermal liquefaction of coal. The results of JPL autociave test runs showed an increase in overall conversions from 5 to $15 \%$ due to surfactant addition over the base case of coal alone. A similar increase in the quality of liquid filtrate was also observed. A study of the mechanism of the surfactant action was made. This study includes an investigation of the surfactant mechanism that indicates that the surfactant appears to act by (a) deagglomerating the coal particles, (b) breaking the crosslinks between different coal molecules, and (c) increasing the hydrogen transport to the coal particles. The combined effect is an increase in the kinetics of coal liquefaction. It was also determined that only a small amount of surfactant $(0.5$ wt\% based on total slurry) is needed and adding additional surfactant does not lead to an additional benefit. Further, the observed improvement was due to the surfactant action and not due to its decomposition to lignin-type products.

A continuous-flow bench scale coal liquefaction process run was conducted over a 5 day period at Hydrocarbon Research Incorporated (HRI). Whereas the previous experimental work conducted prior to the bench scale test were conducted thermally, the bench scale test at HRI utilized a supported Ni-Mo catalyst. This test showed that the surfactant is suitable for an industrial continuous recycle process, and does not interfere with the supported catalyst. 
After the bench scale test, a series of autoclave runs were conducted with coprocessing the surfactant and the Ni-Mo catalyst. These experiments showed that high conversions and product quality can be maintained at milder processing conditions.

Based on results of the autoclave test runs, the overall product values were obtained $t r$ two stage reactors at $400^{\circ} \mathrm{C}$. An economic evaluation was conducted that compared the operating costs and product value for a conceptual 1000 ton/day plant The cases were: (a) coal alone, (b) coal with surfactant, (c) coal with the supported Ni-Mo catalyst, (d) coal with both the surfactant and the Ni-Mo catalyst, and (e) a first stage at $375^{\circ} \mathrm{C}$ with surfactant and the second stage at $400^{\circ} \mathrm{C}$ with Ni-Mo catalyst. The overall product value with surfactant addition had a $7 \%$ increase over the base case of coal alone. However, in comparison to the Ni-Mo supported catalyst, the overall product quality was similar with surfactant addition in place of the catalyst. The best product value was realized for the two-stage case $(\theta)$ which showed an $8 \%$ improvement over the base case.

Based on above analysis, a conceptual design has been proposed for a two-stage continuous-flow industrial process where the first stage utilizes thermal processing of coal with surfactant addition at $375^{\circ} \mathrm{C}$ while the second stage uses the supported Ni-Mo catalyst at $400^{\circ} \mathrm{C}$. Both the stages operate at $1800 \mathrm{psig}$. Due to less intensive processing conditions, a savings of about $5 \%$ is expected in the capital costs. Recommendations for future work include tests with a more thermally stable surfactant which would be expected to lead to even better product quality and a further reduction in the capital costs. 


\section{INTRODUCTION}

The liquefaction of coals is a promising technology for producing alternate fuels that may eventually replace petroleum-based fuels. This technology has implications toward the goal of attaining self sufficiency in the Nation's energy needs. However, in order to make coal liquefaction technology competitive with existing energy sources, high coal conversion without subjecting the coal to extensive processing steps is desired. The fact that the operating conditions (such as solvent type and structure, the hydrogen to carbon (H/C) ratio, temperature etc.) play a significant part in the dissolution of the organic coal matter is long known 1,2. The possible effects of the lowering of the viscosity and the surface tension of the liquid phase in a reactor have mostly been speculated and not systematically investigated. Further, the research emphasis in coal liquefaction has recently shifted away from intensive processing to maximize liquid yields toward milder processing to obtain a more economically attractive slate of products.

A Phase I study 3 using the surfactant approach for milder processing in liquefaction was completed at the Jet Propulsion Laboratory (JPL) in December 1990. This study, though preliminary and of a limited scope, identified sodium lignosulfonate as the surfactant additive which appeared most promising based upon the viscosity tests. A few coal liquefaction autoclave test runs carried out with a small amount of the lignosulfonate additive showed an increase in light soluble solids. These preliminary tests also indicated a possible increase in the liquid yields.

The present work effort relates to an investigation of surfactant-assisted coal liquefaction with the objective of quantifying the enhancement in overall coal conversions and the product quality. It was planned to obtain optimum conditions for a surfactant assisted coal liquefaction run through a set of comprehensive batch autoclave tests and verify those in a continuous-flow bench scale test. It was also proposed to evaluate the economic advantage of such a surfactantassisted coal liquefaction process.

Initial liquefaction tests using the batch autoclave reactor were carried out using Pittsburgh \#8 coal at a processing temperature of $325^{\circ} \mathrm{C}$. These tests showed a favorable effect of surfactant addition on coal liquefaction. Having established this favorable effect for bituminous coal, the remaining detailed tests were carried out with Illinois \#6 coal in order that comparisons could readily be made to earlier data from Wilsonville and the ongoing work at HRI.

At the beginning of this task, the facilities for bench scale tests were visited at HRI. Within the scope of the proposed work, only a couple of tests could be run at HRI with surfactant addition at the tail end of a DOE-funded test run with Illinois \#6 coal. It was also clear that the HRI tests could be run only in presence of their catalyst whereas the JPL tests were primarily non-catalytic. However. it was hoped that the catalyst and the surfactant will not interfere with each other or that the catalyst effect, by itself, will not be so large as to mask the surfactant effect. 
Complete data analysis from the JPL autoclave test runs and the HRI bench scale runs indicates that the second concern mentioned above was a valid one. However, a batch autoclave simulation of the two-stage HRI process distinctly identifies the advantage of incorporating the surfactant addition in a modified scheme. 


\section{EXPERIMENTAL METHODS}

\subsection{EXPERIMENTAL SETUP}

The surfactant assisted coal liquefaction experimental reactor system consists of a Parr series $\mathbf{4 5 0 0}$ autoclave and accessories. A schematic of the reactor system is shown in Figure 2.1. The reactor consists of a one liter stainless steel pressure vessel with a maximum operation pressure of $1900 \mathrm{psig}$ at $400{ }^{\circ} \mathrm{C}$. The reactor contents are mixed by a belt driven stirrer with a six blade turbine-type impeller with a rotation speed from 0 to $1000 \mathrm{rpm}$. The reactor shaft assembly includes a cooling water loop. The reactor system has gas lines and flow valves for nitrogen and hydrogen, and a vent line with burst reservoir. For safety, the reactor has a pressure relief valve rated at 1910 psig, and a burst valve rated at 2200 psig. Pressure is measured by a 3000 psig pressure gauge, and temperature by a thermocouple inserted into a thermowell within the reactor. Temperature is controlled by an automatic temperature controller.

The primary coal being used in this study is Illinois \# 6 obtained from the Penn State Coal Data Bank (PSCD) with PSCD designation DECS-2. The coal particle size is -60 mesh and is stored in a sealed, dry container. An analysis of the coal is given in Table 2.1. The coal was used in as-received condition. The solvent used is a recycle solvent obtained from Hydrocarbon Research Inc. (HRI). Analysis of the solvent is given in Table 2.2. The surfactant is Sodium Lignosulfonate obtained from Pfáltz and Bauer, Catalogue No. S05950.

\section{Batch Bun Procedures}

A batch run procedure has been developed with an emphasis on reproducibility and safety. For each run, $100 \mathrm{gm}$ of coal is weighed and mixed with the appropriate concentration of surfactant $(0.0,0.5,1.0$ or 2.0 wt\% relative to the total slurry). The coal is added to the autoclave and $200 \mathrm{ml}$ of recycle solvent is mixed with it. The reactor is sealed by a split ring closure with Teflon gasket. The reactor is flushed three times with 300 psig dry. nitrogen gas to remove air, and is then pressurized to $1000 \mathrm{psig}$ for 30 minutes to check for leaks. If there are no leaks, the system is vented slowly and purged two times with 50 psig hydrogen, followed by two purges at 300 psig hydrogen to remove the nitrogen. The reactor is then pressurized to between 850 and 1000 psig of hydrogen, so that at the processing temperature $\left(300\right.$ to $\left.400^{\circ} \mathrm{C}\right)$, the system pressure will be 1800 to 1900 psig. A lower initial pressure is used for the 1500 psig experimental runs. The gas inlet valve is closed and the system is heated to the test temperature, and held at that temperature for the appropriate duration of time.

Upon completion of the run the power is turned off to the heater, and the reactor is cooled. The slurry in the reactor is allowed to settle overnight, then the system is vented. If a gas sample is to be collected, it is collected in an eyacuated gas sample cylinder.before the system is vented. The reactor is then opened and the treated slurry is collected for subsequent filtration and analysis. 


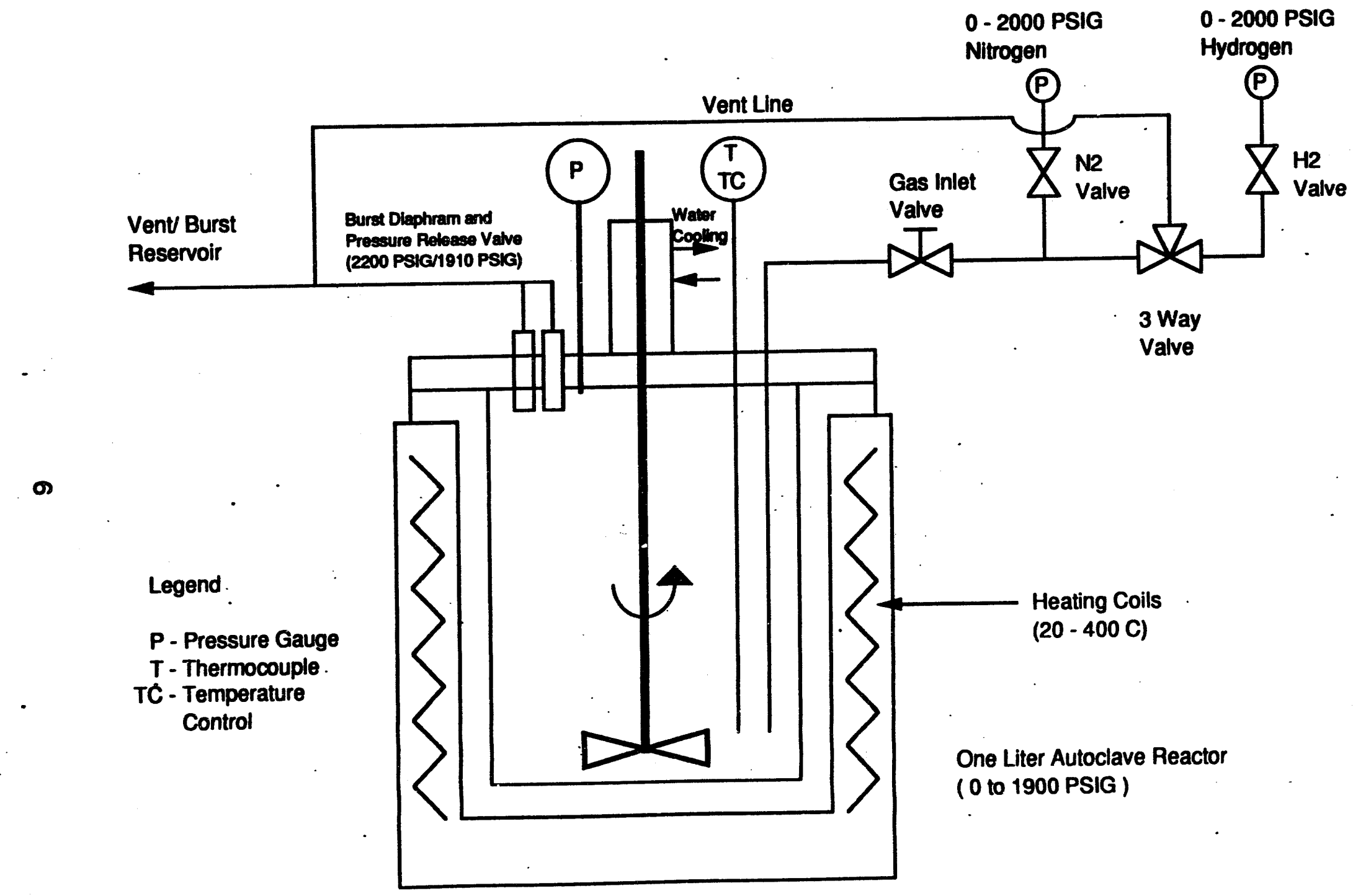

Figure 2.1: Autoclave Reactor System Schematic 
Table 2.1: Illinois \# 6 coal proximate and ultimate analysis.

Coal Sample ldentification

PSCD Designation:

Seam Name:

DECS-2

Alternate Seam Name:

Illinois \#6

Proximate Analysis

$\%$ Moisture

$\%$ Ash

Herrin

$\%$ Volatile

$\%$ Fixed Carbon

\begin{tabular}{cl} 
As Received & Dry \\
\hline 10.43 & \\
14.47 & 16.16 \\
34.16 & 13.14 \\
40.93 & 45.70
\end{tabular}

Ultimate Analysis

$\%$ Ash

As Beceived Dry

$\%$ Carbon

14.47

16.16

$\%$ Hydrogen

$\%$ Nitrogen

$\%$ Total Sulfur

$\%$ Oxygen (Diff)

58.66

65.49

$4.08\left(^{*}\right) \quad 4.56$

$0.99 \quad 1.11$

$4.05 \quad 4.52$

$7.31(*) \quad 8.16$

(") Excludes Moisture

Table 2.2: Recycle solvent physical properties

Density: $\quad 1.07 \mathrm{gm} / \mathrm{cm}^{3}$

Boiling Point Distribution: Temperature

IBP-210 $\mathrm{C}$

$w_{t} \%$

$210-270^{\circ} \mathrm{C}$

$270-300^{\circ} \mathrm{C}$

$300-340^{\circ} \mathrm{C}$

0.00

14.21

12.54

$340+{ }^{\circ} \mathrm{C}$

20.20

53.05 
Great care is taken to collect all liquids and solids by scraping the interior of the reactor, the impeller shaft and supports. Material losses remaining are determined to be generally less than 1 percent. At this point, the reactor is thoroughly cleaned with isopropanol solvent and prepared for the next reactor run.

\subsection{ANALYSIS PROCEDURES}

A detailed analysis procedure has been developed to characterize the coal liquefaction solid and liquid products. A schematic is shown in Figure 2.2 The definition for conversion is the mass fraction of the carbonaceous material that either is directly converted to liquid during the reaction or is extracted during solvent treatments. By definition, conversion is on a moisture and ash free (MAF) basis.

The reactor product slurry is allowed to settle out for a minimum of three days. The product slurry usually separates into two fractions, the top fraction being mostly liquid while the bottom fraction contains the major part of the solids. The top fraction is decanted, filtered and put in a collection vessel; and the remaining wet solids are vacuum filtered for 15 minutes to remove the filterable liquids from the filter cake. The filtration is conducted with a buchner funnel with 5 $\mu \mathrm{m}$ pore size filter paper. The filtered liquid is added to the original filtrate. The filtrate and the filter cake are weighed and the mass balance closure during the filtration step is verified. The mass balances at various mixing and separation steps were found to all close within 3 percent.

The filter cake is subjected to a series of extractions to determine the preasphaltenes, asphaltenes and light oil fractions. The solvents used for successive extractions are hexane, toluene and tetrahydrofuran (THF). All solvents are reagent grade. For the extraction, 10 grams of filter cake are added to $30 \mathrm{ml}$ of hexane stirred, and allowed to sit overnight. The slurry is then vacuum filtered using a conical funnel and $2.5 \mu \mathrm{m}$ pore size filter paper (Whatman 42). The mixture is washed with solvent until the filtrate is clear. The remaining filter cake is then dried by vacuum for 10 minutes to remove a part of the solvent. The remaining solvent is removed by heating the filter cake in an oven maintained at a temperature of about $100^{\circ} \mathrm{C}$ for 4 to 8 hours. The dried filter cake is weighed and then mixed with $30 \mathrm{ml}$ of toluene for the toluene extraction and the extraction procedure is repeated and the sample is dried at $125{ }^{\circ} \mathrm{C}$ for 4 to $8 \mathrm{hrs}$. The final filter cake is then extracted with THF. At the completion of the THF extraction, the THF insoluble solids are dried $16 \mathrm{hrs}$ at 60 ${ }^{\circ} \mathrm{C}$ in air to drive off any residual solvent before a final weight is determined.

Overall conversions were also determined by THF extraction alone for a few selected process runs. In this alternative approach, $10 \mathrm{~g}$ of the filter cake were extracted with $30 \mathrm{ml}$ of THF over a period of $24 \mathrm{hrs}$. After filtration, the extraction with THF was repeated. The final extracted residue was separated by filtration, dried and then weighed. There was good agreement between the two test methods in determining the overall conversion. 


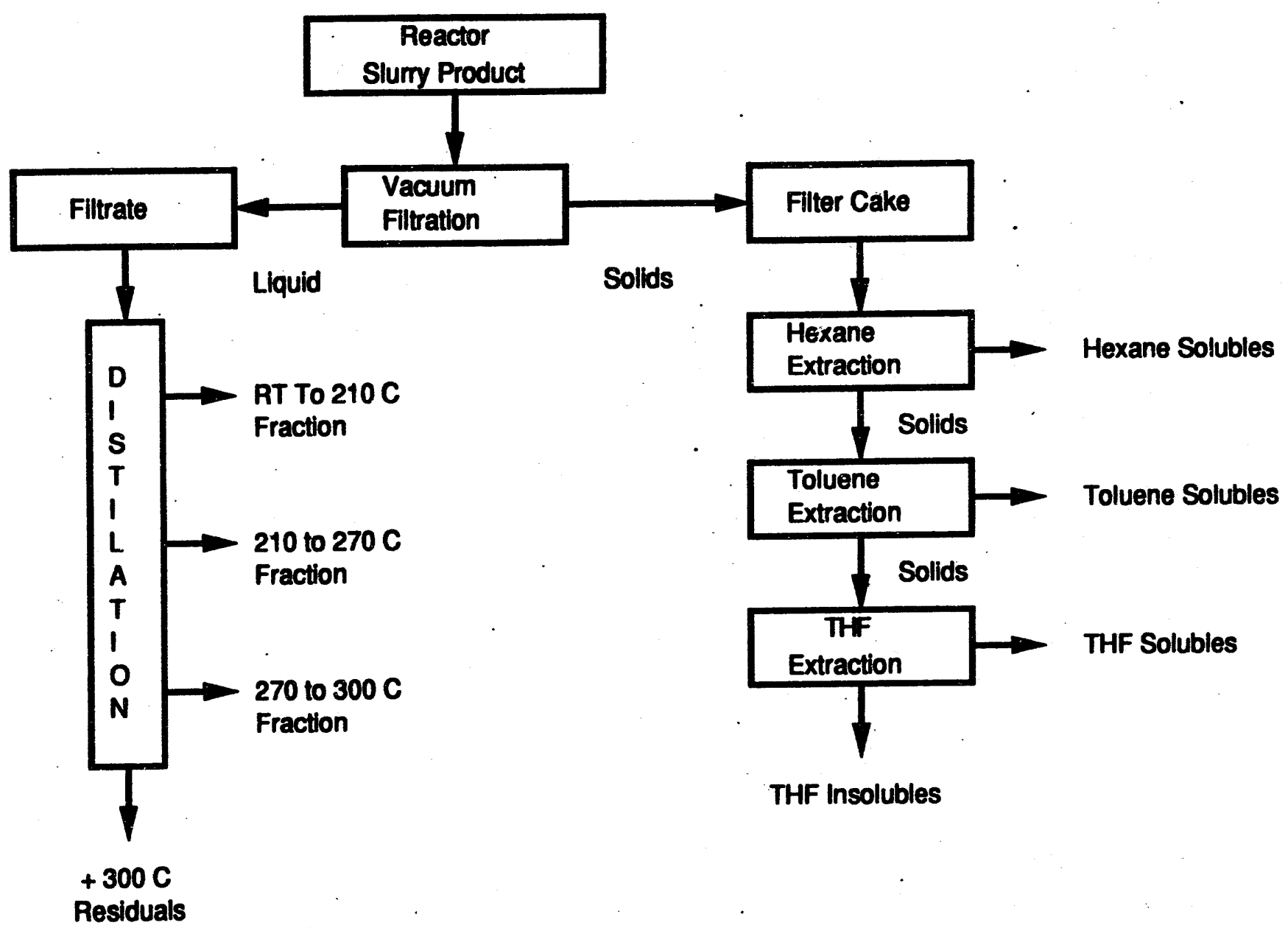

Figure 2.2: Baseline Analysis Scheme 
In summary, a total of 44 processing runs were completed during this study. All runs reported here were made on .llinois \#6 coal with sodium lignosulfonate as the surfactant. At the initiation of the program four runs were completed at $300^{\circ} \mathrm{C}$ using Pittsburgh $\# 8$ coal. The results for these runs are included in the First Quarterly Progress Report ${ }^{4}$ and are not repeated here. Because of this, the data reported here will be sequentiaily starting with Run 5. Process runs were completed from 300 to $400^{\circ} \mathrm{C}$ with the typical reactor pressure adjusted to be nominally 1800 psig at the processing temperature. Selected runs were conducted at lower pressures to determine the sensitivity of conversion on pressure. The average run time was one hour at each temperature. Selected runs were conducted at $375^{\circ} \mathrm{C}$ where time as a processing variable was investigated. At 375 and $400^{\circ} \mathrm{C}$, two catalysts were investigated for their contribution to conversion and liquefaction product quality. These were iron oxide $\left(\mathrm{Fe}_{2} \mathrm{O}_{3}\right)$ powder and Shell 317 (Ni-Mo/Al2 $\mathrm{O}_{3}$ ) catalyst obtained from the $\mathrm{HRI}$ as $1 / 32 "$ extrudates. The $\mathrm{Fe}_{2} \mathrm{O}_{3}$ catalyst was obtained as a fine powder with a particle size less than 10 microns. The Ni-Mo catalyst was ground to a finely ground powder less than 10 microns. To determine the effect of the lignin fraction of the surfactant on the process results, pure lignin was used in selected tests. The lignin used is a solvent extracted lignin obtained from Repap Technologies. This is a solvent extracted lignin with a neutral pH.

Table 2.3 gives a generalized summary of the experimental test matrix that was conducted in this study. It does not include runs conducted with time as a variable or catalyst or lignin addition. Appendix 1 has a detailed description of all the processing conditions for the runs completed. The results on the yields of the liquid filtrate and the solid filter cake together with the corresponding mass balance closure for each test run are given in Appendix 2. The original solvent is distributed between the liquid filtrate and the wet filter cake. The results on the soluble solids for varioi's filter cake samples are reported in Appendix 3 on a weight percent basis of the original weight of the filter cake. The total soluble. solids are separated into hexane solubles, toluene solubles, and THF solubles, as obtained by step-wise extractions in that order. This in good measure, corresponds to the light oil, asphaltenes and preasphaltenes fraction of the liquefaction product.

In order to characterize the liquid obtained as the filtrate, $\mathbf{5 0}$ grams of the filtrate were removed for atmospheric distillation using the procedure outlined in ASTM D 246-895. Distillation fractions are taken for the following cuts: room temperature to $210^{\circ} \mathrm{C}, 210$ to $270^{\circ} \mathrm{C}, 270$ to $300^{\circ} \mathrm{C}$, and residual bottoms. For the $400^{\circ} \mathrm{C}$ runs, an additional distillate fraction was taken from 300 to $340^{\circ} \mathrm{C}$. The various cuts reported are weights of distilled fractions obtained at the specified temperature ranges. Included in tire table is the sum of the lower-boiling distillate fractions that are obtained below $300^{\circ} \mathrm{C}$ or $340^{\circ} \mathrm{C}$. 
Table 2.3: Generalized test matrix for coal liquefaction experiments.

Coaal: Illinois \#6

Surfactant: Sodium Lignosulfonate

Time: 1 hour

Surfactant Concentration

\begin{tabular}{|l|l|l|l|l|l|}
\hline $\begin{array}{c}\text { Temperature } \\
{ }^{\circ} \mathrm{C}\end{array}$ & $\begin{array}{l}\text { Pressure } \\
\text { Psig }\end{array}$ & $0.0 \%$ & $0.5 \%$ & $1.0 \%$ & $2.0 \%$ \\
\hline 300 & $<1800$ & & & & \\
\hline 300 & 1800 & RA & RA & RA & RA \\
\hline 325 & $<1800$ & & & & RA \\
\hline 325 & 1800 & RA & RA & RA & RA \\
\hline 350 & $<1800$ & & RA & & \\
\hline 350 & 1800 & RA & & RA & RA \\
\hline 375 & $<1800$ & RA & & RA & RA \\
\hline 375 & 1800 & RA & RA & RA & RA \\
\hline 400 & $<1800$ & & & & \\
\hline 400 & 1800 & RA & & & RA \\
\hline
\end{tabular}

RA: Run completed and Analyzed 


\section{Coal Conversions}

Coal conversions were obtained based on the conversion of the ash and moisture-free carbonaceous material to either the coal-derived liquid or the fraction that is soluble in solvents used in the extractions with the filter cake. As it is generally believed that the treated coal fractions which are soluble in hexane and toluene will also be soluble in THF, this method of computation of the overall conversion should be nearly the same as the result obtained if the treated slurry were washed with THF alone. Thus, conversion was obtained using the relationship:

\section{Fractional Conversion $=\left(W_{\text {init }}-W_{\text {fin }}\right) W_{\text {init }}$}

where $W_{\text {init }}$ is the initial weight of the coal on moisture and ash-free basis subjected to liquefaction and $W_{\text {fin }}$ is the final weight of the carbonaceous residue obtained from the treated slurry that is not soluble in hexane, toluene, and THF. Note that $W_{\text {fin }}$ is to be corrected by subtracting the ash in the initial sample as well as subtracting the surfactant or catalyst in the runs where surfactant or catalyst were added. To validate that this extraction procedure only extracts reacted coal, the extraction sequence was performed on as-received Illinois \#6 coal. The pseudo-conversion for raw coal (after successive washes with hexane, toluene, and THF) was similarly determined and was found to be only about 2.0 percent. The coal conversions obtained by the successive extractions procedure described above were compared with the more conventional approach of THF extraction alone. In determining the MAF conversion by successive extraction with hexane, toluene and THF, or THF alone, the difference between the coal conversions obtained by these two procedures was within 3 percent.

For completeness, the following discussion describes how the overall conversion was obtained for a given run. For each processed run, the filtrate and the filter cake amounts were measured. The moisture and ash contents were assumed to stay constant in each run and were based on. the Penn. State analysis. The initial $100 \mathrm{~g}$ coal used in each run would appear in some form in either the filter cake or in the filtrate. The fraction gasified was assumed to be small for the processing conditions. The unconverted coal is expected to end up only in the filter cake. For the $10 \mathrm{~g}$ sample of the filter cake, the initial value of the raw coal is determined by multiplying 100 by the ratio 10 divided by the total weight of the filter cake. From this number, the moisture $(10.43 \%)$ and ash $(14.47 \%)$ are subtracted to obtain $W_{\text {init, }}$, the initial moisture and ash free coal. The final unconverted coal, $W_{\text {fin }}$, was obtained by taking the dry weight of the residue from the filter cake that was insoluble at the end of successive extractions and subtracting out the ash (the same amount as used to obtain $W_{\text {init }}$ ) and the unconverted part of the surfactant (and/or the catalyst) when used.

A limited number of thermogravimetric (TGA) tests were carried out to determine the ash content in the filter cake. In these runs, a known amount of filter cake was heated in air to $800^{\circ} \mathrm{C}$ inside a TGA, with continuous monitoring of the sample weight. At $800^{\circ} \mathrm{C}$, only the ash remains. These tests confirmed 
that the values of the ash from the sample were the same as computed above in determining $W_{\text {init }}$ or $W_{\text {fin }}$. 


\section{EXPERIMENTAL RESULTS}

The first part of the experimental work consisted of a parametric study of batch autoclave runs to evaluate the effect the lignosulfonate surfactant would have on the liquefaction of a bituminous coal. The matrix test variables were temperature, hydrogen pressure and time. Results included overall conversion; light oil, asphaltene and preasphaltene distribution and distillation fractions. For completeness, the temperature stability of the surfactant was studied, and the possible effect that lignin fraction of the surfactant may have participated in the liquefaction process. The effect of a catalyst was briefly studied, both in a disposable form as $\mathrm{Fe}_{2} \mathrm{O}_{3}$ and a conventional mixed metal supported catalyst. Additional experimental work was conducted to evaluate the possible mechanism the surfactant may be having on the liquefaction process. This experimental work will be presented in the next section.

\subsection{SURFACTANT EFFECT PARAMETRIC STUDY}

A parametric study was conducted with the lignosulfonate surfactant to determine the effects of temperature, hydrogen pressure and time on the conversion of lllinois \# $6 \mathrm{coal}$ and the product quality of the distillate. slate. The ratio of coal to recycle solvent was kept constant for all the test runs at $100 \mathrm{gm}$ coal to $200 \mathrm{ml}(187 \mathrm{gm})$ of recycle solvent. The two primary variables that were changed were the surfactant concentration and temperature. The surfactant effect was evaluated at concentrations of $0.0,0.5,1.0$ and $2.0 \mathrm{Wt} \%$. The temperature was varied from 300 to $400^{\circ} \mathrm{C}$, in $25^{\circ} \mathrm{C}$ increments. The hydrogen pressure was varied for the $0 \%$ and the $2.0 \%$ surfactant addition runs from 325 to $375^{\circ} \mathrm{C}$. This pressure varied from 1300 to 1800 psig hydrogen. In all other cases, the hydrogen pressure was maintained nominally about 1800 psig. The processing time was set at $1 \mathrm{hr}$ at the processing temperature, excluding heating and cool down. Typical heating times were $\mathbf{3 0}$ minutes to reactor processing temperature, with a cool down to less than $300^{\circ} \mathrm{C}$ in 20 minutes. Processing time was taken as a variable from 30 minutes to 90 minutes for runs conducted at $375{ }^{\circ} \mathrm{C}$, with $0 \%$ and $2.0 \%$ surfactant concentrations.

The distribution of hexane, toluene and THF solubles for the processing runs is given in Appendix 3. These distributions are not corrected for the addition of the surfactant or catalyst, and are not normalized with the mass balance. This sequential extraction allows the separation of the liquefaction products into light oils, asphaltenes and preasphaltenes fractions. The addition of the surfactant increases the production of asphaltenes and preasphaltenes. This effect is enhanced with the increase in temperature. The fraction extracted and the amount of liquid filtrate allows. the determination of the overall conversion. The extraction distributions data in Appendix 3 are not normalized on a moisture and ash free basis.

To obtain accurate measurement of overall MAF conversion it was necessary to understand the stability of the lignosulfonate surfactant at the processing temperatures used in this study. Runs 32, 33, and 35 were conducted to determine the fraction of surfactant that is retained in the filter cake 
as a solid and the fraction that is transferred into the liquid phase in the temperature range 350 to $400{ }^{\circ} \mathrm{C}$. During the liquefaction processing, the surfactant may either be hydrogenated and become liquid product or may decompose into smaller organic species. By processing the surfactant in the recycle solvent without coal and completing a hydrngenation process cycle, the stability of the surfactant could be determined. In these runs, the thermally processed surfactant was filtered at the end of the run and twice extracted with THF. The remaining residue was dried at $100^{\circ} \mathrm{C}$ and weighed to determine the fraction of the surfactant that does not get liquefied and, hence, will stay in the filter cake. At temperatures of 350 to $375{ }^{\circ} \mathrm{C}$, approximately $50 \%$ surfactant is transferred into the liquid phase while at $400{ }^{\circ} \mathrm{C}$, approximately $70 \%$ of the surfactant ends up in the liquid phase. Taking this into account, the coal conversions were accurately determined. The overall MAF conversion was determined using the procedure described in Section 2.

The overall conversion is a measure of the fraction of coal that has undergone either fragmentation and/or hydrogenation due to the processing conditions. The conversion is on a moisture and ash free (MAF) basis of the original coal, and surfactant and catalyst if added. It is a direct measure of the reactivity of the coal to the processing conditions. Illinois \#6 is a bituminous coal that has a high potential reactivity, containing only $2-3 \%$ of inert coal macerals. This would give a theoretical limit of $97-98 \%$ overall MAF conversion. Table 3.1 provides a summary of the MAF conversions for the runs conducted in this study with temperature, pressure, and surfactant concentration as variables. Appendix 4 has the detailed conditions and the conversions of ali iuns completed.

Table 3.1: Test matrix results of Illinois \#6 coal conversion (MAF basis) processed for one hour with varying amount of sodium lignosilfonate surfactant.

Temperature HoPressure

Surfactant Concentration

\begin{tabular}{|c|c|c|c|c|c|}
\hline का क्त & (Psig) & $\frac{0 \%}{21 \%}$ & $0.5 \%$ & $1.0 \%$ & $\frac{2.0 \%}{245 \%}$ \\
\hline $300^{\circ} \mathrm{C}$ & & & & & \\
\hline $325^{\circ} \mathrm{C}$ & $<1800$ & & & & $24.2 \%(A)$ \\
\hline $325^{\circ} \mathrm{C}$ & 1800 & $25.4 \%$ & $29.8 \%$ & $36.5 \%$ & $29.2 \%$ \\
\hline $350^{\circ} \mathrm{C}$ & $<1800$ & & $65.9 \%(B)$ & & $60.0 \%(C)$ \\
\hline $350^{\circ} \mathrm{C}$ & 1800 & $54.4 \%$ & & $62.5 \%$ & $63.1 \%$ \\
\hline $375^{\circ} \mathrm{C}$ & $<1800$ & $77.0 \%(B)$ & & & $82.5 \%(C)$ \\
\hline $375^{\circ} \mathrm{C}$ & 1800 & $83.1 \%$ & $86.0 \%$ & $85.9 \%$ & $87.4 \%$ \\
\hline $400^{\circ} \mathrm{C}$ & 1700 & $84.1 \%$ & & $92.9 \%$ & \\
\hline
\end{tabular}

Notes: A: 1050 Psig, B: 1300 Psig, C: 1500 Psig 
The primary variable that has the largest effect on coal conversion is thie reaction temperature. This is illustrated by Figure 3.1 which compares the temperature dependence on conversion at $1 \%$ surfactari concentration and without surfactant. Below $350^{\circ} \mathrm{C}$ there is very little conversion but the effect of the surfactant can be seen even at the lower temperatures. The surfactant increases the overall conversion from 5 to $15 \%$, generally increasing with temperature with the largest absolute increase occurring at $350^{\circ} \mathrm{C}$. Close analysis of the stability of the suriactant has shown that only a small amount of the surfactant is necessary to have a positive effect on conversion. This is shown in Figure 3.2 which shows the effect of surfactant concentration on MAF conversion.

The second most important process variable is the reactor hydrogen pressure. As.seen from Table 3.1, when the pressure is reduced from 1800 psig, there is a significant decrease in the overall conversion. Hydrogen pressures above 1800 psig were not investigated due to pressure and safety limitations on the autoclave reactor. The standard operation pressure ior bench-scale and pilot plant liquefaction reactors is $2000-2500$ psig.

The effect of reaction time was investigated for the $375^{\circ} \mathrm{C}$ process runs with and without surfactant. Figure 3.3 shows that the residence time at this temperature is significant variable. As would be expected, without the surfactant, with a longer processing time the conversion increased. After 90 minutes at the reaction temperature, the coal did not reach its kinetic limit for maximum conversion. With the addition of $2 \%$ surfactant, the reaction rate has increased significantly. It also appears that with the addition of the surfactant, the reaction may have reached its kinetic limit for maximum conversion at $375^{\circ} \mathrm{C}$.

Figure 3.4 shows the increase in preasphaltenes with processing temperature. The production of preasphaltenes was determined from the THF extraction that succeeded the hexane and toluene washes. There is a greater increase in the amount of preasphaltenes with the addition of the surfactant. This wou'd appear to be due to high molecular weight fragments (preasphaltenes) from the coal entering the liquid product.

Gas samples from the processing runs were analyzed by mass spectroscopy to determine the primary gas products for selected runs. Samples were taken from runs \# 9, 14, 19 and 20 after the runs had been completed and the reactor had cooled down. These runs correspond to $1 \%$ surfactant addition at 325,350 , and $375{ }^{\circ} \mathrm{C}$ respectively, and $375{ }^{\circ} \mathrm{C}$ without surfactant. The primary gas products, in addition to the hydrogen, were light gases consisting of methane, ethane, propane, and water vapor and their fragments. Sulfur containing species could be observed, but were less than $1 \%$ of. the reactor gases. The proportion of hydrocarbon gases increased with temperature and was determined using the amount of water produced as a normalization factor. 


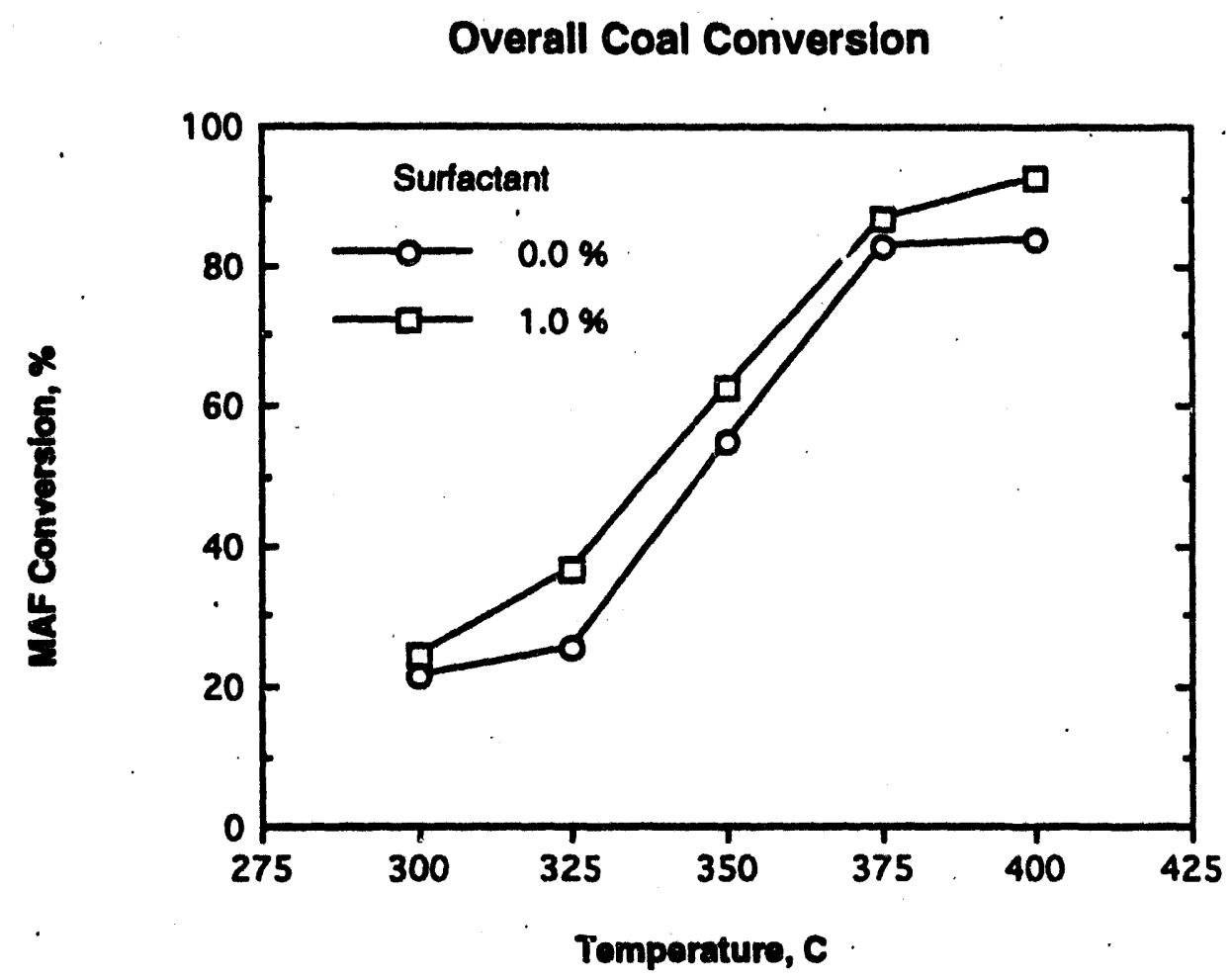

Figure 3.1: Temperature dependence of conversion with and without surfactant.

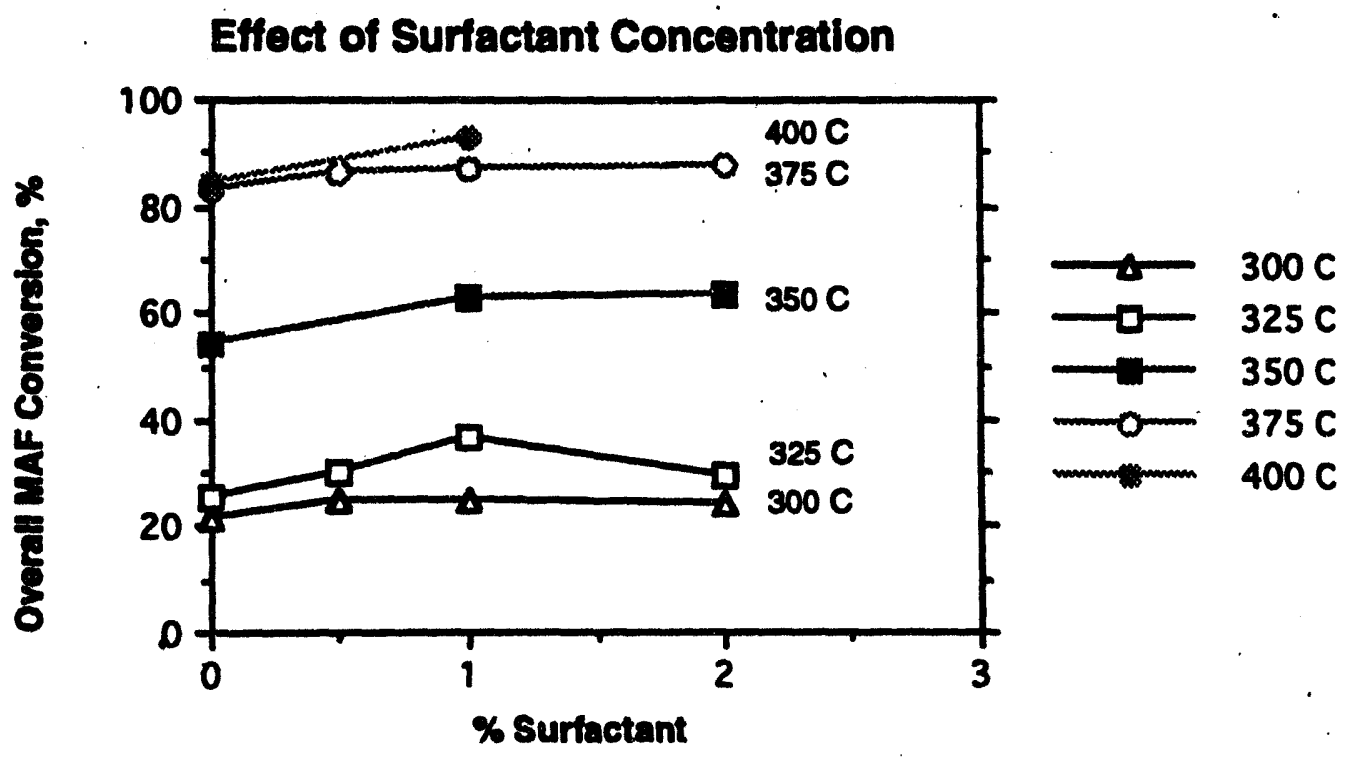

Figure 3.2: Effect of surfactant concentration on MAF conversion 


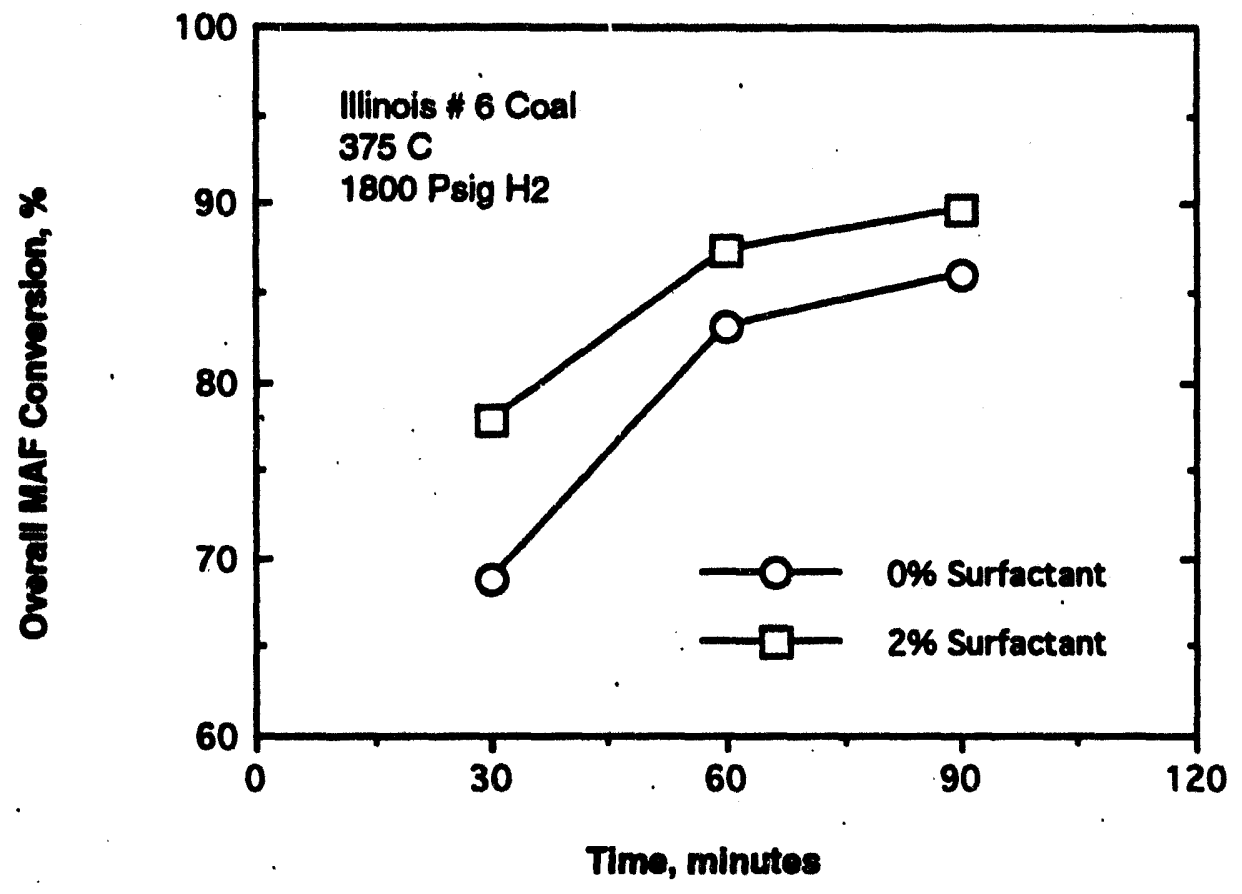

Figure 3.3: Conversion dependence on time, with and without the addition of surfactant. 


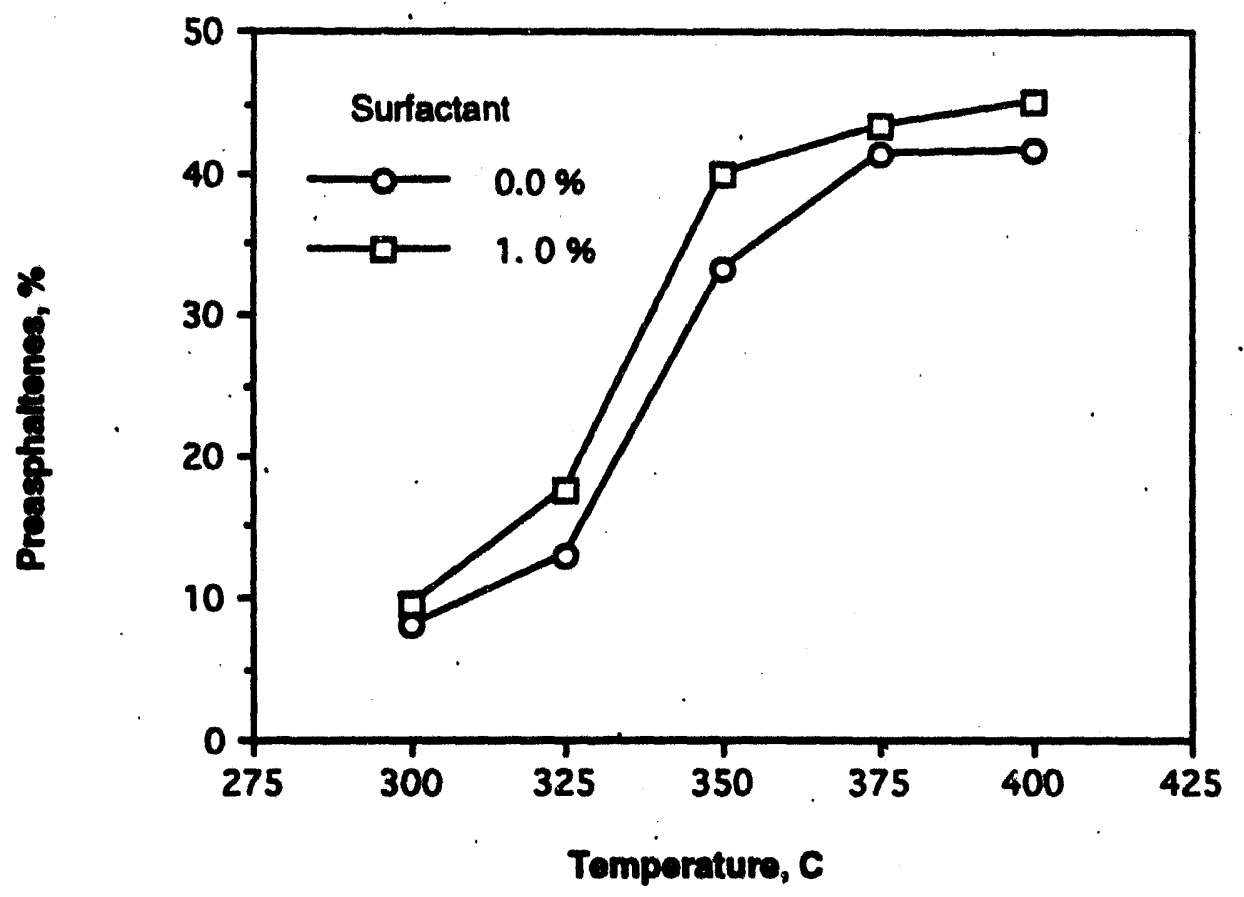

Figure 3.4: Yield of preasphaltenes (as determined from THF extraction) as a function of temperature with and without surfactant. 
The decomposition products due to the thermal instability of the surfactant were also studied by mass spectroscopy. A small quantity of the surfactant (about $50 \mathrm{mg}$ ) was placed in a quartz sample holder flask and was connected to a mass spectrometer sampling system. The quartz flask was heated at a rate of approximately $4{ }^{\circ} \mathrm{C}$ per minute to a final temperature of $420{ }^{\circ} \mathrm{C}$. The vapor emanating from the flask was analyzed by the mass spectrometer at temperature increments of $25^{\circ} \mathrm{C}$.

The decomposition products from the surfactant, sodium lignosulfonate, were seen to be given out at temperatures above $150{ }^{\circ} \mathrm{C}$. A majority of these decomposition products appeared to be miscellaneous hydrocarbons. At temperatures up to $350^{\circ} \mathrm{C}$, the most pronounced set of peaks were in the molecular weight range of 60 to 65 , though smaller amounts of hydrocarbon species of molecular weight up to 138 were also seen. Two peaks, corresponding to atomic-mass-units (amu) of 91 and 94, appeared at temperatures above $300^{\circ} \mathrm{C}$. Above $350{ }^{\circ} \mathrm{C}$, the majority of the hydrocarbon peaks diminished rapidly with the increase of temperature, but the two peaks corresponding to atomic-mass-units of 91 and 94 increased in intensity. These peaks were present even at $420^{\circ} \mathrm{C}$. It is interesting to note that these peaks would correspond to the mass spectra contributions from the functionality $\mathrm{CH}_{2}$ $\mathrm{SO}_{3}$. This observation suggests that the functionality $\mathrm{CH}_{2}-\mathrm{SO}_{3}$ may detach itself from the surfactant at temperatures above $300{ }^{\circ} \mathrm{C}$ and the resulting unstable species may attack the catalyst, thus lowering its performance.

The positive effect of the surfactant is seen not only in the overall conversion but also in the product quality of the distillate slate. This is best illustrated by Figure 3.5 which compares the distillate at $400^{\circ} \mathrm{C}$ with and without surfactant. The results for the distillation are provided in Appendix 5 for all runs analyzed. For the $400^{\circ} \mathrm{C}$ processing run, there was a significant increase in the lower boiling distillate fraction for the case where surfactant was added compared to the case without surfactant. In general for all the runs, there was only a little distillate below $210^{\circ} \mathrm{C}$, approximately an equal amount of distillate between 210 to $270{ }^{\circ} \mathrm{C}$ and 270 to $300^{\circ} \mathrm{C}$. The largest fraction of distillate was from 300 to $340^{\circ} \mathrm{C}$. For the $400^{\circ} \mathrm{C}$ runs, more than $50 \%$ of the distillate had a boiling point below $340^{\circ} \mathrm{C}$. The surfactant has a positive effect on the amount and distribution of the distillate. The trend of improvement in the quality of the liquid yields by the addition of the surfactant is still seen at $400^{\circ} \mathrm{C}$. Figure 3.6 shows the percent increase in light boiling fraction distillate $\left(20\right.$ to $300^{\circ} \mathrm{C}$ ) that is produced by the addition of $1 \%$ surfactant compared to the base case of no surfactant. The greatest percentage increase is still seen at $350^{\circ} \mathrm{C}$ with a $22 \%$ improvement, but there is still a $15 \%$ enhancement in light distillate quality at $400{ }^{\circ} \mathrm{C}$. It is this low boiling fraction distillate that would have the greatest commercial value for an industrial process. 


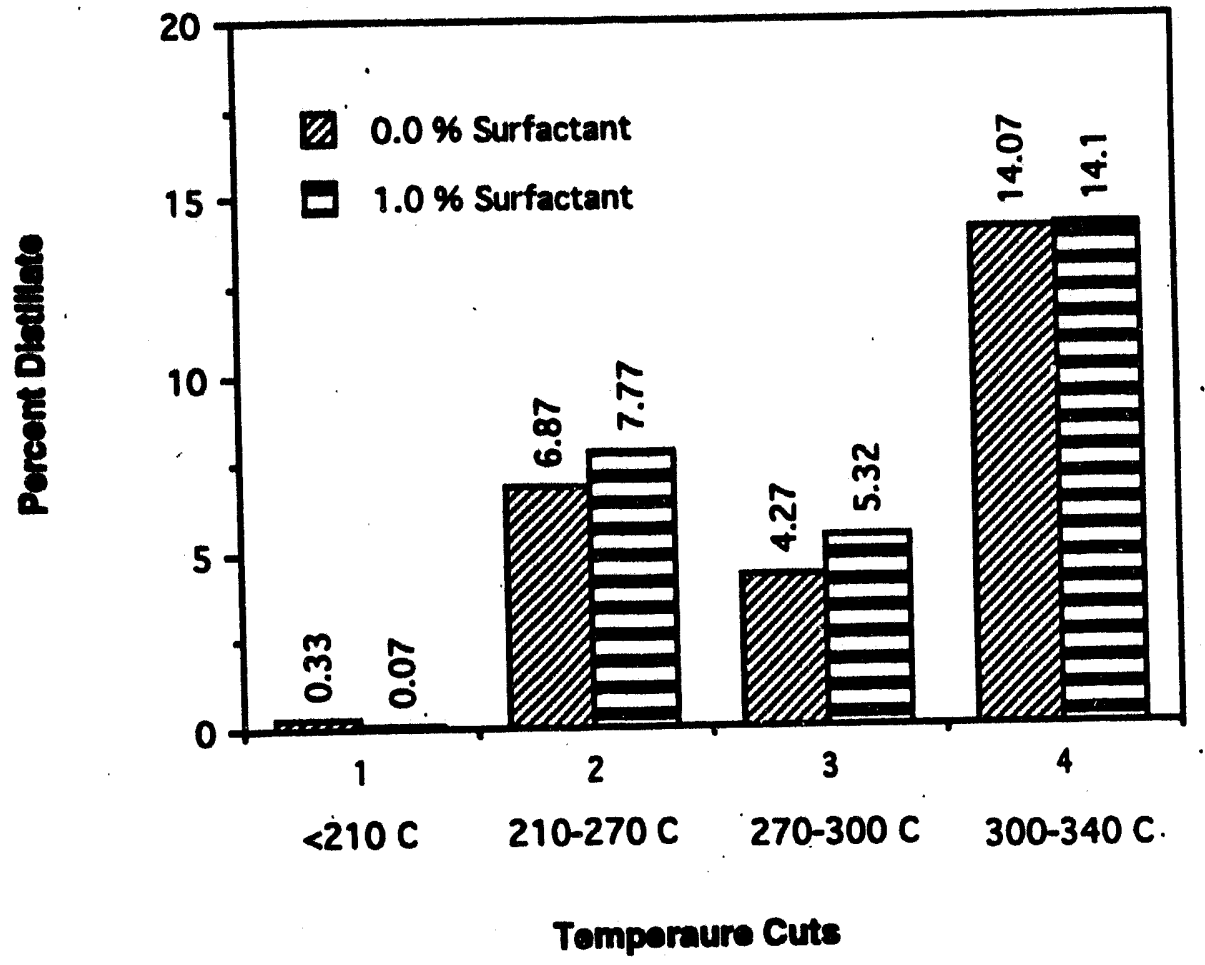

Figure 3.5: Distribution of the low boiling point fraction distillate with and without surfactant at $400^{\circ} \mathrm{C}$ processing temperature. 


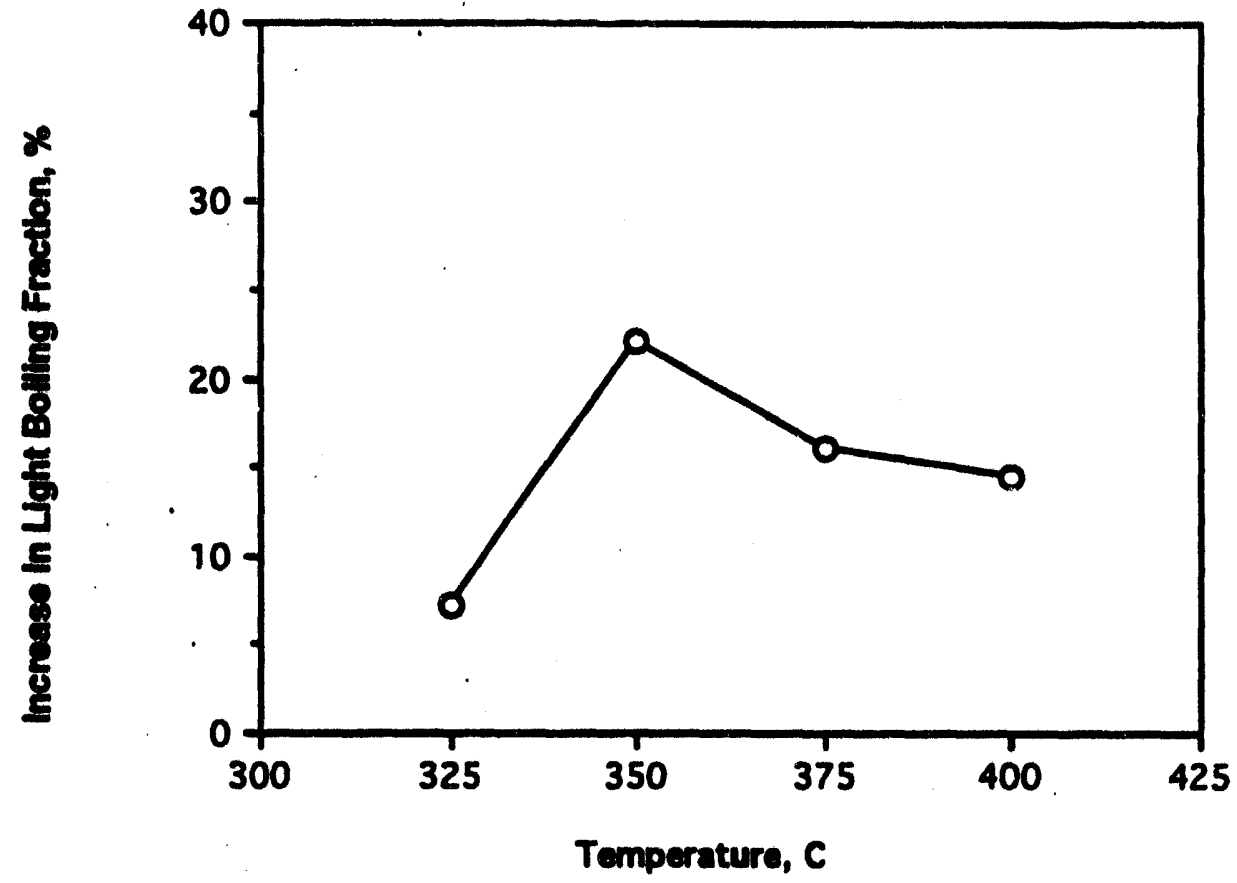

Figure 3.6: Percent increase in light boiling fraction of distillate after $1 \%$ surfactant addition compared to $0.0 \%$ surfactant.

The observed increase in the overall coal conversion due to the addition of the surfactant, sodium lignosulfonate, appears to result mainly from the breakage of crosslinks of the associated coal molecules. This, in turn, appears to lead to greater access of hydrogen to the coal fragments and thus a significant increase in the hydrogenation rate and subsequent solubilization rate. The mechanism of the surfactant will be discussed in Section 4. Figure 3.2 shows that overall conversions are relatively independent of surfactant concentrations from 0.5 to $2.0 \%$. The observation that overall coal conversions are relatively independent of surfactant concentration is consistent with a recent study on the kinetics of adsorption of surfactants on mineral matter. Marbrel and Somasundaran 6 have reported a study of the surfactant adsorption on a mineral at the solid-liquid interface by electron spin resonance spectroscopy. This study showed that $40 \%$ of the total ultimate surfactant adsorption occurred during the first 5 seconds of contact, independent of the initial surfactant concentration (provided sufficient surfactant was present). The second stage of adsorption was much slower and occurred on the order of one to three hours. In our case, where the coal is a mineral-containing solid with preferential acid sites for the surfactant, close to $100 \%$ of the total first stage surfactant adsorption may take place during the first minute of contact, even with very low surfactant concentrations. This is in agreement with the results shown in Figure 3.3 that show an increase in the rate of reaction with the addition of the surfactant. 


\subsection{EFFECT OF LIGNIN A.ND LIGNOSULFONATE}

While the favorable effect of surfactant addition has been well illustrated by the experimental work, there was a concerm that the observed improvement in liquefaction yields may be due to its decomposition to lignin-type products and their participation in the liquefaction process. To address this question, a literature search of the effeci of lignin addition in liquefaction or co-processing of coal and lignin was made and selected experiments were run with pure lignin.

The study of simultaneous coal and lignin liquefaction has been conducted broadly by two groups of investigators: Lalvani, et. al.7,8 at Southern Illinois University, and Coughlin, et. al.9.10 at the University of Connecticut, Storrs. The main findings of these studies are summarized below.

Lalvani, et. al. found that lignin-derived liquids when reacted with coal at about $375{ }^{\circ} \mathrm{C}$ enhance the rate of coal depolymerization by up to 30 percent. The lignin liquid-assisted coal depolymerization liquid products were observed to contain a significant amount of the lighter and desirable pentane soluble fraction. It was hypothesized that the enhancement in coal depolymerization rates can be explained by a reaction pathway involving intermediates formed from lignin derived liquids. For their work; a caustic lignin was obtained from steamexploded aspen. Lignin was added to tetralin and heated to $200^{\circ} \mathrm{C}$ in the presence of hydrogen gas. After reaction for a certain time, the reacted lignin was filtered. The filtrate was referred to as the lignin-derived liquid.

A follow up study indicated that the liquid product from the coal lignin mixture contains a lower fraction of the undesirable benzene insolubles than the liquid product from coal alone. The weight-averaged molecular weight for the overall liquid product (derived from the coal-lignin mixture) was lower than the molecular weight obtained by reacting coal or lignin alone. A $22 \%$ enhancement in coal conversion was seen to result.

Coughlin, et al. also observed that adding lignin to a mixture of coal and solvent caused more extensive depolymerization of the coal at lower temperatures (about $300^{\circ} \mathrm{C}$ ). The coal conversions were strongly dependent upon the ratio of lignin to coal. For processing temperatures of $300^{\circ} \mathrm{C}$ and pressures around 1500 psig, coal conversion without lignin addition was about $5 \%$. With a lignin to coal ratio of 1 to 4 , the coal conversion increased to about $20 \%$. With a lignin to coal ratio of 2 to 1 , the coal conversion was about $43 \%$. The mechanism of the lignin effect was investigated. Thermal depolymerization of the lignin at relatively low temperatures is believed to form resonance-stabilized phenoxy radicals, which appear to attack the coal causing scission of aliphatic carbon-carbon bonds in the coal.

In a later study by Altieri and Coughlin, the coliquefaction of lignin and bituminous coal was investigated at $400{ }^{\circ} \mathrm{C}$. The filterable solids from soliquefaction were about $30 \%$ benzene soluble compared to about $10 \%$ soluble when the same amounts of coal and lignin were reacted individually. 
The above studies can be summarized by the general conclusion that addition of lignin or lignin-derived liquids to coal during liquefaction assists in coal depolymerization and hence results in increased conversions even at low processing temperatures. However, significant improvement appears to result only if the ratio of lignin additive to coal is large enough (from 0.25 to 2.5).

Run 34 was planned to investigate the effect of sodium lignosulfonate or its thermal decomposition products on coal conversion which may run parallel to the surfactant action. In this run, 10.0 grams each of coal and the sodium lignosulfonate surfactant were subjected to liquefaction with 200 . $\mathrm{ml}$ of recycle solvent at $400^{\circ} \mathrm{C}$. The treated slurry was filtered and the filter cake was twice extracted with THF. Knowing that the surfactant liquefaction under these conditions is $70 \%$, the final dried residue was corrected to obtain the coal generated MAF residue. This number corresponds to overall coal conversion of $84.1 \%$, which is the same conversion for the coal alone with no surfactant addition. This indicates that the thermal decomposition products of the sodium lignosulfonate behaves differently than the lignin-derived liquiid and did not aid the liquefaction process. This result is consistent with the earlier observation that a significantly favorable effect of the surfactant is seen by addition of a small amount $(0.5 \%)$, and addition of a significantly larger amount does not produce further. enhancement.

In order to separate the lignin and surfactant effects, it was investigated to see if small amounts of pure lignin would affect the liquefaction process. Two experiments were conducted at 375 and $400{ }^{\circ} \mathrm{C}$ with $1.0 \%$ lignin addition. As seen in Figure 3.7, the addition of the lignin showed a significant decrease in conversion as compared to the lignosulfonate addition and these conversions were even lower than the base case of coal alone.

It is clear from the analysis of the test runs in this experimental work where only the surfactant was processed with the recycle solvent (without coal), that a part of the surfactant is converted to liquid products. These liquid products are likely to cause some enhancement in coal conversions due to lignin generated intermediate species formation as discussed by Coughlin9,10 However, such enhancement in conversions in this work should be very small as the amount of surfactant used is small. Based on the results from the two Coughlin papers, it is estimated that the addition of $1 \%$ lignin would only increase conversion by $0.5 \%$. Further, the overall conversions observed here are relatively independent of the surfactant concentration, whereas, the lignin induced improvement in conversion seen by Coughlin is strongly dependent upon the lignin concentration. This leads to the conclusion that it is the surfactant group of the lignosulfonate that is chemically active in enhancing the liquefaction. Hence, the improvement due to addition of sodium lignosulfonate would appear to be uniquely due to the surfactant effect and relatively free of the artifacts of its decomposition to lignin type products. 


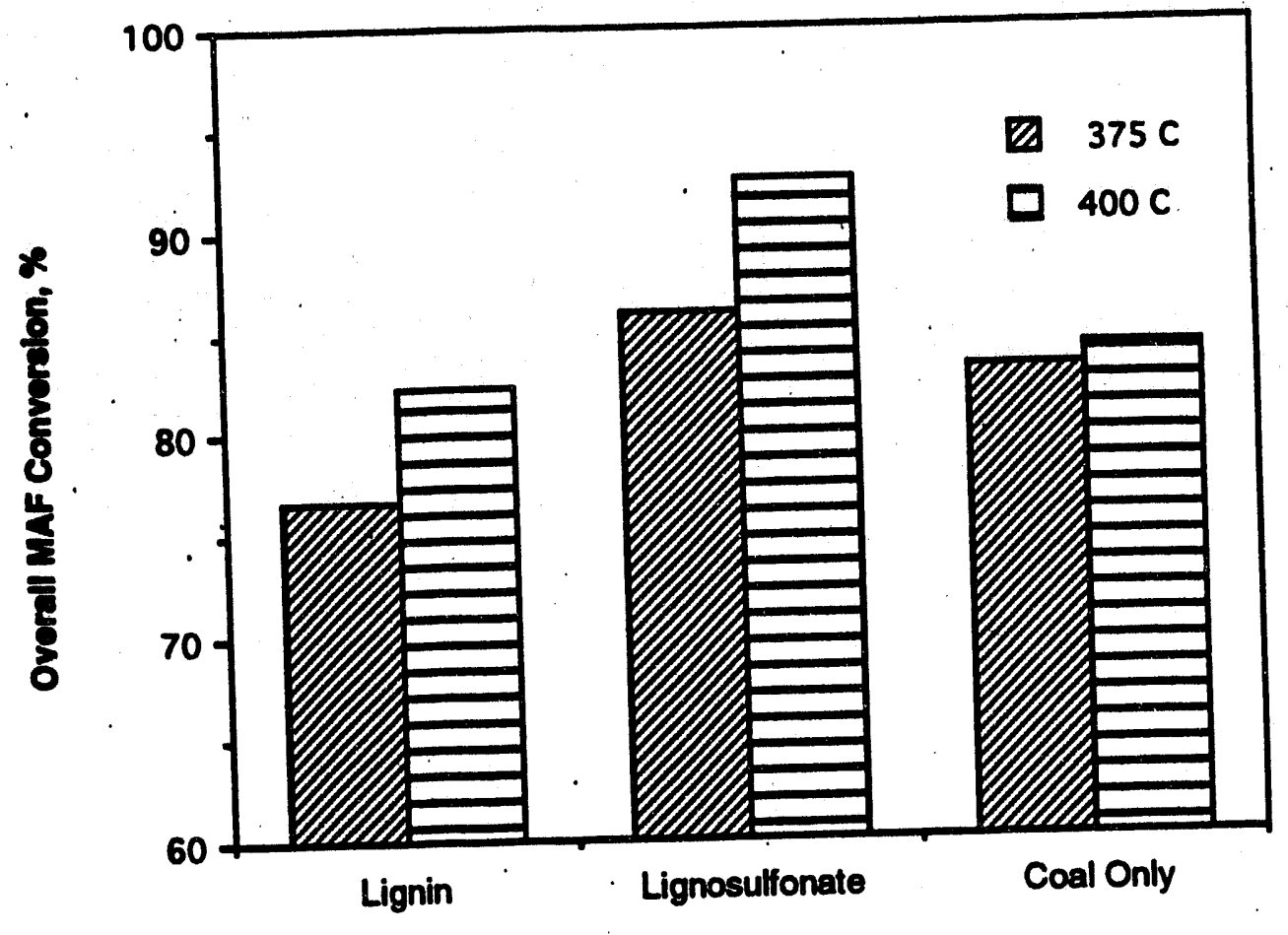

Figure 3.7: Comparison of MAF coal conversion with $1.0 \%$ lignin, $1.0 \%$ lignosulfonate and coal only.

\subsection{INTERACTION OF SURFACTANT WITH DISPOSABLE AND SUPPORTED CATALYSTS}

The current state of the art processing for coal liquefaction makes use of supported mixed metal catalysts in a two stage ebullated bed reactor. The use of a properly selected surfactant may either eliminate the need for the catalyst or reduce the amount of catalyst needed. There is also much current interest in the used of dispersed catalysts for the first stage of a two stage reactor process. In this study selected tests were conducted with $\mathrm{Fe}_{2} \mathrm{O}_{3}$ as a disposable catalyst and Shell 317 Ni-Mo supported catalyst. The Shell 317 was the catalyst that was used by HRI during the bench scale test.

Previous work by Cugini, et. al. 11 at PETC has shown that the addition of iron oxide as a disposable catalyst increases conversion over the noncatalyzed process. Their work focused on adding hydrated iron oxide (FeOOH) dispersed on coal by the incipient wetness precipitation approach. The results shown here are for the direct addition of finely ground iron oxide powder to the coal without further preparation. The addition of a surfactant may enhance the reactivity of a disposable catalyst. One well known disposable catalyst is $\mathrm{Fe}_{2} \mathrm{O}_{3}$ in its mineral form. Table 3.2 shows the results of the effect that $\mathrm{Fe}_{2} \mathrm{O}_{3}$ has on the conversion of coal to recoverable liquid products. The most noticeable effect was seen for 
the experiments at $375{ }^{\circ} \mathrm{C}$. The $1.0 \%$ surfactant addition at $375{ }^{\circ} \mathrm{C}, 1800 \mathrm{psig}$ Hydrogen and one hour processing time was used as the base case. This had a conversion of $85.9 \%$. By adding the $1 \mathrm{wt} \% \mathrm{Fe}_{2} \mathrm{O}_{3}$ to the coal with surfactant the MAF conversion increases to $92.1 \%$ for the batch reactor run. A third run with 1 wt $\% \mathrm{Fe}_{2} \mathrm{O}_{3}$ without surfactant had a conversion of $88.8 \%$. The addition of $\mathrm{Fe}_{2} \mathrm{O}_{3}$ at $400^{\circ} \mathrm{C}$ also showed a positive effect. The addition of the iron oxide increased the overall conversion to $89.6 \%$ over the base case of no surfactant, at $84.1 \%$ conversion compared to $89.6 \%$. at $400{ }^{\circ} \mathrm{C}$ with the addition of $1 \mathrm{gm}$ $\mathrm{Fe}_{2} \mathrm{O}_{3}$ and $1 \%$ surfactant. This is lower than the case of the surfactant alone with conversion of $92.9 \%$ and less than the $375^{\circ} \mathrm{C}$ result. The result at $375{ }^{\circ} \mathrm{C}$ is higher than expected and may be artificially high. The case of the addition of the surfactant with $\mathrm{Fe}_{2} \mathrm{O}_{3}$ alone was not evaluated at $400^{\circ} \mathrm{C}$. This preliminary work indicates that the addition of the iron oxide and surfactant may have a positive synergistic effect on coal conversion at $375^{\circ} \mathrm{C}$, but since the effect is not seen at $400^{\circ} \mathrm{C}$, this interaction should be further investigated.

Table 3.2: Effect of $\mathrm{Fe}_{2} \mathrm{O}_{3}$ addition on MAF conversion at 375 and $400{ }^{\circ} \mathrm{C}$ at 1800 psig Hydrogen and $1 \mathrm{hr}$ processing.

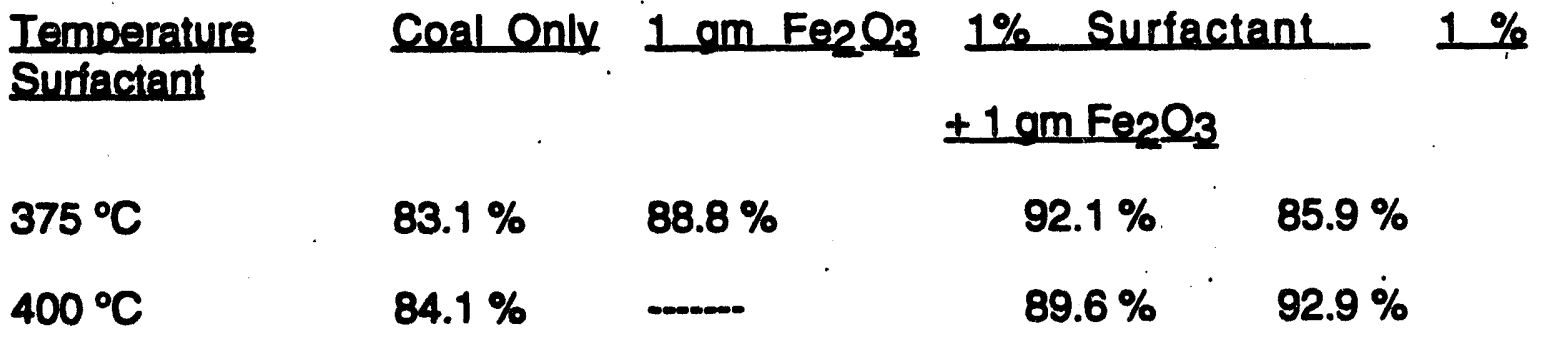

The HRI two-stage ebullated bed liquefaction process makes use of catalyst addition to produce an improvement in product slate quality. Selected tests were conducted to determine the effect of catalyst interaction with the surfactant. Figure 3.8 shows a comparison at $400^{\circ} \mathrm{C}$ between the a) baseline case of thermal processing of coal alone, b) coal with $1 \%$ surfactant, c) coal with $1 \%$ HRI Ni-Mo catalyst, and d) coal with $1 \%$ HRI Ni-Mo catalyst and $1 \%$ surfactant. It is seen that the addition of either the surfactant or the HRI catalyst improves the conversion significantly over the base case, but the HRI catalyst is slightly more effective. However, when both the catalyst and the surfactant are added together at $400^{\circ} \mathrm{C}$, the conversion is decreased slightly compared to the catalyst alone.

The filter cake analysis for these cases showed that the yield of light oils was nearly the same for the runs where the additives were HRI catalyst alone (case c) and HRI catalyst mixed with the surfactant (case d), respectively. However, the yield of asphaltenes was higher and preasphaltenes lower for case d compared to case c. This indicates that at $400^{\circ} \mathrm{C}$, even though surfactant addition to HRI catalyst lowered the conversion by a small amount, it still 
improved the product slate due to generation of increased amounts of lighter components.

Run 43 was conducted to simulate a two stage reactor, with $0.5 \%$ surfactant added with the coal and processed through both stages, with supported catalyst being in the second stage only. The first stage would be at $375^{\circ} \mathrm{C}$ and the second stage would be at $400^{\circ} \mathrm{C}$. Both reactors would be at the same pressure of 1800 psig. The run was conducted by initially adding $0.5 \%$ surfactant with the coal and recycle oil, pressuring and heating to $375{ }^{\circ} \mathrm{C}$ for 30 minutes, then allowing the reactor to cool. The reactor was then opened, the contents mixed again and $1 \mathrm{gm}$ of ground $\mathrm{Ni}$-Mo catalyst obtained from HRI was added. The reactor was repressurized and heated to $400{ }^{\circ} \mathrm{C}$ for an additional 30 minutes. The MAF conversion for this run was $93.4 \%$. This compares well to the $93.8 \%$ MAF conversion for the equivalent run at $400{ }^{\circ} \mathrm{C}$ for one hour.

Table 3.3 provides the distillation fractions for the $400^{\circ} \mathrm{C}$ autoclave runs. At $400^{\circ} \mathrm{C}$ the surfactant has the effect of improving the distillate quality. For comparison, the total distillate up to $340^{\circ} \mathrm{C}$ is summed and will be referred to as the total light distillate. The addition of $1 \%$ surfactant at $400{ }^{\circ} \mathrm{C}$ in Run 37 produces a $6.7 \%$ increase in the total light distillate over the base case of only coal at the same processing conditions in Run 36. The addition of $1 \mathrm{gm}$. Ni-Mo catalyst alone for Run 39 produces about $1 \%$ less light distillate. Because of uncertainty in the distillation technique, these runs should be considered equivalent. When the surfactant is added in addition to the Ni-Mo catalyst there is $17.6 \%$ increase in light distillate over the base case of coal alone and a $10.2 \%$ increase over the surfactant atone or catalyst alone in terms of product quality. This implies that there is a positive synergism between the surfactant and the catalyst. The MAF conversion for the $1.0 \%$ surfactant and $1 \mathrm{gm}$ catalyst is $93.8 \%$. This is nearly the same as the $95.6 \%$ conversion for the catalyst alone and $92.9 \%$ for the surfactant alone, given the margin of uncertainty in the conversion results of about $1-2 \%$. Run 43 for the two stage reactor simulation at milder processing conditions showed light distillate yields that were similar to the surfactant alone or catalyst alone at $400^{\circ} \mathrm{C}$. 


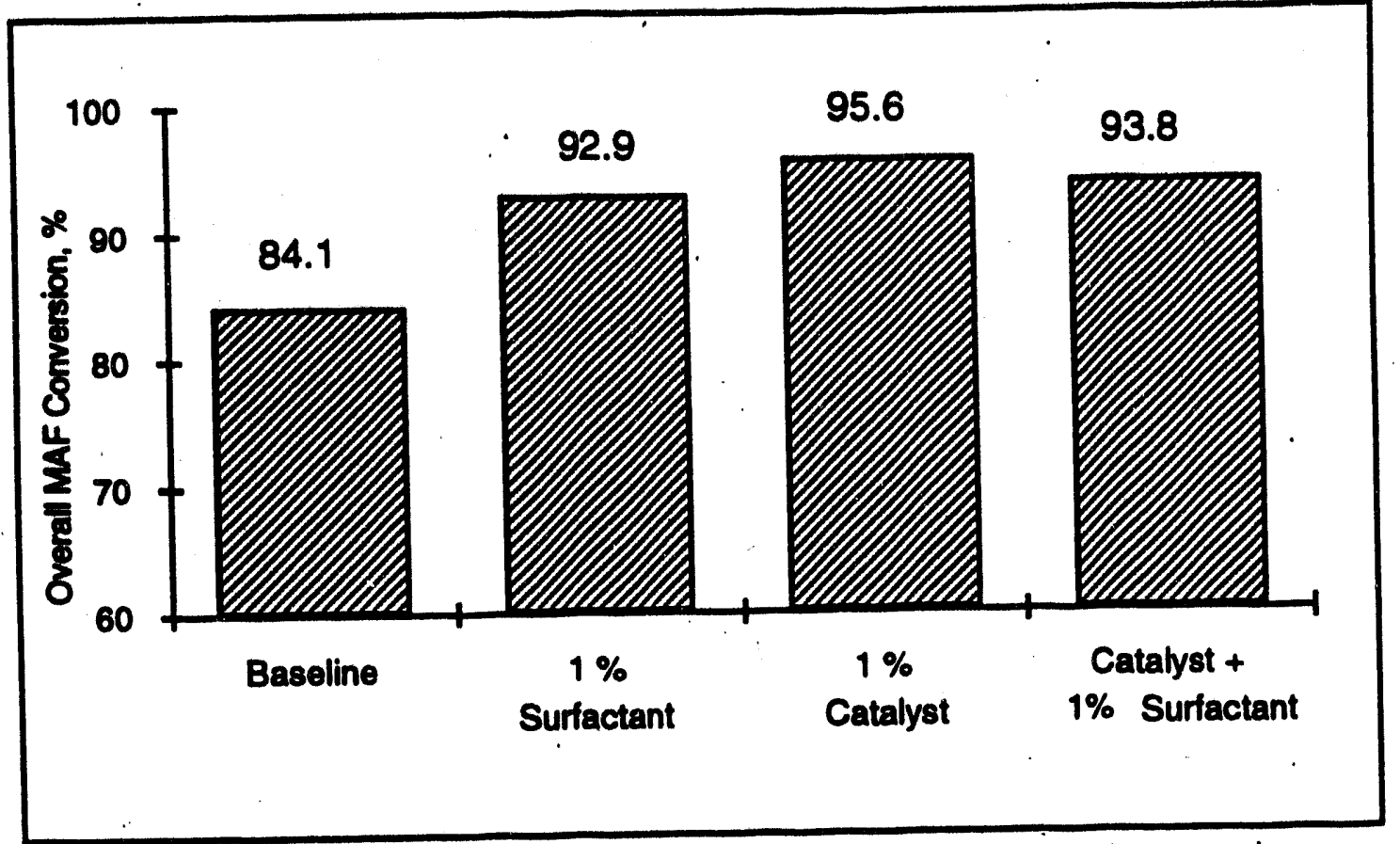

Figure 3.8: Comparison of MAF conversion of catalyst and surfactant interactions at $400^{\circ} \mathrm{C}$.

Table 3.3: Distillation fractions of the liquid filtrate based on a $50 \mathrm{~g}$ sample.

\begin{tabular}{|c|c|c|c|c|c|c|c|c|}
\hline $\begin{array}{l}\text { RUN } \\
\text { No. }\end{array}$ & $\begin{array}{l}\text { TEMP. } \\
\text { OC }\end{array}$ & $\begin{array}{l}\text { SURFACT. } \\
\text { CONC. } \\
\text { w } \%\end{array}$ & $\begin{array}{l}210^{\circ 0} \\
\text { CUTT } \\
9\end{array}$ & $\begin{array}{l}270^{\circ} \\
\text { CUT } \\
9\end{array}$ & $\begin{array}{l}300^{\circ} \mathrm{C} \\
\mathrm{CUT} \\
9\end{array}$ & $\begin{array}{l}340^{\circ} \mathrm{C} \\
\mathrm{CUT} \\
\mathrm{g}\end{array}$ & $\begin{array}{l}\text { BOTTOMS } \\
>340^{\circ} \mathrm{C} \\
g\end{array}$ & $\begin{array}{l}\text { TOTAL LIGHT } \\
\text { UP TO } 340^{\circ} \mathrm{C} \\
\mathbf{g}\end{array}$ \\
\hline 36 & 400 & 0.0 & 0.33 & 6.87 & 4.27 & 14.07 & 23.06 & 25.54 \\
\hline 37 & 400 & 1.0 & 0.07 & 7.77 & 5.32 & 14.10 & 21.89 & 27.26 \\
\hline 38 & 400 & $1.0^{A}$ & 0.22 & 6.56 & 6.04 & 12.17 & 24.32 & 24.99 \\
\hline 39 & 400 & $0.0^{B}$ & 0.11 & 7.61 & 5.06 & 14.23 & 22.46 & 27.01 \\
\hline 40 & 400 & $1.0^{B}$ & 0.69 & 6.60 & 5.97 & 16.92 & 23.96 & 30.06 \\
\hline 43 & $375 / 400$ & $1.0^{B}$ & 0.00 & 7.93 & 4.82 & 14.40 & 22.46 & 27.15 \\
\hline
\end{tabular}

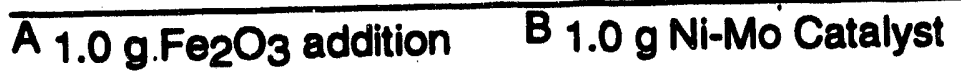




\section{MECHANISM STUDY}

The structure of coal has been investigated by many researchers and it is generally agreed to consider coal as a highly crosslinked amorphous polymer, which consists of a large number of stable aggregates connected by relatively weak crosslinks. Figure 4.1 shows one possible structure. At high temperatures in the presence of a hydrogen donor solvent, the fragments will break up into radicals that are capped by. the solvent to form stable species before reaction. These species consist of aggregates, or groups of aggregates with molecular weights ranging from 300 to 3000 . In the absence of a hydrogen donor solvent, the radicals will react to form either char or coke. These coal derived fragments are primarily preasphaltene and asphaltene particles. They consist of high molecular weight polyaromatic or polycyclic molecules with links to heteroatoms of $N, O$ and $S$.

The coal liquefaction process occurs in three stages: 1) the solubilization and breakage of the crosslinks of the coal in the solvent into smaller fragments, 2) the reaction of hydrogen with the coal tragments by hydrogen transfer to lower molecular weight molecules, and 3) the rehydrogenation of the solvent. All three processes are important to occur to have a functional, self-sustaining continuous industrial process. The three primary considerations for the sustainablilty and high reactivity of the system are the hydrogen donor capability of the liquid solvent produced, the physical solubilization of the coal particles within the solvent, and the hydrogen transfer for reaction within the system.

\subsection{ROLE OF THE SURFACTANT}

Coal particles typically disperse poorly in nonpolar and mildly polar solvents, and tend to agglomerate into aggregates of high molecular weight. The motive for adding a surfactant with an "asphaltene-like" structure was to better disperse the particles and prevent them from aggregating. Sodium lignosulfonate surfactant was chosen, in part, because it is an oil-compatible colloidal surfactant that is commercially available as an inexpensive by-product from waste paper and pulp processing. It has an approximate structure shown in Figure 4.2. It has a molecular weight in the 300 to 1000 range. At mild processing temperatures it readily disperses in hydrocarbon solvents as molecular units. It is typically used in industry as a dispersion agent for solids, and as an oil-water emulsion stabilizer. It is relatively stable at the processing temperatures up to $375^{\circ} \mathrm{C}$. The lignosulfonate may act as an aid in dissolution of the coal particles into asphaltene and preasphaltene units, as micelles and colloids, without the formation of radicals which can recondense and react to form char or coke.

The ability to disperse the coal particles in a slurry would be seen as a reduction in viscosity. The effect of viscosity reduction with the addition of the surfactant at temperatures up to $100{ }^{\circ} \mathrm{C}$ was shown in previous work by $\mathrm{Hsu}^{3}$. The sodium lignosulfonate was found to act better in viscosity reduction over other anionic, cationic, and nonionic surfactants at these lower processing 


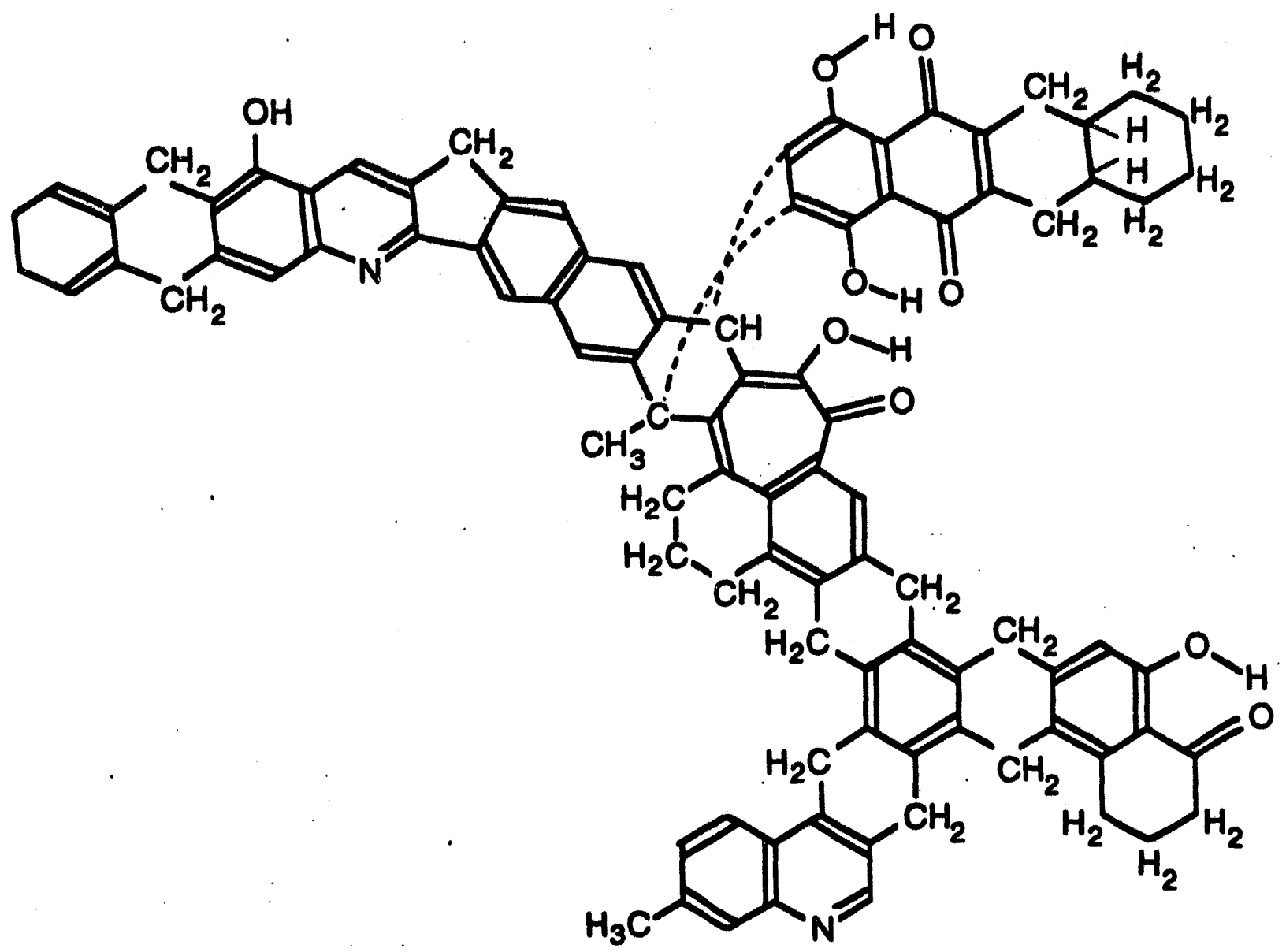

Figure 4.1: Representative structure of coal (from Givens and Peover, Euel, 1960, Vol. 39, p. 463)<smiles>Cc1ccc(CC(C(Cc2ccc(S(=O)(=O)O[AlH2])c(C)c2)C(C)(C)C)C(C)(C)C)cc1C</smiles>

Figure 4.2: Representative structure of sodium lignosulfonate surfactant. 
temperatures. Based upon these results, a systematic analysis of the effect of sodium lignosulfonate on coal liquefaction was carried out.

As seen from the data presented Section 3 , the addition of the surfactant increased conversions at all temperatures and pressures. To better understand how the lignosulfonate works, and to give greater insight into the liquefaction process to develop surfactants that might be more effective and have a broader application range, detalled analysis of the constituent products were conducted.

\subsection{INVESTIGATION OF THE SURFACTANT MECHANISM}

Figure 4.3 shows one possible mechanism for the reaction of the coal with the surfactant. Without the surfactant, the coal would agglomerate and only the outer peripheral groups would react. This would lead to increased gas production and lower conveision. If the preasphaltene coal fragments are separated by the surfactant, larger coal fragments could react with the hydrogen and give higher conversion.

To further evaluate the role of the surfactant, a series of analytical evaluations were made of the processed coal filter cake, filtrate and residue. The primary objectives of the analytical work were to determine the distribution of the surfactant in the product streams, and to quantlfy changes in the liquefaction product due to the addition of the surfactant.

\section{Sodium Analysis on Filter cake and Extracted Residue}

Two residues from $375^{\circ} \mathrm{C}$ processing runs, one with $2 \%$ surfactant, and the other without any surfactant were analyzed by SEM/EDS to determine if any surfactant was retained in the residue after successive extractions with hexane, toluene and THF. The surfactant contains $7.0 \%$ sulfur by weight and $\mathbf{5 . 9 \%}$ sodium by weight. Since the coal has $4.5 \%$ sulfur initially, the presence of sodium was used to quality the presence of surfactant. Sodium was found evenly dispersed in the residue of the surfactant added sample by SEM/EDS analysis. Flame atomic absorption was conducted on the two residues to determine the total sodium. From a mass balance based on the increase in sodium content of the samples where the surfactant was added, it was determined that $53 \%$ and $47 \%$ of the surfactant was retained in the filter cake and extracted residue, respectively.

\section{FTIR Analysis}

The flitrates, filter cakes and residues were characterized by Fourier Transform Infrared Spectroscopy (FTIR) to determine structural differences between samples with and without surfactant. The $0 \%$ and $2.0 \%$ surfactant added runs at $375^{\circ} \mathrm{C}$ were analyzed by the diffuse reflectance method, as were the pure surfactant and recycle solvent. The surfactant was seen in the $2.0 \%$ sample of the filtrate, filter cake and residue as a distinctive sulfonate group stretch at wavenumber $1145 \mathrm{~cm}^{-1}$. The filtrates, filter cakes and residues were all multifunctional group structures. With the exception of the surfactant 
presence, there was only a little difference between the two filtrates and residues. The fliter cake from the surfactant added sample showed some additional C-H stretching at around 2900 to $3000 \mathrm{~cm}^{-1}$ and some additional aromatic stretches near $1000 \mathrm{~cm}^{-1}$. Since there was a significant difference in the light boiling fractions of the filtrates from the $350^{\circ} \mathrm{C}$ runs, the $0 \%$ and $2.0 \%$ surfactant added filtrate products were analyzed by FTIR. These two samples showed more differences than the $375^{\circ} \mathrm{C}$ flitrates. The flitrate corresponding to $2.0 \%$ surfactant showed much stronger C-H stretches and aromatic stretches than the $0 \%$ surfactant added filtrate product. FTIR analysis was also conducted on successive hexane, toluene and THF extracts from the $0 \%$ and $2 \%$ surfactant added filter cake products. No significant structural differences were found between the extracts with and without the surfactant.

\section{NMR Analysis}

Proton NMR and $13 \mathrm{C}$ NMR were conducted on the two $350^{\circ} \mathrm{C}$ filtrates. For these two filtrates, their structures were very similar, consisting of allphatic, polycyclic and polyaromatic compounds. While no clear structural differences with and without the surfactant were observed, the analysis indicated that the majority of the aromatics were of the structure shown in Figure 4.4.

\section{GCMS Analysis}

To better quantlfy the filter cake products, gas chromatography (GC) was conducted on successive hexane, toluene and THF extracts from the $0 \%$ and $2.0 \%$ surfactant added filter cake products from the $375^{\circ} \mathrm{C}$ processing temperature runs. Samples of the extracts were injected into the GC ( a $25 \mathrm{~m}$ length DB5 capillary column) and separated by the column. Selected compounds were routed to a mass spectrometer for species identification. Reference samples of $\mathrm{C}_{10}$ to $\mathrm{C}_{30}$ compounds were also tested to provide a baseline for determining average molecular weights.

The hexane extracts were mainly saturated and unsaturated hydrocarbons. The extract from the $2 \%$ surfactant added product showed the presence of a larger number of species and an average molecular weight of 250 compared to a molecular weight of 230 for the extract without surfactant. The toluene extracts were primarily saturated and unsaturated hydrocarbons with some aromatic species. Both samples had an approximate molecular weight of 260. The THF extracts were mostly aromatic species. Though these species had a longer column retention time, they had a lower average molecular weight. The surfactant added THF extract had an average molecular weight of 150 compared to 125 for the $0 \%$ extract. There was good qualitative agreement regarding species structure between the GCMS and FTIR analyses.

\section{XPS Surface Analysis of the Fitter cakes}

Surface analysis of the hexane-washed filter cakes from the $0 \%$ and $2 \%$ surfactant added processed coals was conducted using X-ray Photoelectron .. Spectroscopy (XPS). The technique analyzes only the top $50 \mathrm{~A}$ of the surface. 

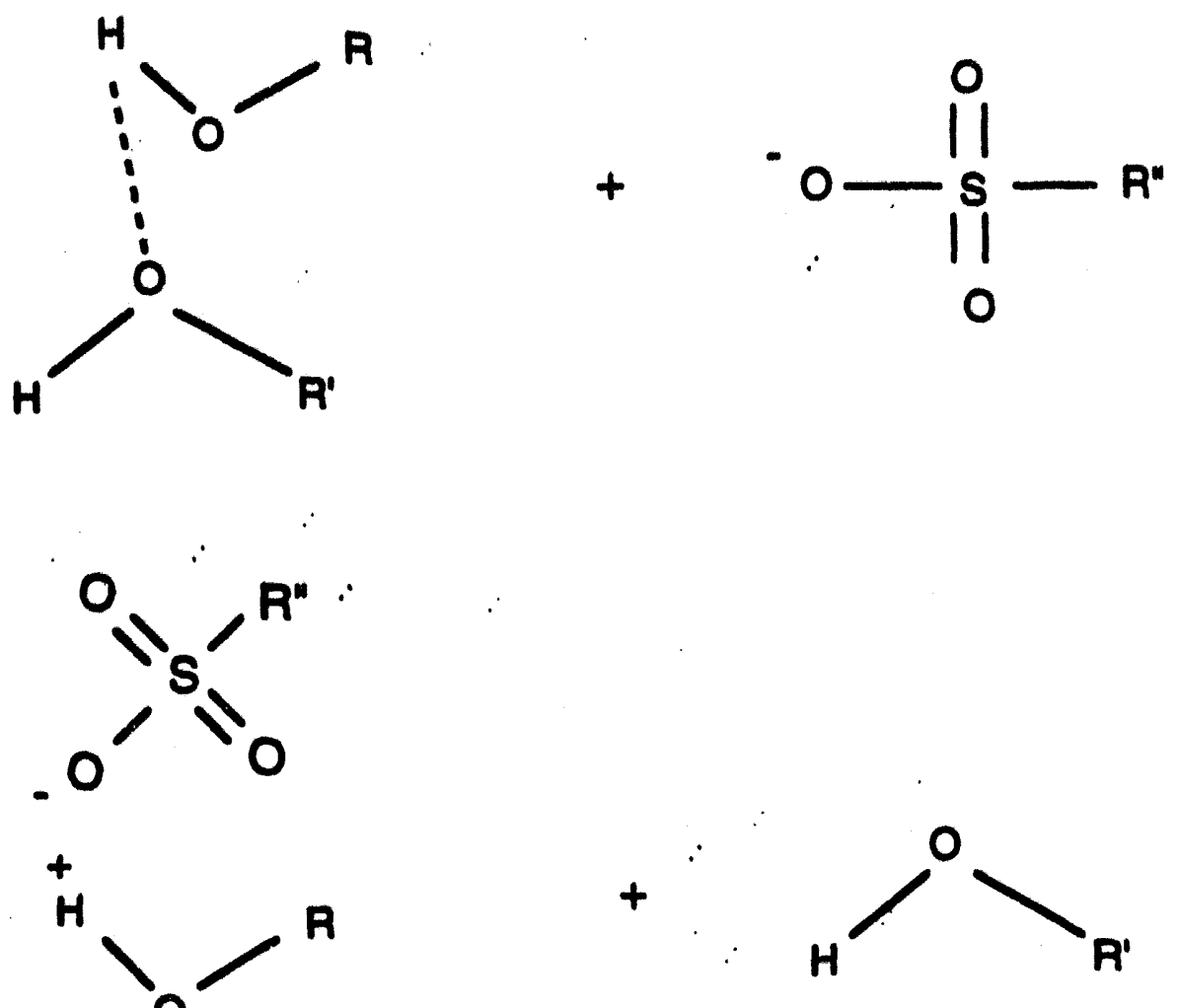

Figure 4.3: Representative mechanism for the role of the surfactant.
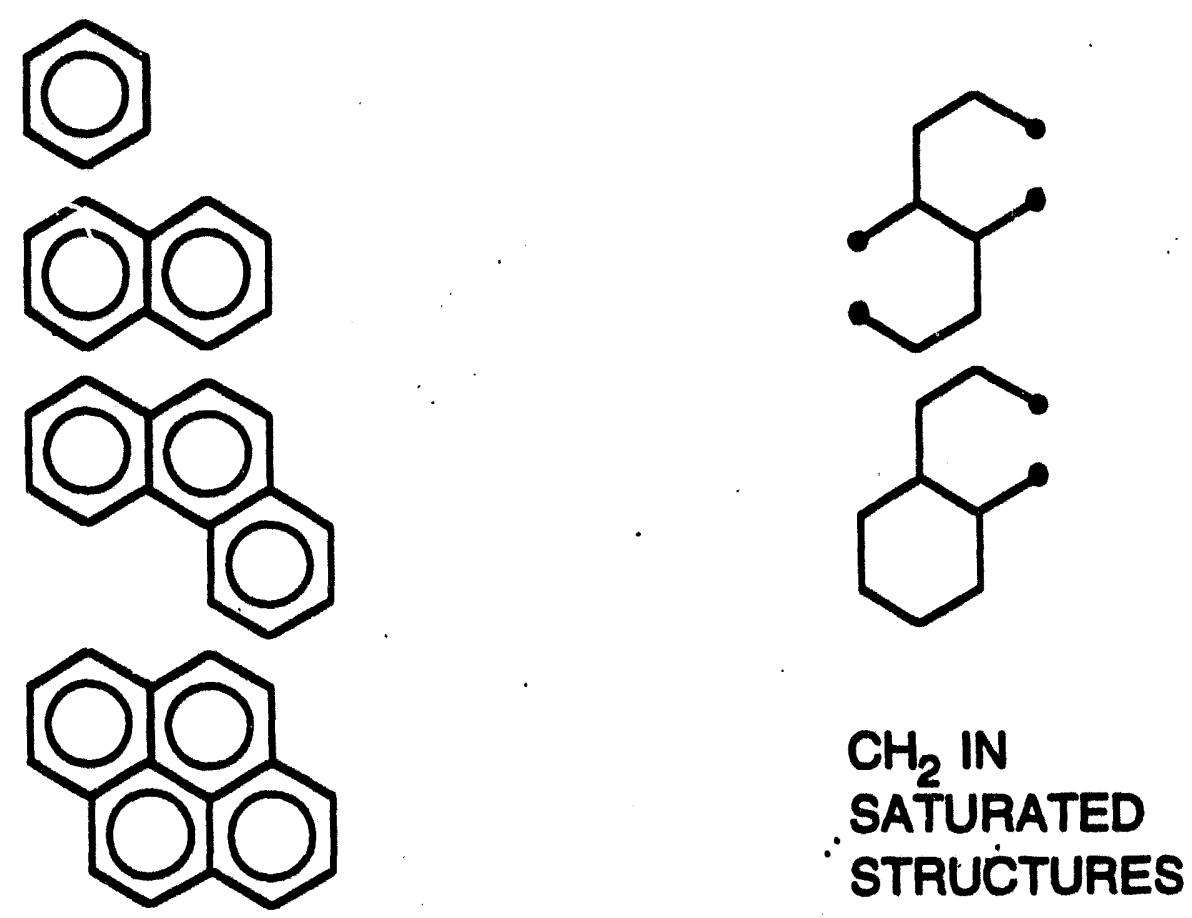

Figure 4.4: Representative functional groups of coal liquids that wt:3 seen by NMR. 
The analysis indicated only a trace level of the sodium on the surface for both the samples. This result is at odds with the quantitative sodium determination by atomic absorption. However, a possible explanation is that a majority of the surfactant migrated to macropores beneath the top surface. As macropore surface area is expected to be significantly greater than the external geometric surface, it is conceivable that the sodium concentretion on the external surface dropped below the detection level of the XPS.

\section{Surface Morphology by SEM Analysis}

The surface morphology of the coal after processing. was exariined by SEM. Samples of the filter cake were extracted with hexane to remove absorbed olls. Examples of the surface morphology are shown in Figure 4.5. The processed coal where surfactant had been added has a more open structure, with greater suriace area than the coal processed without surfactant. The addition of the surfactant appears to have opened up the pore structure of the coal, producing larger macropores. This provides evidence that the surfactant action is being facilitated by opening up the structure of the coal during processing. The coal hydrogenation occurs at the surfaces (internal pore and external) of a coal particle. If one considers the reactions on a macropore surface, in the presence of the surfactant, such reactions will be significantly enhanced due to the open structure of the coal fragments. Thus the macropore will be enlarged relative to its size (or opening) when no surfactant is present. This enlarging of the macropore was observed from the SEM morphological analysis of the hexane washed fitter cakes.

\subsection{DISCUSSION ON SURFACTANT ACTION}

The batch autoclave tests indicate a significant increase in overall coal conversions at all operating temperatures in the range from 300 to $375^{\circ} \mathrm{C}$. The increase in light bolling fractions of the filtrate, on the other hand, is significant up to $350^{\circ} \mathrm{C}$ only. Analytical test results on the structure and functional groups of organic compounds in the filtrate, filter cake and extracted residues show only minor differences in the samples processed with and without surfactant. The same is also true of the structure and functional groups for the successive extracts obtained by weshing the filter cakes with hexane, toluene, and THF. The only significant differences obtained for the hexane and THF extracts are in the average molecular weights, which were higher in the $375^{\circ} \mathrm{C}$ processing run with $2.0 \%$ surfactant than for the case with no surfactant added.

Because the functional groups in various samples analyzed with and without the surfactant did not change drastically, the above results suggest that this surfactant does not significantly alter the three stage progression of coal liquefaction described earlier. The surfactant appears to speed up the first stage, the breakage of the crosslinks in the coal. If this process was rate controlling, the remaining two stages, l.e., the reaction of the hydrogen with coal fragments and the rehydrogenation of the solvent, would also speed up. 
The following discussion will help visualize how the surfactant may help in the breakage of the crosslinks of the coal. Let the coal be represented by R-O-H. Without the surfactant, coal molecules (represented as R-O-H and R'-O-H in Figure 4.3 are associated by hydrogen bonding between the H-atom of one coal molecule and the O-atom of the other. Due to its anionic polar nature, the surfactant attaches itself to the acid site (H atom) on the coal. Thus it breaks the association with the O-atom between different coal molecules, increasing the favorable hydrogenation reactions. Because the lignosulfonate is a Lewis acid and a partially hydrogenated aromatic compound, it is possible that it could act as a hydrogen donor in the reaction. This is a possible additional avenue of increase in favorable liquefaction processes due to the surfactant.

The addition of the surfactant at $375^{\circ} \mathrm{C}$ processing temperature increased coal conversion from $83 \%$ to higher than $90 \%$. The increase was primarily related to the increase in the THF extracted species from the filter cakes. As the THF extracted species are expected to be preasphaltenes and the GC/MS analysis indicate that these species to be polyaromatic compounds, the increase in the average molecular weight of the THF extract was not surprising. The species that converted to a THF soluble product due to the surfactant are expected to be bigger than those that did not require the surfactant.

The effects of the surfactant on the quality of the filtrate (i.e. the light boiling fractions) are clearly dependent on processing temperature. The surfactant increases the straight chain (lower bolling) hydrocarbons (C-H stretch) as well the molecular weight of the polyaromatics. At $350^{\circ} \mathrm{C}$, the increase in straight chain hydrocarbons appears to dominate, resulting in an increase of lighter fractions. At $375^{\circ} \mathrm{C}$, the production of aromatics appears to counter the production of aliphatic hydrocarbons. Hence, a significantly smaller increase in lighter fractions is observed. 


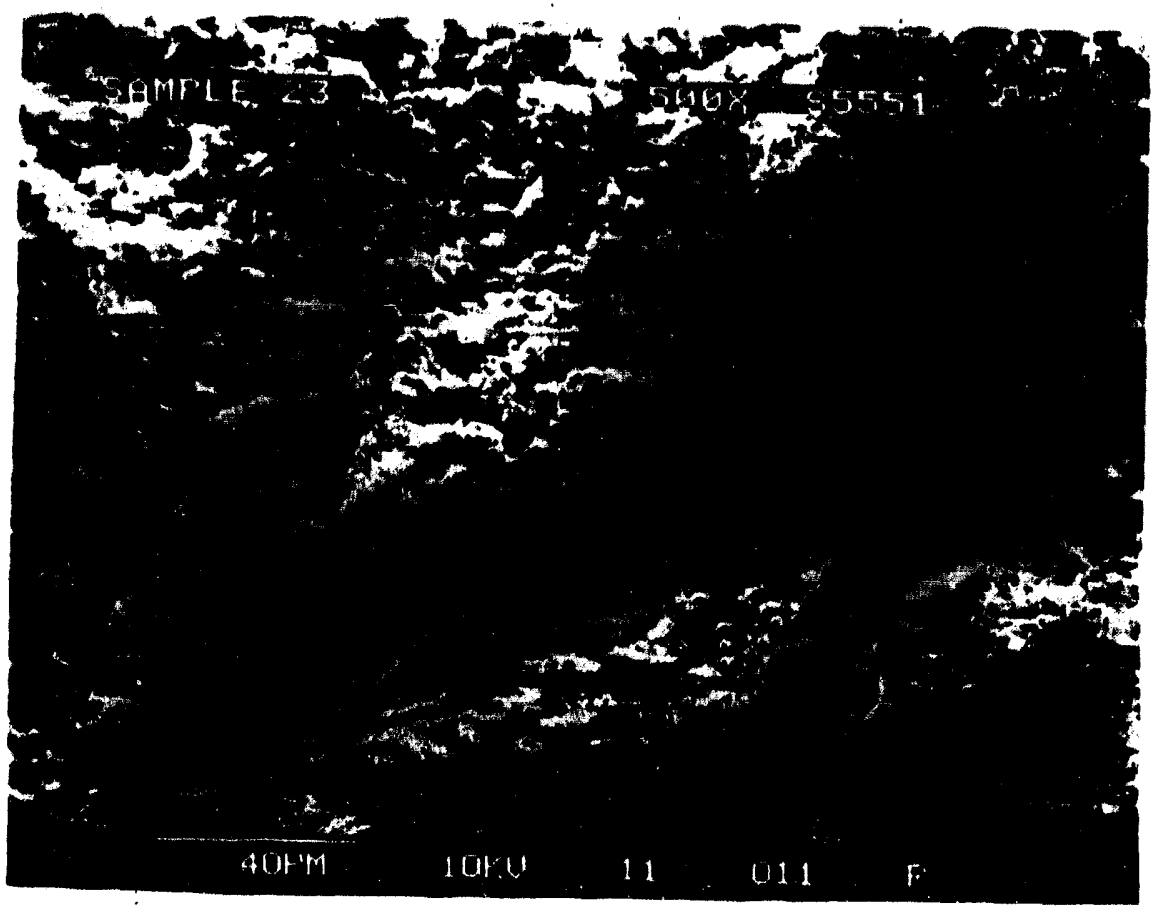

\section{5 a)}

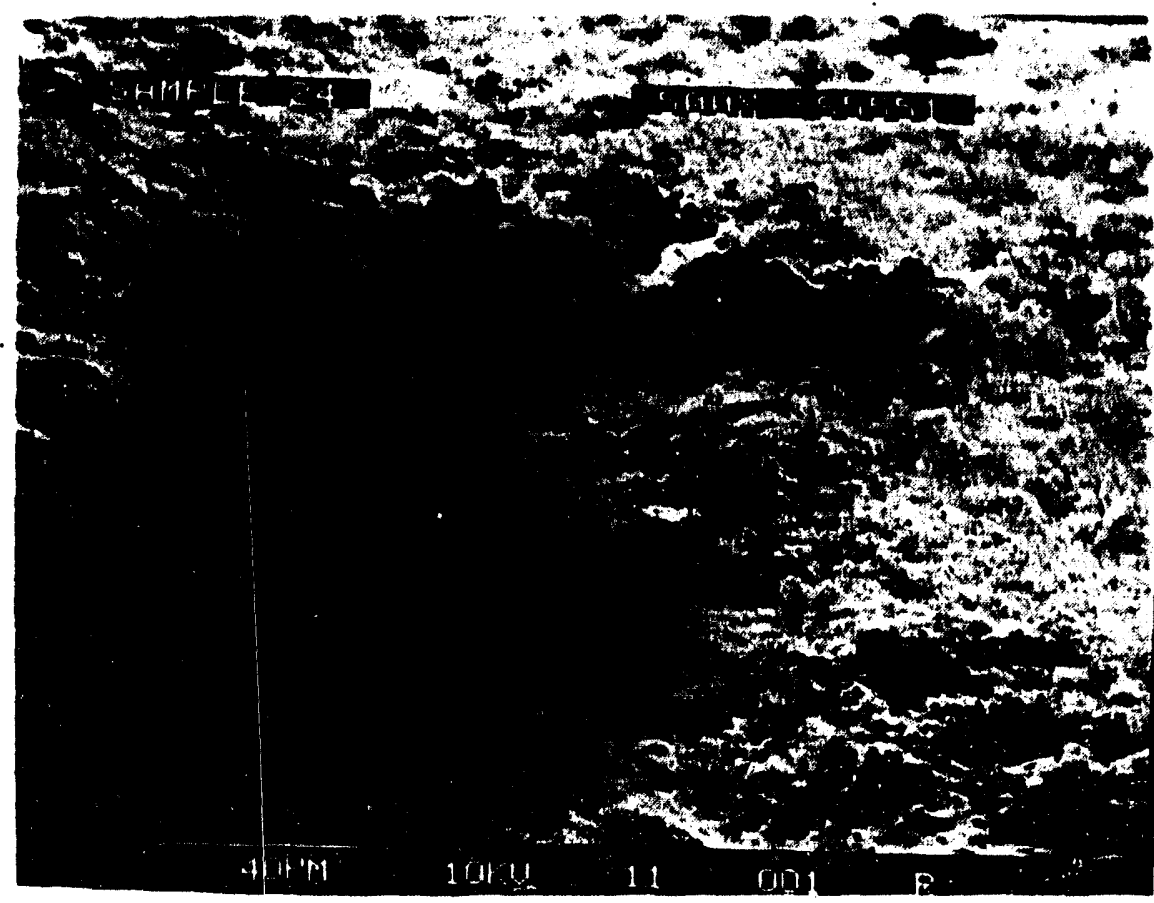

\section{5 b) .}

Figure 4.5: SEM micrographs of hexane extracted filter cakes a) with and b) without the surfactant added during processing. 


\section{HRI BENCH SCALE TEST}

All previous work completed under this research program has evaluated. the effect that surfactant addition would have on thermal liquefaction processes. It had been hoped that a continuous bench scale run could be conducted in a completely thermal operation. However, there was no available outside subcontractor that was capable of conducting a bench-scale cominuous operation with recycle of a completely thermal liquefaction within the scope and funding of this research contract. The only alternative was to utilize an industrial catalytic liquefaction bench-scale facility at HRI.

Hydrocarbon Research, Inc. (HRI) has been under contract to conduct bench-scale test of coal liquefaction by PETC utilizing their Catalytic Two Stage Liquefaction.(CTSL) process. In the month of May of this year, they had a scheduled operation (Run 227-78 (CMSL-2)) to evaluate the impact of lower coal ratios $(0.9-1.1)$ on Illinois \#6 coal. This was a $172 / 3$ day operation, of which the last $42 / 3$ days were devoted to evaluating the effect of sodium lignosulfonate surfactant addition on operation and process performance.

Run 227-78 was carried out using Illinois \#6 Burning Star mine No. 2 coal and Shell-317 (NI-Mo/Al2O3) catalyst (1/32" extrudates) in both reactors. The startup oil was L-769. The first three and $1 / 3$ days of operation were at high stage temperatures ( first stage $775^{\circ} \mathrm{F}$ and second stage $810^{\circ} \mathrm{F}$ ) and one and $1 / 3$ days of operation at reduced temperatures ( first stage $7500^{\circ} \mathrm{F}$ and second stage 810 \% F). The lignosulfonate surfactant was added to the feed slurry at 2 weight $\%$ (relative to the coal). A summary of the operation conditions and results are given in Table 5.1. In this table, periods 10,12, and 13 represent operating conditions and performance before adding the surfactant while periods 16 and $18 \mathrm{~A} B$ represent operating conditions and performance after adding the surfactant.

By a cumparison of the results for period 16 to period 13 , it is seen that the overall coal conversion increased by only 1 percent. Other performance parameters were somewhat lower. This degradation in these performance parameters was the same as would be expected due to the aging of the catalyst. Thus, it appears that no improvement in the process run due to surfactant addition was seen.

There are several reasons for the absence of a process performance improvement due to the surfactant addition. It is possible that the baseline overall conversion for this coal was already close to the maximum before adding the surfactant. The non-reactive carbon macerals in the coal are not expected to liquefy. Also, the surfactant may decompose appreciably at the high operating temperatures used in the bench-scale run, thus losing most of its effectiveness. 
Table 5.1: Summary of the operating conditions for the bench scale test.

RUN $227-78$ (CMSL-2) OPERATWG SUMMARY EVALUATION OF LOW SOLVENT-TOCOAL RATIOS

CON : HLNOLS NO.6 MRL6107

CATALYST: BHELL-317 HFH-5394 (BOTH STACES)

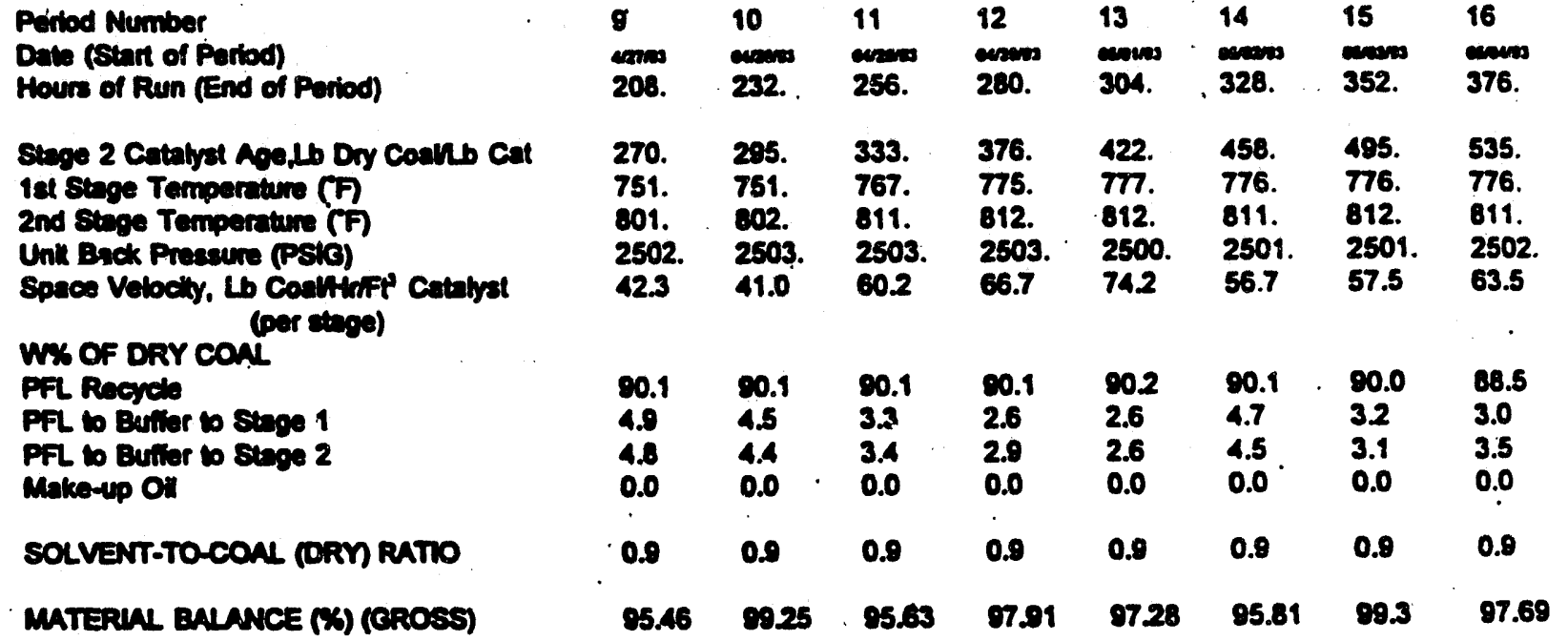

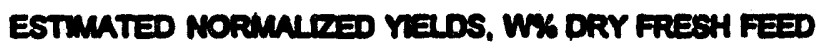

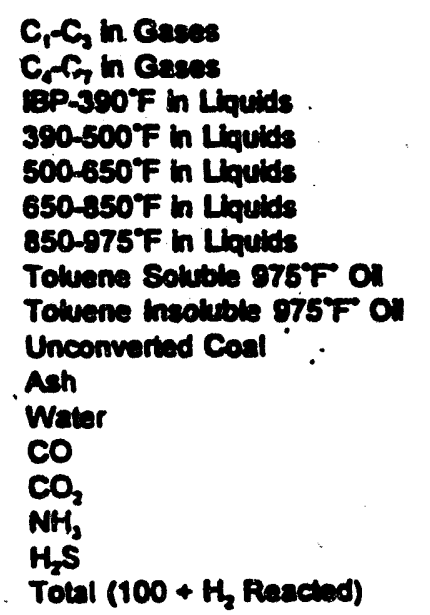

PROCESS PERFORMNUCE

CA-975'F Dietivates, W\% of MAF Coal
975\% Converion, W\% MWF
Coal Conversion, W\% MWF
HDS, W\%
HON, W\%

5.22
3.80
15.89
11.13
27.52
7.38
1.04
1.25
0.02
6.28
12.04
10.18
0.10
0.04
1.40
3.40
107.37


Table 5.1 (Cont.): Summary of the operating conditions for the bench scale test.

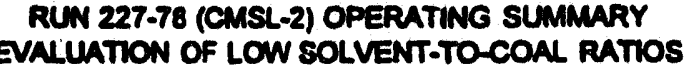

CONL : HLNOHS NO. 6 MRL6107

CATALYST : SHELL-317 HRL5394 (BOTH STAGES)

Pariod Number

Date (Start of Period)

Hours of Run (End of Period)

Suge 2 Chtatyst Aoedb Dry Coanb Cat

Ist Stage Tempernture (F)

and Stage Temperature (F)

Unik Beck Presioure (PSIG)

Space Volochy, Lb Coulfirfif' Catabyt (per stage)

WX OF DRY CON

PFl Rocyede

PFL to Buffor to Siege 1

PFi. to Butior to stege 2

Mako-up ON

SOLVENT-TO-CONL CRRM RATIO

MATERLAL BALNCE (\%) (CROSS)
$17 \quad 18 \mathrm{AB}$

$05105 / 93 \quad 05 / 06 / 93$

400.

$570 . \quad 597$.

763.752.

$801 . \quad 796$.

2506.2500.

$57.1 \quad 63.6$

$90.3 \quad 88.6$

$3.3 \quad 2.4$

$4.7 \quad 2.8$

$\begin{array}{ll}0.0 & 0.0\end{array}$

$0.9 \quad 0.9$

$98.96 \quad 92.96$

ESTMMATE NORMALTED YELOS, W\% DRY FRESH FEED

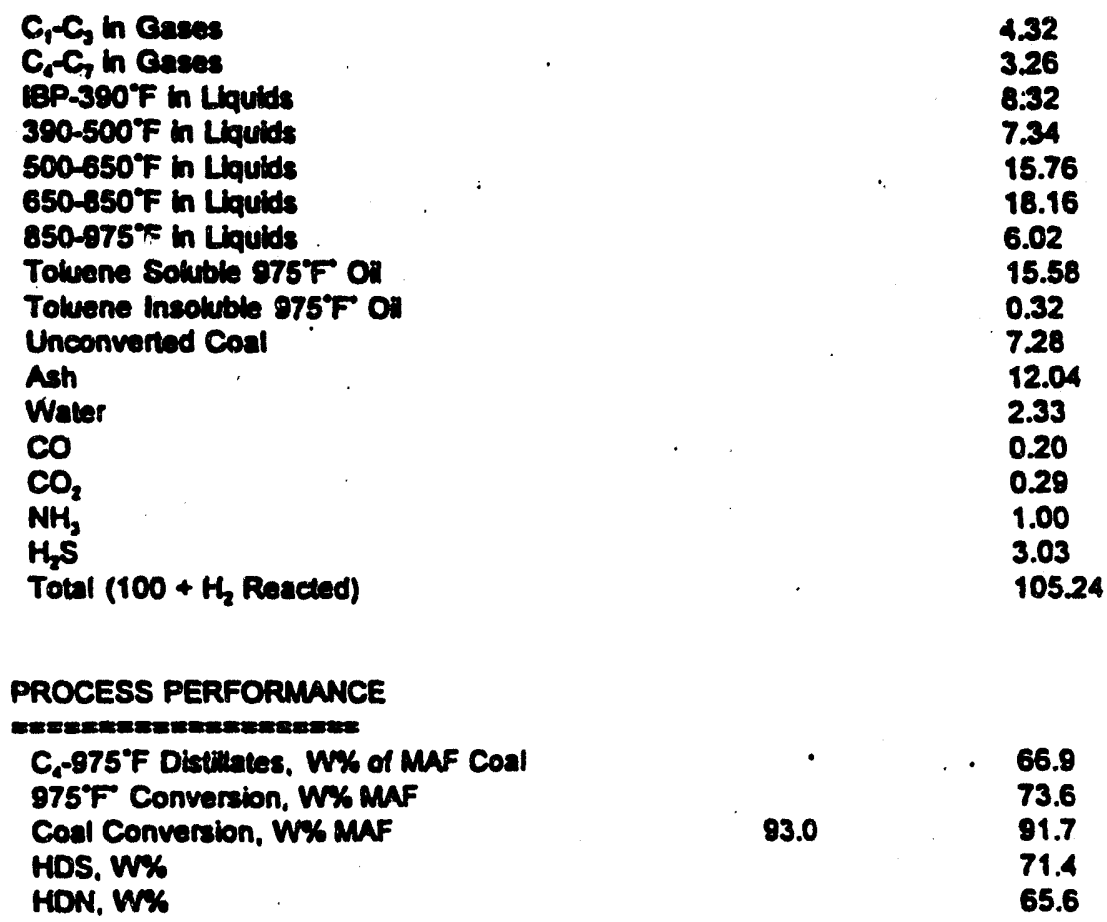




\section{HRL Batch Microautoclave Tests}

HRI also conducted six batch microreactor tests to determine coal conversions at temperatures of 750,800 , and 825 of with and without surfactant addition. There was a modest increase observed in coal conversion due to the surfactant addition at temperatures of 750 and 800 oF, respectively. HRI's results on the coal conversion and the percent increase in coal conversion (due to the surfactant) as a function of processing temperature are plotted in Figure 5.1 along with JPL's results (at lower processing temperatures) with $1 \%$ surfactant (based on total slurry) addition. The left part of Figure 5.1 shows the JPL data while the right part shows the HRI data. It is seen that the HRI results fit the trend established by the JPL results on overall coal conversions. The conversions appear to approach a maximum when they reach 92 percent. Further, at temperatures higher than $375{ }^{\circ} \mathrm{C}$, the increase in conversion due to surfactant addition gradually decreases to zero due to the conversion having reached a maximum.

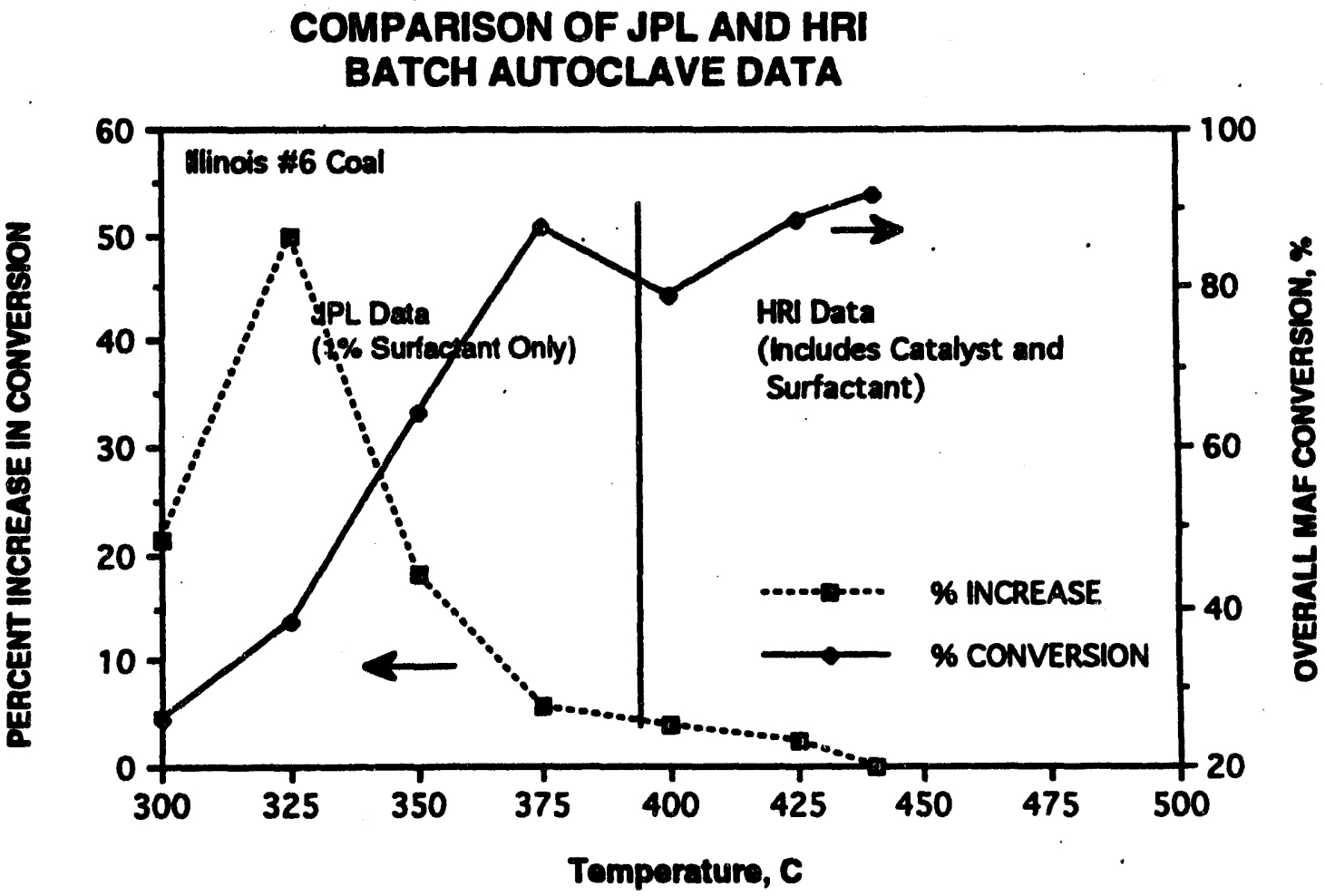

Figure 5.1: Comparison of JPL and HRI autoclave data. 


\section{CONCEPTUAL DESIGN AND ECONOMIC ANALYSIS}

To determine the economic suitability of a surfactant assisted coal liquefaction process, an economic evaluation was carried out. This economic evaluation is limited in scope. It consists of ranking various process options for use of a surfactant in a catalytic and noncatalytic reactor schemes for an industrial coal liquefaction plant. The conversions and product quality are based on the experimental work conducted in this study for process runs at $\mathbf{3 7 5}$ and $400^{\circ} \mathrm{C}$. Then the primary products and reactants were assigned a value to give a relative incremental cost effect of integrating the surfactant in a conventional coal liquefaction process. A conceptual plant design will be presented in. block diagram form. A computerized process flow model with integrated economic analysis was not conducted due to the limited scope of the subtask.

\subsection{PRODUCT VALUE COMPARISON}

The analysis for this study divided the liquefaction products into two : fractions, a liquid filtrate and a vacuum separated filter cake that consisted of unfilterable oil and solids. The filter cake was separated into three fractions, of hexane, toluene and THF solubles, which would correspond to the light oil, asphaltenes and preasphaltenes constituents of the reacted coal. Because the filter cake would be expected to produce distillable products when subjected to atmospheric or vacuum distillation, it is postulated for this analysis to group the solvent extraction fractions with an appropriate distillation fraction. The assigned groupings are as follows: 1) the hexane soluble fraction is grouped with the distillate from the initial boiling point (IBP) to $270^{\circ} \mathrm{C}$ and will be referred to as the light oil; 2) the toluene soluble fraction is grouped with the 270 to $340^{\circ} \mathrm{C}$ distillate fraction, and will be referred to as the middle oil, 3) the THF soluble fraction will be grouped with the greater than $340^{\circ} \mathrm{C}$ distillate fraction and will be referred to as the heavy oil. These fractions are weighted to the corresponding fraction of filtrate and filter cake to total slurry as shown in Appendix 2. These grouping are qualitatively logical and allow a rational comparison of the products utilizing the available data. The comparisons are only valid within this group of data. There is some validation for the extraction groupings with the gas chromatography/ mass spectrometer data that was conducted in the mechanism study presented in Section 4. The hexane extracts were found to consist primarily of light oil hydrocarbons and to have molecular weights that would fit within the less than $270^{\circ} \mathrm{C}$ boiling point range. The toluene extracts were a mixture of higher molecular weight mixed hydrocarbons and aromatics, and the THF fractions consisted primarily of aromatics and high molecular weight hydrocarbons. If anything, these groupings possibly err on the side of proposing a larger fraction of heavy oil that might be obtained from distilling the complete liquefaction product. The sum of the designated light, middle, and heavy oil fractions is less than 1.0. The difference being that fraction of the coal which is unconverted or unreactable coal.

Table 6.1 presents the product distribution of the light, middle and heavy oil for the 375 and $400^{\circ} \mathrm{C}$ batch autoclave runs obtained using the scheme outlined above. Also included in Table 6.1 are the MAF conversions. The 
Table 6.1: Distribution of liquefaction products from distillation and extraction.

\begin{tabular}{|c|c|c|c|c|c|}
\hline Run \# & Description & $\begin{array}{l}\text { Light Oil } \\
\%\end{array}$ & $\begin{array}{l}\text { Middle OII } \\
\%\end{array}$ & $\begin{array}{l}\text { Heavy Oil } \\
\%\end{array}$ & $\begin{array}{l}\text { THF } \\
\text { Conversion }\end{array}$ \\
\hline 24 & $\begin{array}{l}375^{\circ} \mathrm{C} \\
\text { Coal Only }\end{array}$ & 21.98 & 23.22 & 43.85 & $83.1 \%$ \\
\hline 22 & $\begin{array}{l}375^{\circ} \mathrm{C} \\
0.5 \% \text { surf. }\end{array}$ & 23.72 & 22.32 & 44.23 & $86.0 \%$ \\
\hline 19 & $\begin{array}{l}375^{\circ} \mathrm{C} \\
1.0 \% \text { Surf. }\end{array}$ & 23.13 & 26.39 & 40.83 & $85.9 \%$ \\
\hline 23 & $\begin{array}{l}375^{\circ} \mathrm{C} \\
2.0 \% \text { Surf. }\end{array}$ & 23.84 & 22.17 & 43.68 & $87.4 \%$ \\
\hline 36 & $\begin{array}{l}400^{\circ} \mathrm{C} \\
\text { Coal Only }\end{array}$ & 18.84 & 28.19 & 41.69 & $84.1 \%$ \\
\hline 37 & $\begin{array}{l}400^{\circ} \mathrm{C} \\
1.0 \% \text { Surf. }\end{array}$ & 22.32 & 27.76 & 44.33 & $92.9 \%$ \\
\hline 39 & $\begin{array}{l}.400^{\circ} \mathrm{C} \\
1.0 \mathrm{gm} \text { Cat. }\end{array}$ & 22.57 & 27.62 & 45.56 & $95.6 \%$ \\
\hline 40 & $\begin{array}{l}400^{\circ} \mathrm{C} \\
1.0 \% \text { Surf. } \\
1.0 \mathrm{gm} \text { Cat. }\end{array}$ & 21.62 & 33.03 & 39.87 & $93.8 \%$ \\
\hline 43 & $\begin{array}{l}375^{\circ} \mathrm{C} \\
0.5 \% \text { Surt/ } \\
400{ }^{\circ} \mathrm{C} \\
1.0 \mathrm{gm} \text { Cat. }\end{array}$ & 22.12 & 28.42 & 44.77 & $93.5 \%$ \\
\hline
\end{tabular}


improvement in the product quality slate due to the addition of the surfactant can be seen at both 375 and $400^{\circ} \mathrm{C}$. It is seen primarily as increases in the light oil and heavy oil fraction. This is in agreement with the proposed mechanism that the surfactant improves the liquefaction process by increasing the deagglomeration of the coal particle and improving hydrogen mass transport. Greater deagglomeration of the coal would result in more asphaltenes and preasphaltenes reacting to produce product. Improved hydrogen mass transport would result in a shift of the product slate toward a lower molecular weight and boiling point constituents. The $375^{\circ} \mathrm{C}$ runs made use of a different initial recycle oll than the $400{ }^{\circ} \mathrm{C}$ runs, so each set of runs at the particular temperature should be viewed as a group. The difference in the recycle oil should only affect the values for the light oil fraction. In general though, the $400^{\circ} \mathrm{C}$ runs showed a greater improvement in the product quality than the $375^{\circ} \mathrm{C}$ runs due to surfactant addition, in addition to having a greater conversion. For the $400^{\circ} \mathrm{C}$ runs, the addition of the Ni-Mo catalyst in Run 39 does not appear to provide an improvement in the product distribution when compared to the $1.0 \%$ surfactant addition in Run 37. There appears to be a positive synergism between the catalyst and surfactant in the results for Run 40 . This run showed a shift from the heavy oil fraction to the middle oil fraction.

To develop an understanding how the different runs would perform economically, the three oil fractions were given a relative value for a ranking of relative product value. The light oil would consist primarily of naphtha, gasoline, kerosene and light diesel products. These products would have the highest market value. The middle oil fraction would consist of fuel oil such as No. 2 diesel, and would have a lower relative market value. The heavy oil fraction would correspond to heavy fuel oil and other high molecular weight products, and would have the lowest relative value. The light oll could be used for blending with conventional petroleum products. The middle and heavy oll would most likely be subjected to additional reforming and catalytic cracking at a refinery. For the purpose of this ranking, the heavy oil fraction was given a value of 1.0. The middle oil fraction was given a relative value of 1.2, and the light oil fraction was given a relative value of 1.4 to the heavy oil. These rankings are based on the relative prices of naphtha/gasoline, No. 2 diesel, and heavy fuel oil. These ranking factors were applied to the fractions from Table 6.1. The relative product values and total ranking for the 375 and $400^{\circ} \mathrm{C}$ runs are presented in Table 6.2. From this ranking, it is clear that there is an significant improvement in product value by the addition of the surfactant relative to the coal alone. There is also a significant improvement in product value by increasing the reaction temperature from 375 to $400^{\circ} \mathrm{C}$. An interesting result of this ranking is that there is essential no difference in the ranking between Runs 37 and 39, for the addition of the surfactant as compared to the catalyst. These both come out with a slight improvement in value than the mixed catalyst and surfactant at $400^{\circ} \mathrm{C}$. For Run 43, which attempted to simulate a two stage reactor, with the first stage at a lower temperature, there appears to be only a slight decrease of the product value. This is encouraging, because a reactor operating at a lower temperature would have a lower operational cost. Lower reactor temperatures would have a minor effect on capital costs. A reduction in pressure would have a significant 
Table 6.2: Relative product value of coal liquefaction products.

\begin{tabular}{|c|c|c|c|c|c|}
\hline$\frac{\text { Run \# }}{24}$ & $\begin{array}{l}\text { Description } \\
375^{\circ} \mathrm{C}\end{array}$ & $\frac{\text { Uight oll }}{30.77}$ & $\frac{\text { Middle OII }}{27.86}$ & $\frac{\text { Heavy OII }}{43.75}$ & $\frac{\text { Total }}{102.39}$ \\
\hline 22 & $\begin{array}{l}375^{\circ} \mathrm{C} \\
0.5 \% \text { Surf. }\end{array}$ & 33.21 & 26.78 & 44.23 & 104.22 \\
\hline 19 & $\begin{array}{l}375^{\circ} \mathrm{C} \\
1.0 \% \text { Surf. }\end{array}$ & 32.38 & 31.67 & 40.83 & 104.88 \\
\hline 23 & $\begin{array}{l}375^{\circ} \mathrm{C} \\
2.0 \% \text { Surf. }\end{array}$ & 33.38 & 26.60 & 43.68 & 103.66 \\
\hline 36 & $\begin{array}{l}400^{\circ} \mathrm{C} \\
\text { Coal Only }\end{array}$ & 26.37 & 33.82 & 41.69 & 101.88 \\
\hline 37 & $\begin{array}{l}400^{\circ} \mathrm{C} \\
1.0 \% \text { Surf. }\end{array}$ & 31.25 & 33.31 & 44.33 & 108.89 \\
\hline 39 & $\begin{array}{l}400^{\circ} \mathrm{C} \\
1.0 \mathrm{gm} \text { Cat. }\end{array}$ & 31.59 & 33.14 & 45.56 & 110.30 \\
\hline 40 & $\begin{array}{l}400^{\circ} \mathrm{C} \\
1.0 \% \text { Surf. } \\
1.0 \mathrm{gm} \text { Cat. }\end{array}$ & 30.27 & 39.63 & 39.87 & 109.77 \\
\hline 43 & $\begin{array}{l}370^{\circ} \mathrm{C} \\
0.5 \% \text { Surt/ } \\
400^{\circ} \mathrm{C} \\
1.0 \mathrm{gm} \mathrm{Cat} \text {. }\end{array}$ & 30.97 & 34.10 & 44.77 & 109.84 \\
\hline
\end{tabular}

Ranking: Light OII $=1.4$

Middle Oil $=1.2$

Heavy Oll $=1.0$ 
effect in lowering the capital costs. These product value rankings are subjective and should only be considered in the context of this work.

From this evaluation, it is apparent that only the $4000^{\circ} \mathrm{C}$ process runs would be economically viable based on their product values. Runs 36, 37, 39, 40 and 43 have been chosen for a more detalled product comparison This product comparison has a complete material balance that includes the material inputs and outputs. and their associated costs and values These are the raw material costs, energy costs, and product values based on light hydrocarbon gases, and light, middle and heavy oll products described above. The economic comparison for operational costs will only include the liquefaction reactor segment of the coal liquefaction plant. It will not include handling, storage, and support faclities, power and hydrogen generation, distillation and separation unit operations and other required facilties which are considered briefly in a separate estimate of the capital costs.

For comparison, the conceptual plan will have for a basis a capacity of 1000 tons of coal per day. All balances are completed on a mass basis for a single day of operation. A schematic for the material balance is shown in Figure 6.1. The material inputs are raw Illinols $\# 6$ coal, hydrogen from a hydrogen production plant located nearby the plant. The product outputs are light hydrocarbon gases, and light middle and heavy oil. The waste or byproducts are ash, char, tall gases and water. These byproducts are not assigned a value. It is assumed that the coal is recelved as mined and has $10 \%$ water. The ash is based on the inert or unreactable mineral matter in the coal. It is set at $12 \%$ of the feed coal. The char consists of the unreacted carbonaceous material in the coal based on the experimental MAF conversions. The tail gases result from the heteroatoms oxygen, nitrogen and sulfur from the coal and are set at $4.7 \%$ MAF feed. The sulfur is assumed to be recovered but no value is assigned for this comparison. These are general values based on detalled economic evaluations conducted by Bechtel12. The electrical costs for the operation of the reactor are costed at $\$ 0.00107 / \mathrm{Mb}$ coal for a $400^{\circ} \mathrm{C}$ operation. It is prorated down for case 43 with one reactor at $375^{\circ} \mathrm{C}$. This is a value based on work conducted at Auburn University 13 .

The cost of Illinois $\# 6$ coal in large quantities is estimated to be $\$ 20 /$ ton. After initial pressurization of the reactor, it is assumed that hydrogen is consumed at a rate of $6 \%$ of the coal feed. This is a simplification for this analysis. The hydrogen consumption would be expected to vary with catalyst and reactor design. The cost of hydrogen is estimated to be $\$ 0.24 / \mathrm{b}$. This is a recently estimated amortized cost for hydrogen for a medium scale hydrogen plant utilizing steam reforming of natural gas 14 . The price of the lignosulfonate surfactant is costed at $\$ 0.20 / \mathrm{lb}$. This is based on recent price quotes from "Chemical Market Reporter." Its consumption is set at the rates described for the different cases. Though some fraction of the surfactant may be recycled, continuous fresh feed of the surfactant is assumed. It is also assumed that the surfactant will be physically mixed with the raw coal, and no special handling equipment would be required. Since the catalyst has a finite life before deactivation, for the case studies where it is used, it is assumed to have a $0.1 \%$ 
Figure 6.1: Material flow streams used in the economic comparison.

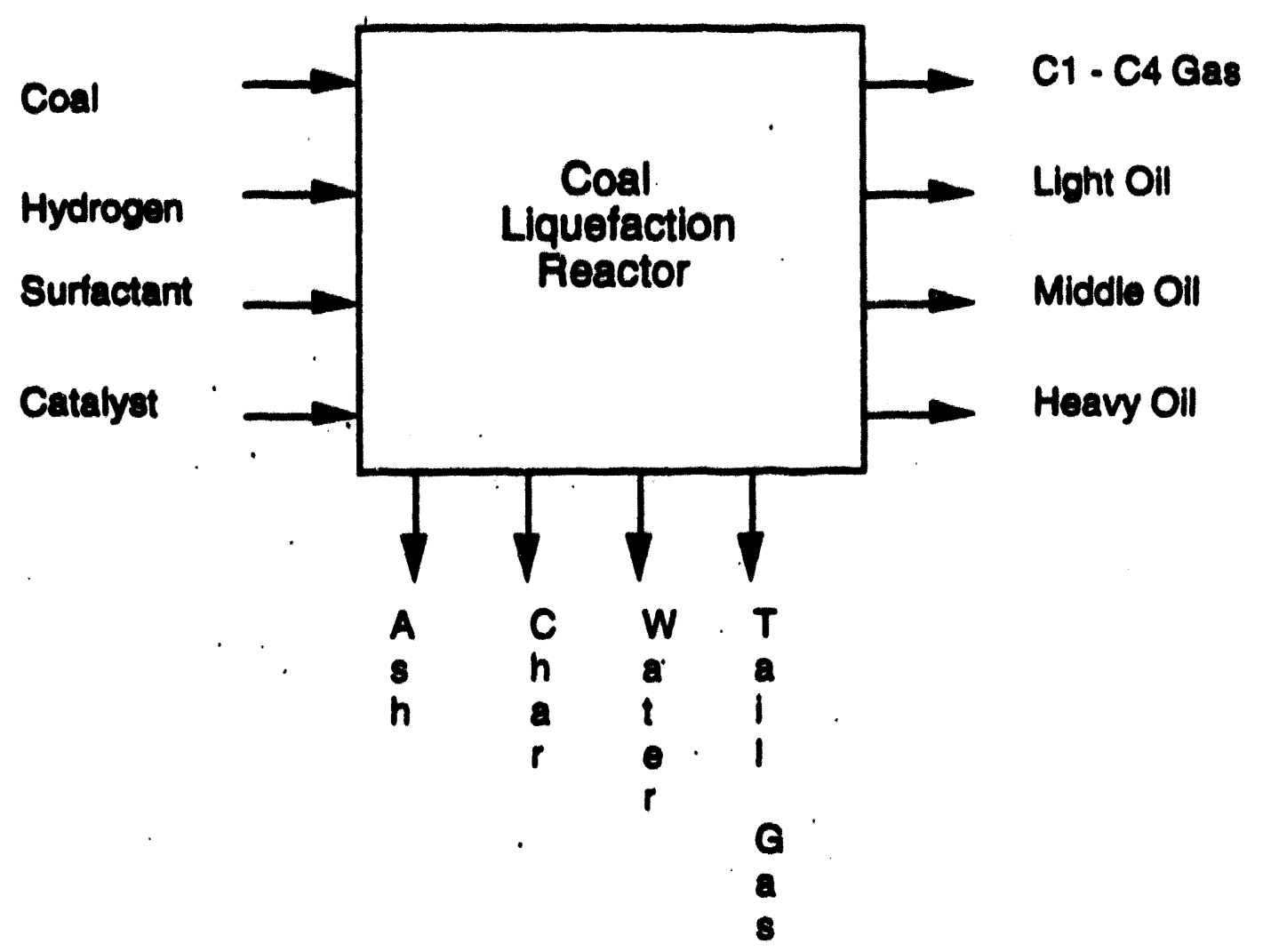

46 
replacement rate by welght compared to the coal feed. This is based on the experimental work for Shell 317 catalyst deactlvation rates from HRI. The cost of the catalyst was set at $\$ 3.00 \mathrm{hb}$ based on current market prices.

The four product streams are light hydrocarbon gases $\left(C_{1}\right.$ to $\left.C_{4}\right)$, light, middle and heavy oll. The most valuable product is the light oll fraction and for this comparison it is given a product value of $\$ 0.12 / \mathrm{b}$. Using the relative product values described above, the middle oll has a product value of $\$ 0.103 / \mathrm{b}$ and the heavy oll has a product value of $\$ 0.086 / \mathrm{hb}$. Since the light hydrocarbon gases are a mixture and would require further separation to increase their market value, they are given a product value of $\$ 0.08 / \mathrm{b}$.

For this analysis, It is assumed that all the cases have two stage reactors, and vary only in the surfactantcatalyst addition and reactor temperature. Table B.3 presents the case studies for conceptual commercial coal liquefaction plants utilizing surfactant. The case numbers correspond to the experimental run numbers. Case 36 is the base case of thermal processing of the coal alone at $400^{\circ} \mathrm{C}$. Case 37 is the case of adding $1 \%$ surfactant at $400^{\circ} \mathrm{C}$. Case 39 is the case of no surfactant, but instead having a supported catalyst at $400{ }^{\circ} \mathrm{C}$. Case 40 is the case of having both the $1 \%$ surfactant and the supported catalyst at $400{ }^{\circ} \mathrm{C}$. Case 43 is the two-stage reactor case adding $0.5 \%$ surfactant with the first reactor at $375{ }^{\circ} \mathrm{C}$ and having catalyst in the second reactor only which is operated at $400^{\circ} \mathrm{C}$. The hydrogen pressure for all the ceses is assumed to be the same at $1800 \mathrm{psig}$ to match the experimental work.

For all cases, the cost of the coal and hydrogen are equal for the five cases. The material costs only vary due to differences in the consumable costs of the surfactant and catalyst, and the slightly lower energy cost. for the lower first stage reactor for case 43 . Case 40 has the highest dally materials costs since it utilized both surfactant and catalyst. It also has the highest value product quality slate. Since the conversions for cases $37,39,40$ and 43 are very similar there is only a small difference in the dally product value sum for the four runs. Case 43 has the highest product value sum of the five runs based on the strength of the large amounts of heavy oil that is produced. Whereas this is a lower valued product, its greater production provides a slight cost advantage. As expected, the catalytic process for case 39 produced more light oll, but it was only slightly greater than the case for surfactant alone. The case of having both surfactant and catalyst produced a slate that has a greater proportion of middle oil and as a result had the second ranked dally product sum value.

When the consumable costs are subtracted from the dally product value, case $\mathbf{4 3}$ has the best economic advantage. The second ranked process was the surfactant only case, followed by the catalytic only process. The combined catalyst and surfactant case at $400^{\circ} \mathrm{C}$ was lower primarily due to the cost of surfactant and catalyst. As expected, the coal only case had the lowest ranking. Case 43 with the lower temperature first stage reactor and using $0.5 \%$ surfactant and catalyst only in the second stage reactor shows a cost advantage primarily based on a lower consumable costs while producing a product slate with a slight cost advantage. 
Table 6.3: Comparison of surfactant and surfactant/catalytic assisted coal liquefaction economics

\begin{tabular}{|c|c|c|c|c|c|c|c|}
\hline 3285 & Materalinp & Uts (b/day) & Process & & & & \\
\hline 1000 ton & coalday & & Case 36 & Case 37 & Case 39 & Case 40 & Case 43 \\
\hline & Coal & & 2000000 & 2000000 & 2000000 & 2000000 & 2000000 \\
\hline & Hydrogen & $6 \%$ Coal Foed & 120000 & 120000 & 120000 & 120000 & 120000 \\
\hline & Surtactant & & 0 & 20000 & 0 & 20000 & 10000 \\
\hline & Catalyst & 0.1\% Replacament & 0 & 0 & 2000 & 2000 & 1000 \\
\hline & & & & & & & \\
\hline & MAF Cogls & urfactant & 1560000 & 1575600 & 1560000 & 1575600 & 1567800 \\
\hline & & & & & & & \\
\hline & Material inp & It Sum (b/day) & 2120000 & 2140000 & 2122000 & 2142000 & 2131000 \\
\hline & Cogा & 520,100 & कू.00 & 30000 & उ20.000 & 520,000 & 820,000 \\
\hline & Hudrogen & 5.2416 & 528,800 & $\$ 28,800$ & $\$ 28,800$ & 528,800 & $\$ 28,800$ \\
\hline & Surfactant & $5.20 / 1 b$ & 50 & $\$ 4,000$ & SO & $\$ 4,000$ & $\$ 2,000$ \\
\hline & Catalyst & $\$ 3.0 / 6$ & 50 & $\$ 0$ & $\$ 6,000$ & $\$ 6,000$ & $\$ 3,000$ \\
\hline & & & & & & & \\
\hline & Material Su & $n($ (\$day) & $\$ 48,800$ & $\$ 52,800$ & $\$ 54,800$ & $\$ 58,800$ & $\$ 53,800$ \\
\hline & & & & & & & \\
\hline & Energy Cos & (\$/day) & $\$ 2,140$ & $\$ 2,140$ & $\$ 2,140$ & $\$ 2,140$ & $\$ 2,033$ \\
\hline & & & & & & & \\
\hline & Material ou & put (Lb/day) & & & & & \\
\hline & & & & & & & \\
\hline & C1.C4 gas & 5\% MAF Foed & 78000 & 78780 & 78000 & 78780 & 78390 \\
\hline & Lught Oा & & 288003 & 344346 & 345023 & 333546 & 339702 \\
\hline & Middde OाI & & 430935 & 428272 & 422221 & 509576 & 444131 \\
\hline & Heavy OII & & 637307 & 683909 & 696467 & 615101 & 687543 \\
\hline & Ash & $12 \%$ Feed & 240000 & 242400 & 242000 & 244400 & 242200 \\
\hline & Char & & 172435 & 86241 & 64969 & 84544 & 64347 \\
\hline & Tall Gas & 4.7\% MAF Foed & 73320 & 74053 & 73320 & 74053 & 73687 \\
\hline & Water & $10 \%$ Foed & 200000 & 202000 & 200000 & 202000 & 201000 \\
\hline & Material Su & $n$ (lb/day) & 2120000 & 2140000 & 2122000 & 2142000 & 2131000 \\
\hline & & & & & & & \\
\hline & Product Va & $1 \theta$ (\$/day) & & & & & \\
\hline & & cenosth & & & & & \\
\hline & $\begin{array}{l}\text { C1-C4 gas } \\
\text { LLoht OII }\end{array}$ & $\frac{\$ .08 / 1 b}{5.12 / 1 b}$ & $\frac{\$ 6,240}{3,560}$ & $\$ 6,302$ & $\frac{\$ 6,240}{914,103}$ & $\$ 6,302$ & $\frac{\$ 6,271}{910761}$ \\
\hline & Middle OII & $\$ .103 \sqrt{b}$ & $\frac{\$ 4,386}{\$ 44,386}$ & $\frac{\$ 41,321}{\$ 44.112}$ & $\frac{\$+1,400}{\$ 43,489}$ & $\$ 52,486$ & $\$ 45,746$ \\
\hline & Heavy OII & $\$ .086 / 1 \mathrm{~b}$ & $\$ 54,808$ & $\$ 58,816$ & $\$ 59,896$ & $\$ 52,899$ & $\$ 59,129$ \\
\hline & & & & & & & \\
\hline & Product Su & $n$ (\$/day) & $\$ 139,995$ & $\$ 150,552$ & $\$ 151,028$ & $\$ 151,713$ & $\$ 151,910$ \\
\hline & & & & & & & \\
\hline & Dally Net ( & ay) & $\$ 89,055$ & $\$ 95,612$ & $\$ 94,088$ & $\$ 90,773$ & 77 \\
\hline
\end{tabular}


The result that case 43 has a cost advantage agrees well with the understanding how the lignosulforiate functions in the coal liquefaction process. It acts primarily to deagglomerate the coal to smaller molecular units and to allow an increase in the mass transfer of hydrogen for reaction. This is particularly sulted for a first stage reactor where there is only partial reaction of the coal. The catalyst is more offective in the second stage where it can participate in the reactions to produce smaller molecular units. The design with the first stage at lower temperature is also consistent with what is known about the thermal stablity of the lignosulfonate surfactant.

\subsection{CONCEPTUAL DESIGN AND ECONOMICS}

The use of a surfactant in the coal liquefaction process will have some economic mert primarly if it can reduce operating costs while maintaining a high quality product slate similar to catalytic reactor system. Figure 6.2 presents a conceptual desion of a coal liquefaction process that would incorporate the use of a surfactant. It is presented in a block diagram form only, and does not include unit operation elements such as pumps; compressors, and instrumentation. The solids separation equipment is not defined. Based upon the product evaluation presented above, it appears that a surfactant might find use in an industrial application for a two-stage reactor system where the first reactor is at a lower temperature and the second reactor contains a supported catalyst. This is the continuous recycle equivalent process of Run 43 that was conducted as a batch process.

This conceptual design of a surfactant catalytic reactor system would have several advantages over a catalytic/catalytic system. The surfactant would be added with the coal into the initial mixer. From the work with the lignosulfonate surfactant, no special mixing processing would be required beyond physical mixing. Since the surfactant is believed to primarily increase the deagglomeration of the coal particles and its surface activity is relatively fast compared to the residence time in the first reactor, this would allow simplification of the first reactor design. Because the surfactant decomposes at high temperatures, the first reactor would operate a lower temperature than the second reactor. The work in this report shows that there is only a small decrease in conversion and product quality by having a slightly lower first stage reactor. This lower temperature would allow reduced heating costs, an extended reactor life due to less severe operating conditions and a lower initial capital cost. Since there is no supported catalyst, there would be a less complicated reactor design. The second stage reactor would operate at a higher temperature and contain a supported catalyst. The higher temperature is necessary to improve the overall conversion, and the supported catalyst is necessary to improve the distillate quality. Absence of a catalyst would only produce a product that would require more catalytic processing at a separate refinery. The fraction of the surfactant that does not decompose, but remains with the unreacted coal would be recycled with the slumy. Having the catalyst only in the second reactor would reduce the overall catalyst consumption and handling cost. 


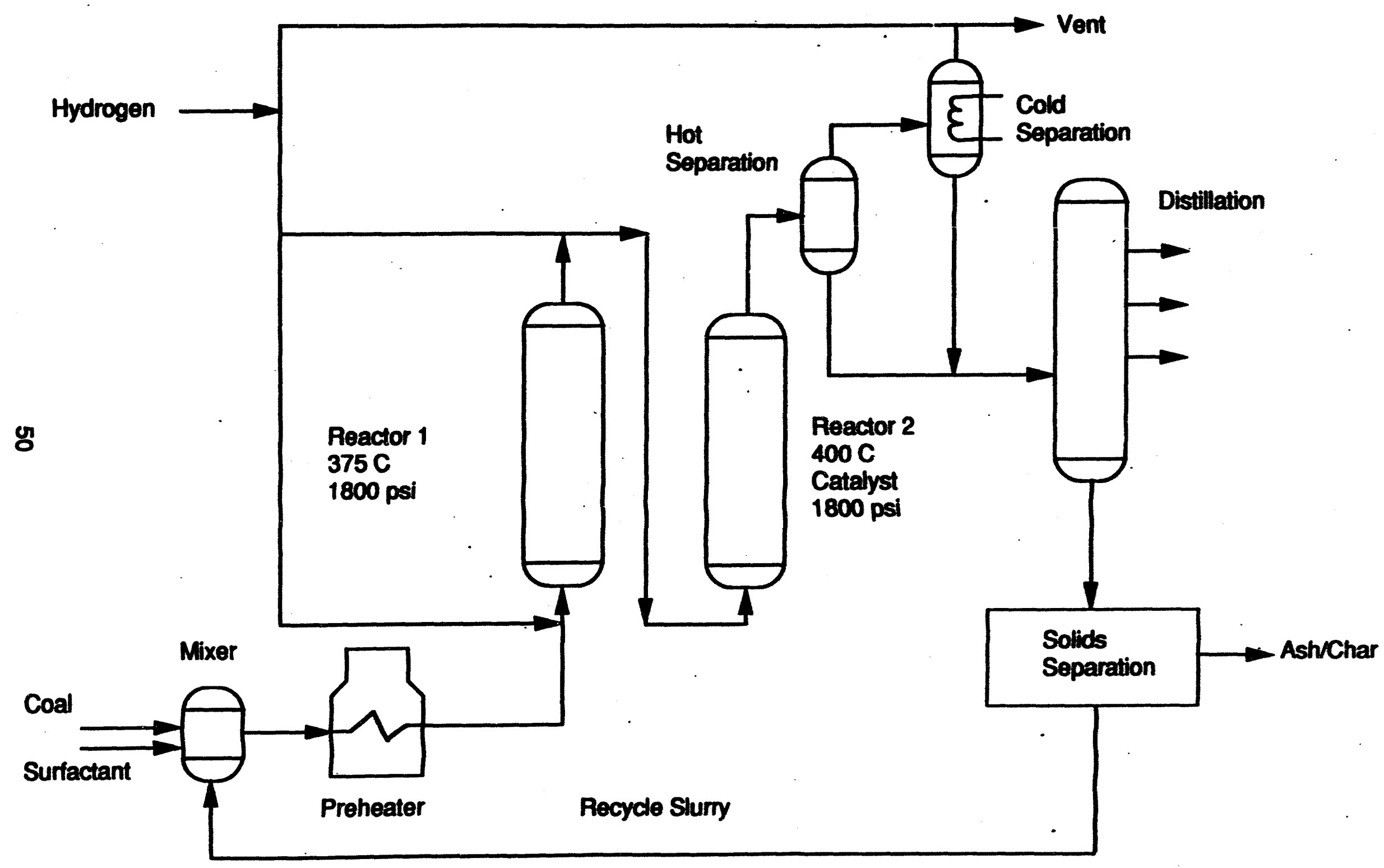

Figure 6.2: Conceptual Coal Liquefaction Plant Design 
The bench-scale test run at HRI validates several of the features of this conceptual design. While the HRI bench scale test was conducted with a catalyst in both reactors, it did validate that the lignosulfonate surfactant could be used in a conventional liquefaction process. These tests showed that the surfactant does not poison or deactivate the catalyst. Whereas the HRI test raised some questions about heteroatom removal, this concern might be addressed by a different catalyst system. The lower operating temperatures may pose some operational concerns that would require either a lower coal to slurry ratio or additional pumping. This is an unknown that would have to be addressed. In general, this conceptual design offers many potential benefits for reducing the operational and capital costs of a coal liquefaction plant.

The above economic analysis only considered the daily operating costs for the reactor portion of a coal liquefaction plant. The proposed conceptual design is expected to have additional cost advantages in addition to the product values. Because of the high capital costs of a coal liquefaction plant, the capital costs are the largest single cost driver for the economical operation of a coal liquefaction plant. These cost advantages would come from a reduction in the capital costs for the plant resulting from a simplification in the design and operation of the plant due to having a less complicated first stage reactor and operating the entire plant at 1800 psig instead of 2200 psig. Since there would be less catalyst consumed, there would be a reduction in the capital costs associated with the materials handling. One recent report breaks up the associated capital costs due to coal and catalyst preparation, boiler and power generation, and other capital costs. ${ }^{15}$ This report estimates the coal and catalyst preparation and handling costs would be equal to $6.3 \%$ of the total capital costs. Assume that $1 \%$ of this cost was due to catalyst preparation and handling, if only half the catalyst was used there would be a $0.5 \%$ reduction in capital costs. The boiler and power generation costs are estimated to be $8.8 \%$ of the total capital costs. If there was a $10 \%$ reduction due to a lower first stage reactor anid simpler operation, this would provide a $0.88 \%$ reduction in the capital costs. The largest segment of the liquefaction plant is the capital costs for the hydrogenation pressure reactors. This is estimated to be $23.4 \%$ of the total capital costs. If the pressure was reduced from 2200 psig to 1800 psig, this might lower the total capital costs by $4.25 \%$ assuming that the cost of pressure vessels are linear with respect to pressure. Adding these three segments together, it is possible to have up to a $5.6 \%$ reduction in the total capital costs for the proposed conceptual design. 


\subsection{CONCLUSIONS}

Sodium lignosulfonate is a surfactant which when used as an additive shows considerable promise in improving coal liquefaction economics. This surfactant acts by deagglomerating the coal particles, helps in breaking the cross links between different coal molecules, and thereby increases the favorable mass transport and kinetic processes for coal liquefaction. The surfactant is also expected to lower the viscosity for the coal-recycle solvent mixture. The surfactant would be highly effective in a thermal coal liquefaction process if the processing temperatures are $400^{\circ} \mathrm{C}$ or below .

The autoclave test runs and resulting product analysis show a distinct benefit of surfactant addition on overall coal conversion and the quality of the liquid filtrate. (in terms of an increase in the light boiling fractions) at all temperatures between 350 and $400^{\circ} \mathrm{C}$. Further, it was ascertained (by running separate tests with lignin addition) that the observed improvement by addition of sodium lignosulfonate was distinctly due to the surfactant action and not a result of its lignin-like structure. Another important conclusion was that only a small amount of the surfactant ( 0.5 wt\% or less) suffices and adding too much does not lead to an additional benefit.

The autoclave tests also show that sodium lignosulfonate begins to decompose appreciably at temperatures above $375^{\circ} \mathrm{C}$. Our SEM analysis on coal samples processed at $375^{\circ} \mathrm{C}$ shows that the favorable effect of opening of the coal's pore structure is still present even though $30 \%$ of the surfactant has decomposed. This means that the surfactant is partly effective even in the decomposed state. Mass spectrometric analysis of the thermal decomposition products of the sodium lignosulfonate indicated that the sulfonate group begins to detach itself from the lignin part of the molecule at temperatures above $375^{\circ} \mathrm{C}$. This apparently leads to a partial loss in the surfactant effectiveness. The bench scale tests conducted at HRI were at temperatures higher than $400^{\circ} \mathrm{C}$. Hence, it is not surprising that no significant improvement in overall conversion and product quility was seen due to surfactant addition. This is attributed to the significantly higher first and second stage operating temperatures $\left(420-430^{\circ} \mathrm{C}\right)$ used at HRI and the presence of a very effective liquefaction catalyst. These high operating temperatures may also have resulted in a loss of the expected lowering of viscosity of the coal-solvent slurry as no improvement in the reactor hydrodynamics was observed.

The thermal decomposition of the surfactant apparently limits its direct use in the HRI process. However, a two-stage conceptual design has been worked out where each stage operates at temperatures significantly lower than for the HRI process, and in addition, the first stage operates without a catalyst. In this conceptual design, product quality equivalent to the HRI process is obtained while the overall capital costs are reduced by about 5 percent. This incremental improvement, by itself, may not be large enough to readily advance the commercialization of coal liquefaction. However, use of a more thermally stable surfactant might make a significantly larger impact by (a) further improving the 
product quality slate, and (b) facilitating even less intensive operating conditions by further reducing the operating temperatures and pressures in the liquefaction.

$\therefore$

-

, 


\section{RECOMMENDATIONS FOR FUTURE WORK}

The concept of surfactant assisted coal liquefaction was proposed, in part, on basis of its ability to deagglomerate the coal particles, and in part, due to the earlier limited data on some observed improvement in the filter cake quality. Also, it was expected that a lowering in viscosity of the recycle solvent-coal slurry would result in lower power consumption.

The present effort was completely based on tests with sodium lignosulfonate as the surfactant additive. In order for the JPL effort to be incorporated in the HRI process, it was necessary to carry out liquefaction tests at temperatures of $420-430^{\circ} \mathrm{C}$. Operating at these relatively high temperatures where a part of the surfactant decomposes was not visualized at the time of selecting the surfactant for our detailed parametric study. Our test runs at $400{ }^{\circ} \mathrm{C}$ have shown that the surfactant is only partly effective in the decomposed state.

The favorable effect of the surfactant could be enhanced by selection of a more thermally stable surfactant. Selection of a more thermally stable surfactant would balance considerations of cost and physical properties such as bond strength and thermodynamic properties. Such a surfactant would enhance processing by lowering viscosity and reducing pumping requirements, and improve hydrogen mass transport. While such a surfactant may not be as inexpensive as sodium lignosulfonate, cost is not expected to be prohibitive as only a very small amount of the surfactant (less than $0.5 \%$ ) may be sufficient.

The recommendations for future work then include viscosity determination tests at actual liquefaction temperatures with a set of surfactants having a higher level of thermal stability. The two more promising surfactants could then be tested in coal liquefaction runs in the temperature range 375 to $425^{\circ} \mathrm{C}$. If the basic premise regarding surfactant addition is correct, one may be able to achieve a further improved product slate and a larger improvement in process economics that will bring closer the commercialization of the coal liquefaction technology. 


\section{REFERENCES}

1. CoalLiquefaction Products Vol. 1, edited by H.D. Schultz, John Wiley, New York (1983).

2. Whitehurst, D.D., Mitchell, T.O., and Farcasiu, M., CoalLiquefaction Academic Press, New York (1980).

3. Hsu,G.C., "Surfactant Studies for Coal Liquefaction," Final Internal Report submitted to U.S. Department of Energy. Pittsburgh Energy Technology Center, Contract No. DE-Al22-89PC89882 by Jet Propulsion Laboratory, Pasadena California (December 1990).

4. "Surfactant Studies for Bench-Scale Operation," First Quarterly Technical Progress Report submitted to US Department of Energy, Pittsburgh Energy Technology Center, Contract No. DE-Al22-92PC92150. JPL Publication 92-30, December 1992.

5. "Standard Test Methods for Distillation of Creosote and Creosote-Coal Tar Solutions," ASTM D-246-89. American Society for Testing and Materials, Philadelphia; Pennsylvania (1989).

6. Malbrel, C.A., and Somasundaran, P., "Study of Adsorbed Surfactant Layers at the Solid/Liquid Interface Using Electron Spin Resonance Spectroscopy," in Eundamentals of Adsorrtion. A.B. Mersmann and S.E. Scholl, Editors, Engineering Foundation, United Engineering Trustees, Inc., (1991)

7. Lalvani, S.B., "Coal Liquefaction in Lignin-Derived Liquids Under Low Severity Conditions," Euel, Vol. 70, pg. 1433, (1991).

8. Akash, B.A., et al., "Investigations of Simultaneous Coal and Lignin Liquefaction: Kinetic Studies," Enerav \& Fuels, Vol. 6, pp. 629-634, (1992).

9. Coughlin, R.W. and Davoudzadeh, F., "Coliquefaction of Lignin and Bituminous Coal," Euel. Vol. 65, pp 95-106, (1986).

10. Altieri, P. and Coughlin, W., "Characterization of Products Formed during Coliquefaction of Lignin and Bituminous Coal at $400^{\circ} \mathrm{C}$," Eneroy and Fuels. Vol. 1, pp 253-256, (1987).

11. Cugini, A, et. al. "Recent Progress In The Use Of Disposable Catalysts For Coal Liquefaction," Proceedings of the 1991 Liquefaction Contractors Review Conference, Pittsburgh PA, September 3-5, 1991.

12. Poddar, S.K., et. al. , "Direct Coal Liquefaction-Capital Costs and Economics For Improved Baseline Design," Proceedings of the 1992 Liquefaction Contractors Review Conference, Pittsburgh PA, September 27-29, 1993. 
13. Warren, A., El-Halwagi, M., "Technical and Economic Evaluation of a New Process For Co-Liquetying Coal and Scrap Tires," Proceedings of the 1992 Liquefaction Contractors Review Conference, Pittsburgh PA, September 27. 29, 1993.

14. Veziroglu, T.N., Editor, Hydrogen Prooress Vl. pg. 48, Pergammon Press, 1986.

15. Katsushima, S., et. al., " Concoptual Design and Economic Evaluation of BCL Project," Proceedings of the 1992 Liquefaction Contractors Review Conference, Pittsburgh PA, September 27-29, 1993. 


\section{ACKNOWLEDGMENTS}

The authors would like to thank several individuals whose help and cooperation was important to the successful completion of this effort. We would like to thank Mark Anderson and Gary Plett of the JPL Analytical Chemistry group for help with analysis of several samples. We would also like to thank Professor George Gavalas of California Institute of Technology, and Drs. Gerald Voecks and Les Compton of JPL for their many useful discussions. The technical assistance of Richard Zanteson was valuable in setting up the experimental system.

We would like to thank Al Comolli for his assistance in coordinating the bench scale test at HRI. 
11. APPENDIX

Appendix 1: Summary Of Processing Conditions Of Autoclave Runs.

Appendix 2: Yields Of Liquid Filtrate And The Filter cake For The Autoclave Runs.

Appendix 3: Extraction Distributions For The Autoclave Runs.

Appendix 4: Overall MAF Conversions For The Autoclave Runs.

Appendix 5: Distillation Results For The Autoclave Runs.

58 
Appendix 1: Summary of Processing Conditions For Autoclave Runs.

\begin{tabular}{|c|c|c|c|c|c|}
\hline $\begin{array}{l}\text { RUN } \\
\text { NO }\end{array}$ & $\begin{array}{l}\text { AVERAGE } \\
\text { TEMP. } \\
\text { OC }\end{array}$ & $\begin{array}{c}\text { AVERAGE } \\
\text { PRESSURE } \\
\text { psig }\end{array}$ & $\begin{array}{l}\text { PROCESS } \\
\text { TIME } \\
\text { hr. }\end{array}$ & $\begin{array}{c}\text { SURFACTANT } \\
\text { CONC. } \\
w t \%\end{array}$ & $\begin{array}{l}\text { ADDITIVE } \\
\text { CONC. } \\
\text { gm. }\end{array}$ \\
\hline 5 & 300 & 1800 & 1.0 & 1.0 & $\ldots$ \\
\hline 6 & 300 & 1800 & 1.0 & 0.5 & $\ldots$ \\
\hline 7 & 300 & 1700 & 1.0 & 0.0 & $\ldots$ \\
\hline 8 & 300 & 1800 & 1.0 & 2.0 & -... \\
\hline 8 & 325 & 1800 & 1.0 & 1.0 & ... \\
\hline 10 & 325 & 1050 & 1.0 & 2.0 & $\cdots$ \\
\hline 11 & 325 & 1850 & 1.0 & 0.5 & $\cdots$ \\
\hline 12 & 325 & 1800 & 1.0 & 0.0 & $\cdots$ \\
\hline 13 & 325 & 1700 & 1.0 & 2.0 & $\cdots$ \\
\hline 14 & 350 & 1850 & 1.0 & 1.0 & $\cdots$ \\
\hline 15 & 350 & 1800 & 1.0 & 0.0 & $\ldots$ \\
\hline 16 & 350 & 1500 & 1.0 & 2.0 & $\cdots$ \\
\hline 17 & 350 & 1850 & 1.0 & 2.0 & $\ldots$ \\
\hline 18 & 350 & 1300 & 1.0 & 0.5 & $\cdots$ \\
\hline 19 & 375 & 1800 & 1.0 & 1.0 & $\cdots$ \\
\hline 20 & 375 & 1300 & 1.0 & 0.0 & $\cdots$ \\
\hline 21 & 375 & 1500 & 1.0 & 2.0 & $\cdots$ \\
\hline 22 & 375 & 1650 & 1.0 & 0.5 & $\cdots$ \\
\hline 23 & 375 & 1800 & 1.0 & 2.0 & $\cdots$ \\
\hline 24 & 375 & 1800 & 1.0 & 0.0 & $\cdots$ \\
\hline
\end{tabular}




\begin{tabular}{|c|c|c|c|c|c|}
\hline $\begin{array}{l}\text { RUN } \\
\text { NO }\end{array}$ & $\begin{array}{l}\text { AVEAACE } \\
\text { TEMP. } \\
\text { OC }\end{array}$ & $\begin{array}{c}\text { AVERACE } \\
\text { PRESSURE } \\
\text { pSIg }\end{array}$ & $\begin{array}{l}\text { PROCESS } \\
\text { TIME } \\
\text { hr. }\end{array}$ & $\begin{array}{l}\text { SURFACTANT } \\
\text { CONC. } \\
w \%\end{array}$ & $\begin{array}{l}\text { ADDITIVE } \\
\text { CONC. } \\
\mathrm{gm} .\end{array}$ \\
\hline$\overline{26}$ & 375 & 1800 & 1.0 & 1.0 & g. $\mathrm{Fe}_{2} \mathrm{O}_{3}$ \\
\hline 26 & 375 & 1800 & 1.0 & 0.0 & g. $\mathrm{Fe}_{2} \mathrm{O}_{3}$ \\
\hline 27 & 375 & 1800 & 1.0 & 1.0 & $\ldots$ \\
\hline 28 & 375 & 1800 & 0.5 & 2.0 & - \\
\hline 29 & 375 & 1800 & 1.5 & 2.0 & - \\
\hline 30 & 375 & 1820 & 0.5 & 0.0 & - \\
\hline 31 & 375 & 1800 & 1.5 & 0.0 & $\cdots$ \\
\hline 32 & 375 & 1700 & 1.0 & 2.04 & 0.0 \\
\hline 33 & 400 & 1690 & 1.0 & 2.04 & 0.0 \\
\hline 34 & 400 & 1700 & 1.0 & \multicolumn{2}{|c|}{$10 \mathrm{gm}$ Coav10 gm Surf. } \\
\hline 35 & 350 & 1670 & 1.0 & 2.04 & 0.0 \\
\hline 36 & 400 & 1710 & 1.0 & 2.0 & 0.0 \\
\hline 37 & 400 & 1745 & 1.0 & 0.0 & 0.0 \\
\hline 38 & 400 & 1740 & 1.0 & 1.0 & $1.0 \mathrm{~g} . \mathrm{Fe}_{2} \mathrm{O}_{3}$ \\
\hline 39 & 400 & 1680 & 1.0 & 0.0 & $1.0 \mathrm{~g} \cdot \mathrm{Ni}-\mathrm{Mo}$ \\
\hline 40 & 400 & 1730 & 1.0 & 1.0 & $1.0 \mathrm{~g} . \mathrm{Ni}-\mathrm{Mo}$ \\
\hline 41 & 375 & 1610 & 1.0 & 0.0 & $1.0 \%$ Lignin \\
\hline 42 & 400 & $\$ 840$ & 1.0 & 0.0 & $1.0 \%$ Lignin \\
\hline 43 & $\begin{array}{l}375 / \\
400\end{array}$ & $\begin{array}{l}1800 \\
1800\end{array}$ & $\begin{array}{l}0.5 / \\
0.5\end{array}$ & $\begin{array}{l}0.5 \\
0.5\end{array}$ & $\begin{array}{l}0.0 \\
1.0 \mathrm{~g} \mathrm{Ni}-\mathrm{Mo}\end{array}$ \\
\hline 44 & 400 & 1750 & 1.0 & 0.0 & $\begin{array}{l}10 \mathrm{~g} \text { Lignin } \\
\text { No Coal }\end{array}$ \\
\hline
\end{tabular}

$\therefore$ Note: A: Surfactant Only, No Coal 
Appendix 2: Yields of the Liquild Filtrate and the Filtercake for the Autoclave Runs.

\begin{tabular}{|c|c|c|c|c|}
\hline $\begin{array}{l}\text { RUN } \\
\text { NO. }\end{array}$ & $\begin{array}{c}\text { LIQUID } \\
\text { FILTRATE } \\
\mathbf{9}\end{array}$ & $\begin{array}{l}\text { FILTER } \\
\text { CAKE } \\
9\end{array}$ & 0 & $\begin{array}{l}\text { VERALL MASS } \\
\text { BALANCE } \\
(\%)\end{array}$ \\
\hline 5 & 128.53 & 141.64 & & 97.13 \\
\hline 6 & 148.55 & 128.20 & & 98.33 \\
\hline 7 & 147.84 & 126.98 & & 98.29 \\
\hline 8 & 139.92 & 139.42 & & 98.07 \\
\hline 9 & 127.23 & 150.40 & & 97.98 \\
\hline 10 & 136.67 & 141.54 & & 98.13 \\
\hline 11 & 134.99 & 136.72 & & 96.63 \\
\hline 12 & 136.68 & 137.77 & & 97.79 \\
\hline 13 & 134.81 & 146.05 & & 88.00 \\
\hline 14 & 153.12 & 120.44 & & 97.10 \\
\hline 15 & 153.23 & 118.16 & & 97.40 \\
\hline 16 & 150.26 & 123.97 & & 98.00 \\
\hline 17 & 147.94 & 127.03 & & 98.00 \\
\hline 18 & 140.56 & 127.88 & & 97.90 \\
\hline 19 & 155.40 & 121.03 & & 98.40 \\
\hline 20 & 156.80 & 119.42 & & 98.00 \\
\hline 21 & 154.06 & 121.49 & & 97.50 \\
\hline 22 & 158.10 & 118.12 & & 98.40 \\
\hline 23 & 158.16 & 120.51 & : & 98.10 \\
\hline 24 & 157.35 & 117.77 & & 98.40 \\
\hline
\end{tabular}




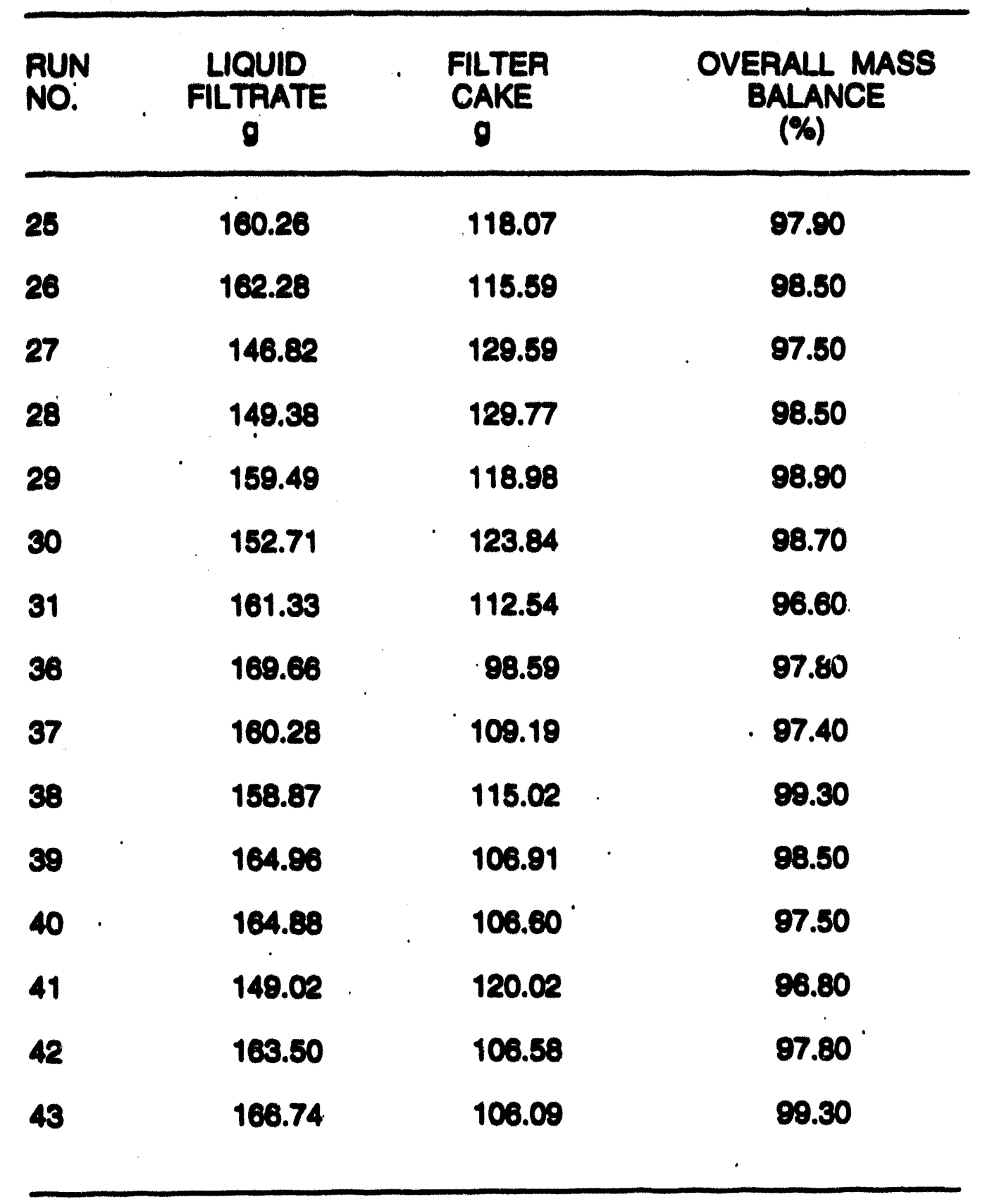


Appendix 3: Extraction Distributions For The Autoclave Runs.

\begin{tabular}{|c|c|c|c|c|}
\hline RUNNO. & $\begin{array}{l}\text { SUAFACTANT } \\
\text { CONC. } \\
w \%\end{array}$ & $\begin{array}{l}\text { HEXANE } \\
\text { SOLUBLES } \\
\text { Wt\% }\end{array}$ & $\begin{array}{l}\text { TOLUENE } \\
\text { SOLUBLES } \\
\text { W\% }\end{array}$ & $\begin{array}{l}\text { THF } \\
\text { SOLUBLES } \\
\text { Wt\% }\end{array}$ \\
\hline 5 & 1.0 & 33.7 & 2.7 & 6.7 \\
\hline 6 & 0.5 & 29.3 & 2.8 & 5.8 \\
\hline 7 & 0.0 & 26.9 & 2.5 & 6.3 \\
\hline 8 & 2.0 & 31.4. & 2.2 & 5.6 \\
\hline $\boldsymbol{\theta}$ & 1.0 & 38.2 & 3.4 & 11.7 \\
\hline 10 & 2.0 & 31.8 & 2.9 & 9.4 \\
\hline 11 & 0.5 & 32.4 & 2.9 & 9.7 \\
\hline 12 & 0.0 & 32.1 & 2.7 & 8.4 \\
\hline 13 & 2.0 & 33.9 & 3.2 & 9.6 \\
\hline 14 & 1.0 & 23.9 & 6.2 & 33.2 \\
\hline 15 & 0.0 & 25.0 & 5.7 & 28.0 \\
\hline 16 & 2.0 & 24.6 & 8.6 & 28.2 \\
\hline 17 & 2.0 & 26.3 & 9.0 & 29.1 \\
\hline 18 & 0.5 & 29.8 & 11.2 & 27.0 \\
\hline 19 & 1.0 & 31.3 & 10.4 & 35.9 \\
\hline 20 & 0.0 & 31.2 & 7.1 & 34.0 \\
\hline 21 & 2.0 & 29.5 & 7.2 & 36.6 \\
\hline 22 & 0.5 & 30.5 & 7.2 & 38.1 \\
\hline 23 & 2.0 & 29.9 & 9.7 & 38.1 \\
\hline 24 & 0.0 & 29.5 & 8.0 & 37.8 \\
\hline
\end{tabular}




\begin{tabular}{|c|c|c|c|c|}
\hline RUNNo. & $\begin{array}{l}\text { SURFACTANT. } \\
\text { CONC. } \\
\text { wt } \%\end{array}$ & $\begin{array}{l}\text { HEXANE } \\
\text { SOLUBLES } \\
\text { W\% }\end{array}$ & $\begin{array}{l}\text { TOLUENE } \\
\text { SOLUBLES } \\
\text { W\% }\end{array}$ & $\begin{array}{l}\text { THF } \\
\text { SOLUBLES } \\
\text { W\% } \%\end{array}$ \\
\hline 25 & $\begin{array}{l}1.0 \\
1.0 \mathrm{~g} \mathrm{Fe}_{2} \mathrm{O}_{3}\end{array}$ & 30.0 & 6.8 & 44.4 \\
\hline 26 & $\begin{array}{l}0.0 \\
1.0 \mathrm{~g} \mathrm{Fe}_{2} \mathrm{O}_{3}\end{array}$ & 29.0 & 8.0 & 41.2 \\
\hline 28 & 2.0 & 28.1 & 6.5 & 33.6 \\
\hline 29 & 2.0 & 32.7 & 9.8 & 35.8 \\
\hline 30 & 0.0 & 39.8 & 6.4 & 29.6 \\
\hline 31 & 0.0 & 32.0 & 10.8 & 39.9 \\
\hline 36 & 2.0 & 27.6 & 11.6 & 34.1 \\
\hline 37 & 0.0 & 34.6 & 9.1 & 37.3 \\
\hline 38 & $\begin{array}{l}1.0 \\
1.0 \mathrm{~g} \mathrm{Fe}\end{array}$ & 34.0 & 10.5 & 34.5 \\
\hline 39 & $\begin{array}{l}0.0 \\
1.0 \mathrm{~g} \mathrm{Ni}-\mathrm{Mo}\end{array}$ & 33.7 & 9.4 & 39.4 \\
\hline 40 & $\begin{array}{l}1.0 \\
1.0 \mathrm{~g} \mathrm{Ni}-\mathrm{Mo}\end{array}$ & 32.7 & 12.1 & 35.5 \\
\hline 41 & $\begin{array}{l}0.5 / \\
0.5 \mathrm{~g} \mathrm{Ni}-\mathrm{Mo}\end{array}$ & 30.0 & 12.7 & 37.6 \\
\hline
\end{tabular}


Appendix 4: Overall MAF Conversions For The Autoclave Runs.

\begin{tabular}{|c|c|c|c|c|c|}
\hline $\begin{array}{l}\text { RUN } \\
\text { NO }\end{array}$ & $\begin{array}{l}\text { AVERAGE } \\
\text { TEMP. } \\
\text { OC }\end{array}$ & $\begin{array}{c}\text { AVERAGE } \\
\text { PRESSURE } \\
\text { psig }\end{array}$ & $\begin{array}{l}\text { SURFACTANT } \\
\text { CONC. } \\
w t \%\end{array}$ & $\begin{array}{l}\text { ADDITIVE } \\
\text { CONC. } \\
\text { gm. }\end{array}$ & $\begin{array}{l}\text { OVERALL MAF } \\
\text { CONVERSION } \\
\%\end{array}$ \\
\hline 5 & 300 & 1800 & 1.0 & $\cdots$ & $\overline{24.6}$ \\
\hline 6 & 300 & 1800 & 0.5 & $\cdots$ & 24.7 \\
\hline 7 & 300 & 1700 & 0.0 & $\cdots$ & 21.4 \\
\hline 8 & $300 \ldots$ & 1800 & 2.0 & $\cdots$ & 24.5 \\
\hline 9 & 325 & 1800 & 1.0 & $\cdots$ & 36.5 \\
\hline 10 & 325 & 1050 & 2.0 & 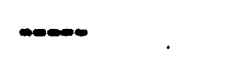 & 24.2 \\
\hline 11 & 325 & 1850 & 0.5 & - & 29.8 \\
\hline 12 & 325 & 1800 & 0.0 & $\cdots$ & 25.4 \\
\hline 13 & 325 & 1700 & 2.0 & $\cdots$ & 29.2 \\
\hline 14 & 350 & 1850 & 1.0 & $\cdots$ & 62.5 \\
\hline 15 & 350 & 1800 & 0.0 & $\cdots$ & 54.4 \\
\hline 16 & 350 & 1500 & 2.0 & $\cdots$ & 60.0 \\
\hline 17 & 350 & 1850 & 2.0 & $\cdots$ & 63.1 \\
\hline 18 & 350 & 1300 & 0.5 & - & 65.9 \\
\hline 19 & 375 & 1800 & 1.0 & - & 85.9 \\
\hline 20 & 375 & 1300 & 0.0 & $\ldots$ & 77.0 \\
\hline 21 & 375 & 1500 & 2.0 & $\cdots$ & 82.5 \\
\hline 22 & 375 & 1650 & 0.5 & $\ldots$ & 86.0 \\
\hline 23 & 375 & 1800 & 2.0 & $\cdots$ & 87.4 \\
\hline 24 & 375 & 1800 & 0.0 & - & 83.1 \\
\hline
\end{tabular}




\begin{tabular}{|c|c|c|c|c|c|}
\hline $\begin{array}{l}\text { RUN } \\
\text { NO. }\end{array}$ & $\begin{array}{l}\text { AVERAGE } \\
\text { TEMP. } \\
\text { OC }\end{array}$ & $\begin{array}{c}\text { AVERAGE } \\
\text { PRESSURE } \\
\text { psig }\end{array}$ & $\begin{array}{l}\text { SURFACTAN } \\
\text { CONC. } \\
\text { wt } \%\end{array}$ & $\begin{array}{l}\text { IT ADDITIVE } \\
\text { CONC. } \\
\text { gm. }\end{array}$ & $\begin{array}{l}\text { OVERALL MAF } \\
\text { CONVERSION } \\
\%\end{array}$ \\
\hline$\overline{25}$ & 375 & 1800 & 1.0 & $1.0 \mathrm{~g} . \mathrm{Fe}_{2} \mathrm{O}_{3}$ & 92.1 \\
\hline 26 & 375 & 1800 & 0.0 & $1.0 \mathrm{~g} . \mathrm{Fe}_{2} \mathrm{O}_{3}$ & 88.8 \\
\hline 27 & 375 & 1800 & 1.0 & $\ldots$ & 85.9 \\
\hline 28 & 375 & 1800 & 2.0 & $\cdots$ & 78.0 \\
\hline 29 & 375 & 1800 & 2.0 & $-\infty$ & 89.9 \\
\hline 30 & 375 & 1820 & 0.0 & $-\cdots$ & 83.1 \\
\hline 31 & 375 & 1800 & 0.0 & $\cdots$ & 86.4 \\
\hline 36 & 400 & 1710 & 0.0 & $\cdots$ & 84.1 \\
\hline 37 & 400 & 1745 & 0.0 & $\cdots$ & 92.9 \\
\hline 38 & 400 & 1740 & 1.0 & 1.0 g. $\mathrm{Fe}_{2} \mathrm{O}_{3}$ & 89.6 \\
\hline 39 & 400 & 1680 & 0.0 & $1.0 \mathrm{~g} . \mathrm{Ni}-\mathrm{Mo}$ & 95.6 \\
\hline 40 & 400 & 1730 & 1.0 & 1.0 g. Ni-Mo & 93.8 \\
\hline 41 & 375 & 1610 & 0.0 & $1.0 \%$ Lignin & 76.8 \\
\hline 42 & 400 & 1840 & 0.0 & $1.0 \%$ Lignin & 82.3 \\
\hline 43 & $\begin{array}{l}375 / \\
400\end{array}$ & $\begin{array}{l}1800 \\
1800\end{array}$ & $\begin{array}{l}0.5 \\
0.5\end{array}$ & $\begin{array}{l}0.0 \\
.1 .0 \mathrm{~g} \mathrm{Ni}-\mathrm{Mo}\end{array}$ & 93.4 \\
\hline
\end{tabular}


Appendix 5: Distillation Results for the Autoclave Runs.

\begin{tabular}{|c|c|c|c|c|c|c|}
\hline $\begin{array}{l}\text { RUN } \\
\text { No. }\end{array}$ & $\begin{array}{l}\text { SURFACT. } \\
\text { CONC. } \\
w t \%\end{array}$ & $\begin{array}{c}210^{\circ} \mathrm{C} \\
\mathrm{CUT} \\
9\end{array}$ & $\begin{array}{l}270^{\circ} \mathrm{C} \\
\text { CUT } \\
g\end{array}$ & $\begin{array}{c}300^{\circ} \mathrm{C} \\
\text { CUT } \\
g .\end{array}$ & $\begin{array}{l}\text { BOTTOMS } \\
>3000^{\circ} \mathrm{C} \\
g\end{array}$ & $\begin{array}{l}\text { TOTAL LIGHT } \\
\text { UP TO } 300 \text { ०C } \\
\mathbf{g}\end{array}$ \\
\hline 9 & 1.0 & 0.67 & 5.61 & 9.14 & 34.04 & 15.42 \\
\hline 11 & 0.5 & 0.92 & 7.13 & 9.28 & 32.09 & 17.33 \\
\hline 12 & 0.0 & 0.24 & 6.16 & 7.95 & 34.65 & 14.35 \\
\hline 13 & 2.0 & 0.98 & 6.97 & 10.49 & 30.87 & 18.44 \\
\hline 14 & 1.0 & 1.29 & 5.60 & 9.33 & 33.57 & 16.22 \\
\hline 15 & 0.0 & 0.98 & 4.00 & 8.30 & 36.15 & 13.28 \\
\hline 16 & 2.0 & 1.08 & 5.13 & 8.47 & 35.14 & 14.68 \\
\hline 17 & 2.0 & 1.28 & 5.72 & 10.12 & 32.67 & 17.12 \\
\hline 18 & 0.5 & 1.06 & 5.45 & 8.27 & 34.98 & 14.78 \\
\hline 19 & 1.0 & 0.03 & 8.47 & 10.69 & 30.53 & 19.19 \\
\hline 20 & 0.0 & 0.08 & 7.51 & 7.82 & 34.31 & 15.41 \\
\hline 21 & 2.0 & 1.01 & 5.53 & 6.52 & 36.66 & 13.06 \\
\hline 22 & 0.5 & 1.41 & 7.39 & 8.38 & 32.54 & 17.18 \\
\hline 23 & 2.0 & 0.88 & 8.81 & 7.93 & 32.11 & 17.62 \\
\hline 24 & 0.0 & 1.23 & 8.26 & 7.06 & 32.25 & 16.55 \\
\hline 25 & $1.0^{A}$ & 0.71 & 6.92 & 6.05 & 36.13 & 13.68 \\
\hline 26 & $0.0 \mathrm{~A}$ & 0.91 & 6.84 & 7.02 & 34.97 & 14.77 \\
\hline
\end{tabular}

A $1.0 \mathrm{~g} \mathrm{Fe} 2 \mathrm{O}_{3}$ addition 


\begin{tabular}{|c|c|c|c|c|c|c|c|c|}
\hline $\begin{array}{l}\text { RUN. } \\
\text { No. }\end{array}$ & $\begin{array}{l}\text { TEMP. } \\
\text { OC. }\end{array}$ & $\begin{array}{l}\text { SURFACT. } \\
\text { CONC. } \\
w \%\end{array}$ & $\begin{array}{l}210^{\circ} \mathrm{C} \\
\text { CUT } \\
g\end{array}$ & $\begin{array}{l}270^{\circ} \\
\text { CUT } \\
g\end{array}$ & $\begin{array}{l}300^{\circ} \mathrm{C} \\
\mathrm{CUT} \\
g\end{array}$ & $\begin{array}{l}340^{\circ} \mathrm{C} \\
\mathrm{CUT} \\
\mathrm{g}\end{array}$ & $\begin{array}{l}\text { BOTTOMS } \\
>340^{\circ} \mathrm{C} \\
g\end{array}$ & $\begin{array}{l}\text { TOTAL LIGHT } \\
\text { UP TO } 340^{\circ} \mathrm{C} \\
\mathbf{g}\end{array}$ \\
\hline$\overline{36}$ & 400 & 0.0 & 0.33 & 6.87 & 4.27 & 14.07 & 23.06 & 25.54 \\
\hline 37 & 400 & 1.0 & 0.07 & 7.77 & 5.32 & 14.10 & 21.89 & 27.26 \\
\hline 38 & 400 & $1.0 \mathrm{~A}$ & 0.22 & 6.56 & 6.04 & 12.17 & 24.32 & 24.99 \\
\hline 39 & 400 & $0.0^{B}$ & 0.11 & 7.61 & 5.06 & 14.23 & 22.46 & 27.01 \\
\hline 40 & 400 & $1.0 \mathrm{~B}$ & 0.69 & 6.60 & 5.97 & 16.92 & 23.96 & 30.06 \\
\hline 43 & $375 / 400$ & $1.0^{B}$ & 0.00 & 7.93 & 4.82 & 14.40 & 22.46 & 27.15 \\
\hline
\end{tabular}



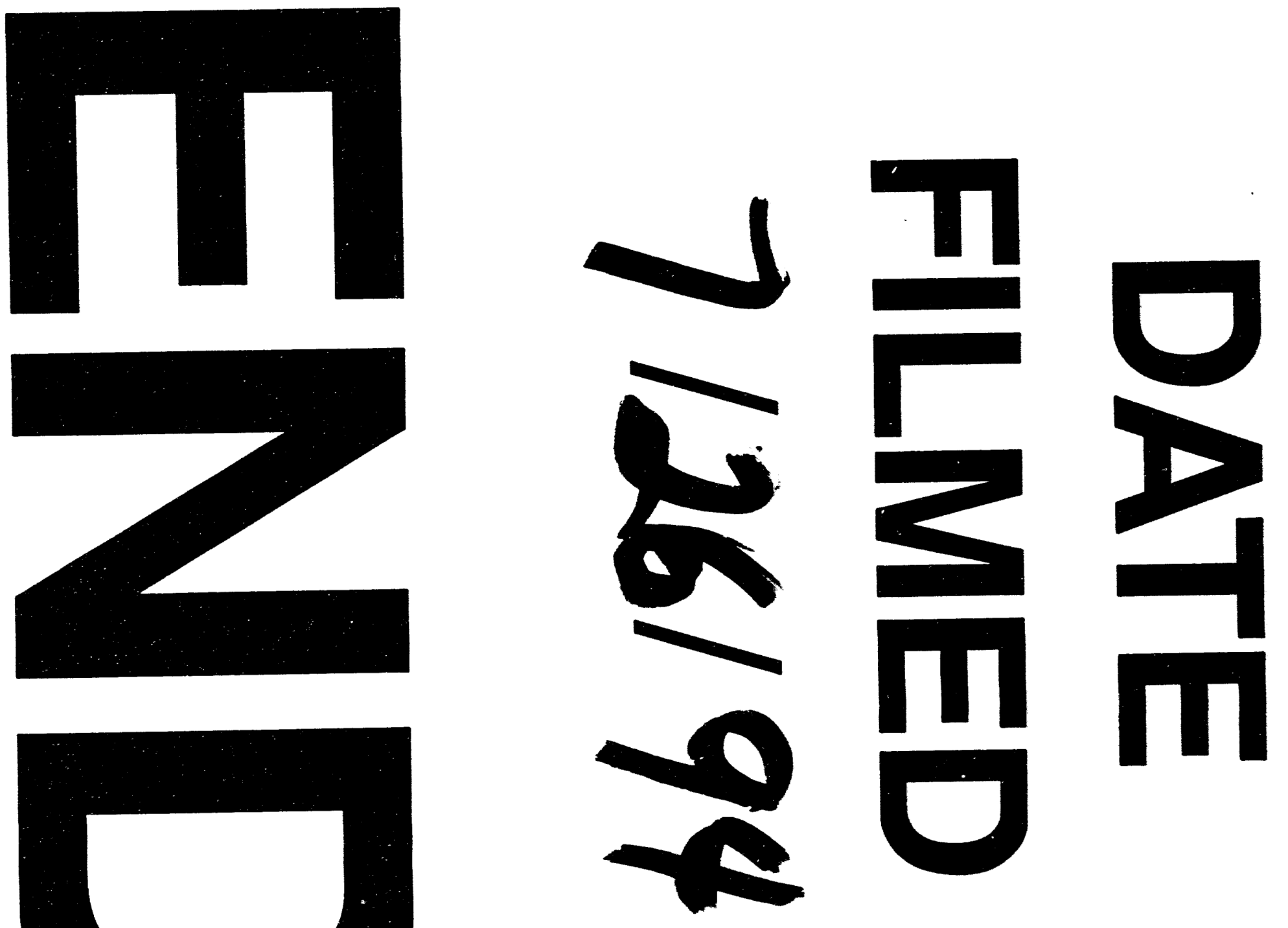
